Florida International University

FIU Digital Commons

FIU Electronic Theses and Dissertations

University Graduate School

3-21-2014

\title{
Auto-antigenic Properties of the Spliceosome as a Molecular Tool for Diagnosing Systemic Lupus Erythematosus and Mixed Connective Tissue Disease Patients
}

Annia Mesa

Florida International University, amesa003@fiu.edu

DOI: $10.25148 /$ etd.FI14040818

Follow this and additional works at: https:// digitalcommons.fiu.edu/etd

Part of the Bioinformatics Commons, Biology Commons, $\underline{\text { Immunity Commons, and the Other }}$ $\underline{\text { Immunology and Infectious Disease Commons }}$

\section{Recommended Citation}

Mesa, Annia, "Auto-antigenic Properties of the Spliceosome as a Molecular Tool for Diagnosing Systemic Lupus Erythematosus and Mixed Connective Tissue Disease Patients" (2014). FIU Electronic Theses and Dissertations. 1126.

https://digitalcommons.fiu.edu/etd/1126 


\title{
FLORIDA INTERNATIONAL UNIVERSITY \\ Miami, Florida
}

\begin{abstract}
AUTO-ANTIGENIC PROPERTIES OF THE SPLICEOSOME AS A MOLECULAR TOOL FOR DIAGNOSING SYSTEMIC LUPUS ERYTHEMATOSUS AND MIXED CONNECTIVE TISSUE DISEASE PATIENTS
\end{abstract}

A dissertation submitted in partial fulfillment of the requirements for the degree of DOCTOR OF PHILOSOPHY

in

BIOLOGY

by

Annia Mesa

2014 
To: Dean Kenneth G. Furton

College of Arts and Sciences

This dissertation, written by Annia Mesa, and entitled Auto-antigenic Properties of the Spliceosome as a Molecular Tool for Diagnosing Systemic Lupus Erythematosus and Mixed Connective Tissue Disease Patients, having been approved in respect to style and intellectual content, is referred to you for judgment.

We have read this dissertation and recommend that it be approved.

Alejandro Barbieri

Charles H. Bigger

Ophelia I. Weeks

Wensong $\mathrm{Wu}$

DeEtta K. Mills, Major Professor

Date of Defense: March 21, 2014

The dissertation of Annia Mesa is approved.

Dean Kenneth G. Furton

College of Arts and Sciences

Dean Lakshmi N. Reddi

University Graduate School

Florida International University, 2014 


\section{DEDICATION}

I dedicate this research work to my parents: Silvia Celika Avila León and Aldo Benito Mesa Dias. For as long as I can remember, they have been determined to provide me with opportunities and resources to improve my education and reach my goal to become a Ph.D. For that, I will be endless in debt.

Gracias Mami y Papi. 


\section{ACKNOWLEDGMENTS}

I would like to recognize the constant advice and directions of my $\mathrm{PhD}$ committee members, Dr. Wu, Dr. Weeks, Dr. Bigger and Dr. Barbieri, have facilitated the understanding and progress of my research work. Especially, I would like to acknowledge Dr. DeEtta Kay Mills, my PhD thesis director, for all her mentoring, guidance and support during successful and difficult times through my graduate studies. In addition, I would like to acknowledge the Minority-Biomedical-Research-Support program (MBRS number: NIH/NIGMS R25 GM061347) and its team including Dr Bigger, Ms' Aileen Landry, Courtney Aiken, Amy Reid, Thelma Robles and Melvis Hidalgo for providing the funding that allow me to concentrate only on my Ph.D. studies as well as offering me endless professional opportunities to network with other peers across the country.

Likewise, I would like to thank Dr. Somarelli, Dr. Greidinger, Dr. Giri, Dr. Regueiro, Mr. Mitch Fernandez, Ms. Laisel Martinez, Mr. Emmanuel Martinez, Ms. Rosa Rodriguez, Ms. Carol E. Rodriguez and Mr. Alvaro Velandia for their intellectual contributions and inspiring scientific discussions during my $\mathrm{PhD}$ research. Moreover, I highly appreciated the much needed technical assistant of Ms. Shaina Hernandez, Mr. Jonathan Levis, Ms. Mylene Rios, Ms. Shantal Alvarez and Diane Barret. Furthermore, am extremely grateful for the support of my entire family including my brothers (Alexis and Alejandro) and my grandmother (Mima).

Last, but definitely not least, I would like to express my thanks and appreciation to Mr. Miguel Angel Sanchez for his constant encouragement to keep going for my goal even when I thought it was impossible. 


\begin{abstract}
OF THE DISSERTATION
AUTO-ANTIGENIC PROPERTIES OF THE SPLICEOSOME AS A MOLECULAR

TOOL FOR DIAGNOSING SYSTEMIC LUPUS ERYTHEMATOSUS AND MIXED

CONNECTIVE TISSUE DISEASE PATIENTS
\end{abstract}

by

Annia Mesa

Florida International University, 2014

Miami, Florida

Professor DeEtta K. Mills, Major Professor

Systemic Lupus Erythematosus (SLE) and Mixed Connective Tissue Disease (MCTD) are chronic, autoimmune disorders that target overlapping autoantigens and exhibit similar clinical manifestations. Despite 40 years of research, a reliable biomarker capable of diagnosing these syndromes has yet to be identified. Previous studies have confirmed that components of the U1 small nuclear ribonucleoprotein complex (U1 snRNP) such as U1A are 1000 fold more autoantigenic than any other nuclear component in SLE patients. Based on these findings, I hypothesize that models derived from the U1 snRNP autoantigenic properties could distinguish SLE from MCTD patients. To test this hypothesis, 30 peptides corresponding to protein regions of the U1 snRNP were tested in triplicates by indirect ELISA in sera from SLE or MCTD subjects. In addition laboratory tests and clinical manifestations data from these patients were included and analyzed in this investigation. Statistical classification methods as well as bioinformatics pattern recognition strategy were employed to determine which combination, if any, of all the variables included in this study provide the best segregation power for SLE and MCTD. 
The results confirmed that the IgM reactivity for U1 snRNP and U1A have the power to significantly distinguish SLE from MTCD patients as well as identify kidney and lung malfunctions for these subjects $(p \leq 0.05)$. Furthermore, the data analysis revealed eight novel classification rules for the segregation of SLE and MCTD which are a better classification tool than any of the currently available methods $(p \leq 0.05)$. Consequently, the results derived from this study support that SLE and MCTD are indeed separate disorders and pioneer the description of eight novel classification criteria capable of significantly discerning between SLE and MCTD patients $(p \leq 0.05)$. 


\section{TABLE OF CONTENTS}

CHAPTER

PAGE

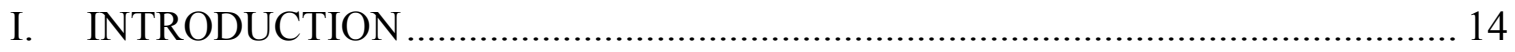

II. CHAPTER 1: Uncovering the IgM auotimmune response for U1Ap in patients diagnosed with SLE or MCTD ........................................................................... 19

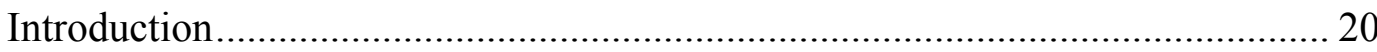

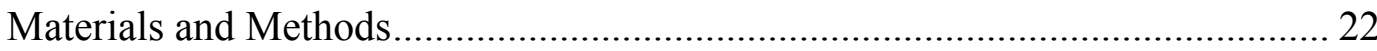

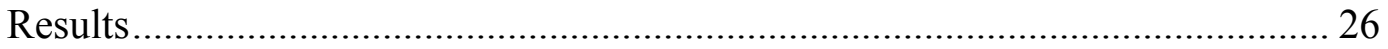

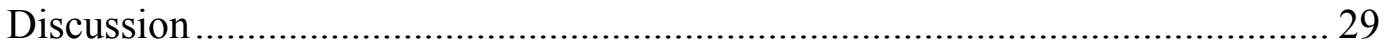

III. CHAPTER 2: Production of spliceosomal derived biomarkers for identification of

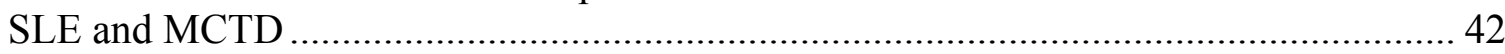

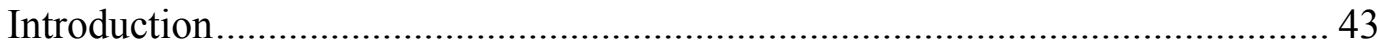

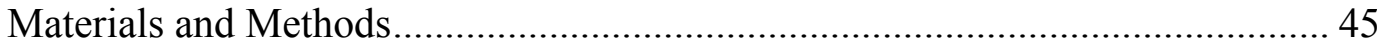

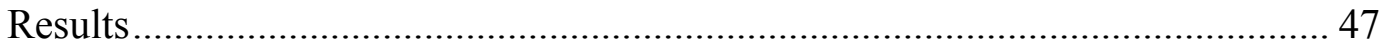

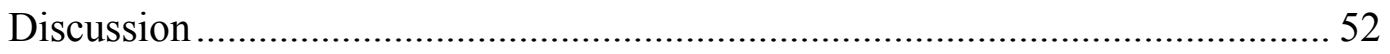

IV. CHAPTER 3: Deceloping novel classification rules customized to distinguished

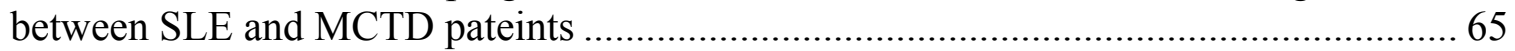

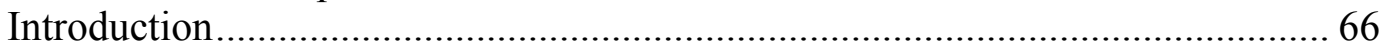

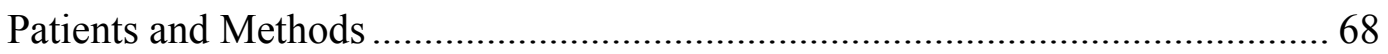



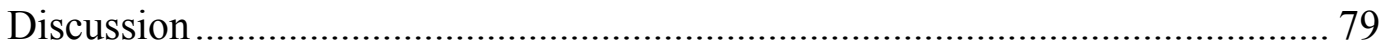

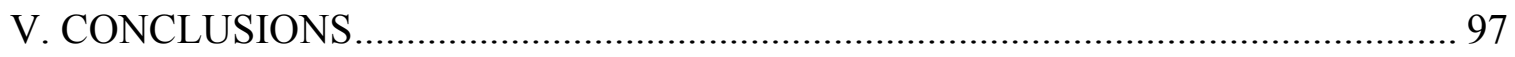

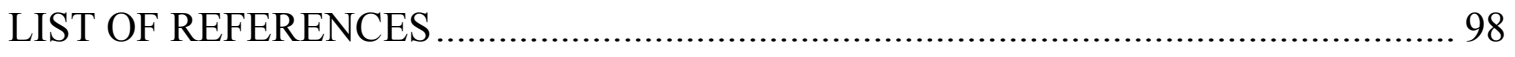

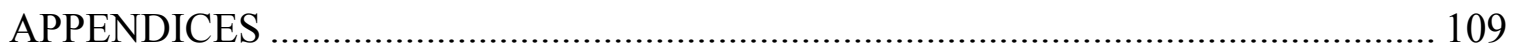

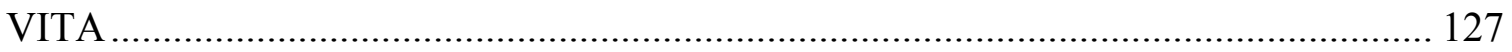




\section{LIST OF TABLES}

TABLE

PAGE

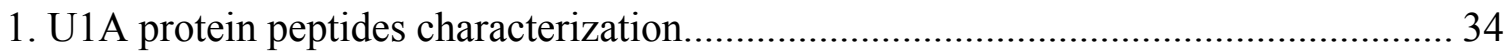

2. Clinical tests evaluated in SLE and MCTD patients .................................................. 56

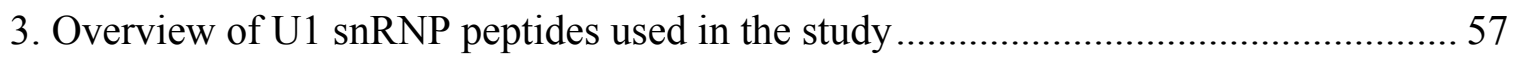

4. List of clinical symptoms observed in SLE and MCTD .......................................... 58

5. List of molecular markers associated with clinical manifestations in SLE and

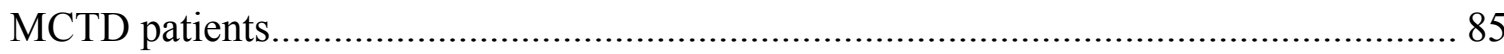

6. Evaluating SLE and MCTD classification criteria sets in patient cohort included in

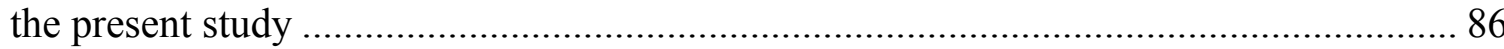

7. Description of reduced models for each SLE and MCTD classification criteria ......... 87

8. Description of novel models for segregation of SLE and MCTD patients................... 88 


\section{LIST OF FIGURES}

FIGURE

PAGE

1. SLE but not MCTD patients show predominant IgM response to U1Ap subunits ..... 38

2. U1A protein epitope map for IgM antigencity in SLE and MCTD patients. .............. 39

3. IgM reactivity for U1Ap is a candidate marker for kidney damage........................ 40

4. IgM anti-U1Ap titers are potential biomarkers for lung damage. ............................ 41

5. Contrasting IgM-specific anti-U1 snRNP peptide responses observed in SLE and



6. Identification of a two-step ELISA system for classification of SLE, MCTD and

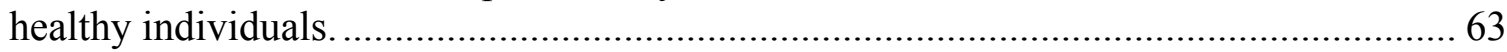

7. Area under the curve analysis reveals the classification power of IgM anti-P4/P10... 64

8. SLE and MCTD differ in the prevalence of clinical characteristics and molecular

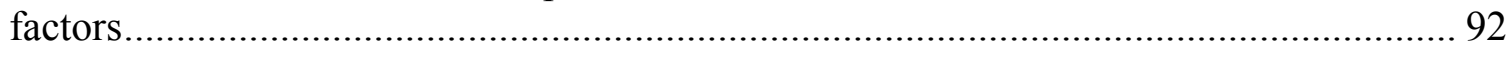

9. Proposed biomarker panel for clinical manifestations observed in SLE patients........ 93

10. Specific blood markers correlate with clinical symptoms in MCTD patients ........... 94

11. Reduced models for each SLE and MCTD classification criteria exhibit better power in discriminating between SLE and MCTD patients .................................... 95

12. Proposed Model 1 exhibits the highest discrimination power in identifying SLE

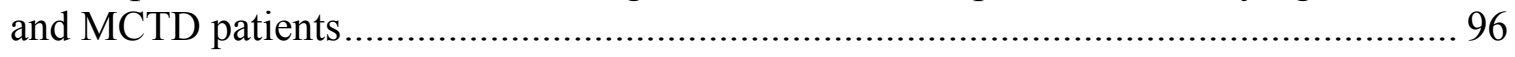




\section{ABBREVIATIONS AND ACRONYMS}

ANA

ACR

BAFF

BLR

BSA

C-score

CPK

CNS

DNA

dsDNA

e.g.

ELISA

FANA

FN

FP

$\operatorname{Ig} \mathrm{A}$

$\operatorname{IgD}$

$\operatorname{IgE}$

$\operatorname{IgG}$
Positive

No significant correlation

Three-Dimensional

Activated Antinuclear Assay

American College of Rheumatology

B cell Activated Factor

Binomial Logistic Regression

Bovine Serum Albumin

Confidence Scores

Creatine Phosphate Kinase

Central Nervous System

DeoxyriboNucleic Acid

Double Stranded DeoxyriboNucleic Acid

Exempli Gratia

Enzyme Linked Immunosorbent Assays

Fluorescent Activated Antinuclear Assay

False Negative

False Positive

Immunoglobulin A

Immunoglobulin D

Immunoglobulin E

Immunoglobulin G 


\begin{tabular}{|c|c|}
\hline $\operatorname{IgM}$ & Immunoglobulin $\mathrm{M}$ \\
\hline IL & Interleukin \\
\hline IRB & Institutional Review Board \\
\hline MCTD & Mixed Connective Tissue Disease \\
\hline$n$ & sample number \\
\hline NCBI & National Center for Biotechnology Information \\
\hline NGAL & Neutrophil Gelatinase Associated Lipocalin \\
\hline NMR & Nuclear Magnetic Resonance \\
\hline OD & Optical Density \\
\hline $\mathrm{OD} \%$ & Percentage of Optical Density \\
\hline $\mathrm{P}$ & Peptide \\
\hline PBS & Phosphate Buffered Saline \\
\hline PBS-T & Phosphate Buffered Saline with $0.05 \%$ Tween-20 \\
\hline PDB & Protein Data Bank \\
\hline PMSF & Phenylmethylsulphonyl Fluoride \\
\hline PM & Polymyositis \\
\hline $\operatorname{Pr}(S L E)$ & Probability of Systemic Lupus Erythematosus \\
\hline $\operatorname{Pr}(M C T D)$ & Probability of Mixed Connective Tissue Disease \\
\hline rAlarcón-Segovia & Reduced Alarcón-Segovia model \\
\hline RA & Rheumatoid Arthritis \\
\hline $\mathrm{RF}$ & Rheumatoid Factor \\
\hline rKahn & Reduced Kahn model \\
\hline rKasukawa & Reduced Kasukawa model \\
\hline
\end{tabular}




$\begin{array}{ll}\text { RMSD } & \text { root mean square deviation } \\ \text { ROC } & \text { Receiving Operating Characteristics } \\ \text { RRM } & \text { RNA Recognition Motif } \\ \text { rSharp } & \text { Reduced Sharp model } \\ \text { Scl70 } & \text { Topoisomerase 1 } \\ \text { SLE } & \text { Systemic Lupus Erythematosus } \\ \text { SLICC } & \text { Systemic Lupus International Collaborating Clinics } \\ \text { Sm } & \text { Smith protein } \\ \text { snRNP } & \text { Small Nuclear Ribonucleoprotein Particle } \\ \text { SS } & \text { Systemic Sclerosis } \\ \text { SSA } & \text { anti-Ro antibodies } \\ \text { SSB } & \text { anti-La antibodies } \\ \text { SmD } & \text { Smith protein D } \\ \text { SPSS } & \text { Utatistical Product and Service Solutions } \\ \text { TN } & \text { U1 Small Nuclear Ribonucleoprotein Particle } \\ \text { TP } & \text { Urue Negative } \\ \text { U1-70K } & \text { True Positive } \\ \text { U1Ap } & \text { U1-70K protein } \\ \text { U1C } & \text { U1 protein } \\ \text { U1 snRNP } & \text { Un snRNP }\end{array}$


U6 snRNP

VCAM

$X$

$\overline{\mathrm{X}}$ OD of sample

$\overline{\mathrm{X}}$ OD of control group
U6 Small Nuclear Ribonucleoprotein Particle

Vascular Cell Adhesion Molecule

Chi square

Optical Density Value of the Sample Group

Optical Density Value of the Control Group 


\section{INTRODUCTION}

Autoimmune diseases develop when the immune system stops recognizing self antigens and produces aberrant antibodies capable of developing equally over-reactive responses to self as well as non-self antigens (Carroll, 2004). In general, individuals diagnosed with these syndromes represent a heterogeneous population characterized by a broad number of clinical manifestations that have unpredictable courses and often cannot be associated with a unique autoimmune illness (Konforte et al., 2012). It is without doubt that early and accurate recognition of these diseases could dictate the patient's treatment which in turn has the potential to improve the prognosis as well as reduce the financial burden to the ill subject and family (Bodolay et al., 2007). Nevertheless, the lack of recognition and categorization methods for autoimmune syndromes exhibiting clinical and molecular features common in other well characterized autoimmune illnesses has hampered diagnosis. As result, patients exhibiting characteristic overlapping clinical manifestations observed in different autoimmune syndromes are often misdiagnosed and go through years of clinical investigations and laboratory tests before obtaining the accurate diagnosis (Adsay et al., 2005; Simao, 2010; Niţescu et al., 2011; Quinkler, 2012; Bertsias et al., 2013; Pena et al., 2013).

Mixed Connective Tissue Disease (MCTD) is one of the most commonly known syndromes showing overlapping characteristics with other autoimmune disorders (Rebora and Parodi, 1990; Aringer et al., 2005; Swanton and Isenberg, 2005; Nowicka-Sauer et al., 2012). Sharp et al. (1972) initially described MCTD as a systemic autoimmune disease characterized by elevated antibodies directed to subunits of the U1 small nuclear ribonucloprotein particle (snRNP). Since then, diverse research groups defined it as a 
non-specific autoimmune syndrome with clinical and molecular features observed in others syndromes such as Systemic Lupus Erythematosus (SLE), Systemic Sclerosis (SS), Rheumatoid Arthritis (RA) and Polymyositis (PM) (Mukerji and Hardin, 1993; Egner, 2000; Haustein, 2005). The initial, but not always reliable, description of MCTD as a benign disease that transforms into other well known autoimmune disorders has limited its recognition during the study of SLE and other cohorts of autoimmune patients (Sharp et al., 1972; Tan et al., 1982; Hochberg et al., 1997; Lundberg, 2005; Petri et al., 2012; Shi et al., 2012). Recent studies have shown lung disease seems to be specifically associated with MCTD but not SLE patients (Shirai et al., 2012; Watanabe et al., 2012; Gunnarsson et al., 2013). By contrast, renal disorders have long been a characteristic prevalent in SLE but not the MCTD population (Everett and Harrell, 1956; Natali et al., 1972; Cavagna et al., 2013; Lin et al., 2013). The fact that independent studies have described that SLE and MCTD patients are associated with malfunction of different organs highlights the relevance of the recognition of MCTD concept as a clinical tool to identify patients that could develop lung disease as oppose to kidney malfunction, for example. Given that four different criteria sets currently coexist to identify MCTD patients illustrates the significant challenges in uncovering clinical symptoms and/or biomarkers that could be specifically associated with this autoimmune syndrome (Sharp, 1987; Kasukawa et al, 1988; Kahn et al., 1991; Amigues et al., 1996).

During the past six decades, extensive studies have provided evidence to support the following: first, MCTD exhibited a considerable number of overlapping features with SLE making virtually impossible the segregation of some patients using currently available classification criteria sets (Sharp et al., 1972; Tan et al., 1982; Amigues et al., 
1996; Hochberg et al., 1997; Lundberg, 2005; Petri et al., 2012; Shi et al., 2012). Second, the concept of MCTD has clinical relevance since malfunction of vital organs has been reported to be prevalent in this syndrome when compared to SLE, for example (Everett and Harrell, 1956; Natali et al., 1972; Shirai et al., 2012; Watanabe et al., 2012; Gunnarsson et al., 2013). Third, new classification rules with significant power to distinguish between SLE and MCTD patients need to be developed given that available classification criteria sets were designed to identify either SLE or MCTD subjects but not to segregate between these two autoimmune disorders (Sharp, 1987; Kasukawa et al, 1988; Kahn et al., 1991; Amigues et al., 1996; Hochberg et al., 1997; Petri et al., 2012). Prompted by the clinical need for developing accurate methods to segregate between SLE and MCTD patients, the present study explores auto-antigenic properties of the spliceosome; a potential novel molecular tool for the discrimination of these two autoimmune syndromes.

The spliceosome is a macromolecule composed of five distinguished RNA and protein complexes known as U1 small nuclear ribonucleoprotein (U1 snRNP), U2 snRNP, U4 snRNP, U5 snRNP and U6 snRNP (Moore et al., 1993). All these snRNP composites are arranged around the nascent pre-mRNA to remove introns and link exons through the splicing reaction producing a final mature mRNA (Staley and Guthrie, 1998). Earlier reports have confirmed the auto-antigenic properties of U1 snRNP in SLE and MCTD patients. The U1 snRNP is the first spliceosomal subunit binding the pre-mRNA and is composed of three specific U1 snRNP proteins (U1-70K, U1Ap and U1C) and seven Smith (Sm) proteins (Pomeranz Krummel et al., 2009). Specifically, MCTD subjects show prevalence of autoimmune response to U1 snRNP specific proteins 
(snRNP) while SLE individuals have a predominance response to Sm proteins (Luyckx et al., 2005). Interestingly, the majority of previous analyses have focused on the autoantigenic properties of U1-70K and Sm proteins but not on U1A and U1C (McClain et al., 2004; Luyckx et al., 2005). Likewise, the immunoglobulin G (IgG) immune response for these and other nuclear antigens have been extensively documented in SLE and MCTD patients while the potential role of other immunoglobulins (IgM, $\operatorname{IgD}$, IgE and IgA) has been limited (Zhang et al., 1995; Vlachoyiannopoulos et al., 1996; Witte et al., 1998; Palafox Sanchez et al; 2009).

The present study will apply novel classification rules specifically designed for SLE and MCTD discrimination by exploring the IgM response for $15 \mathrm{U} 1 \mathrm{~A}$ and 15 additional U1 snRNP peptides, as well as analyzing the frequency and correlations of 183 clinical symptoms and biomarkers recorded in patients with these autoimmune syndromes. The data analyses confirmed previous findings that the immune response for U1A and U1 snRNP peptides mature from IgM to IgG in MCTD patients while SLE subjects appear to retain IgM responses for these autoantigens. In addition, the results revealed that models derived from the IgM reactivity for U1 snRNP and IgM anti-U1A titers have the power to significantly segregate between SLE and MTCD patients as well as identify kidney and lung malfunctions in subjects diagnosed with any of these two illnesses $(p \leq 0.05)$, respectively. Furthermore, eight novel classification rules for the segregation of SLE and MCTD were described and showed better classification power than any of the currently available methods $(p \leq 0.05)$. Consequently, the results derived from this study provide evidence to support the notion that SLE and MCTD are indeed separate disorders while pioneer the description of eight novel classification criteria sets 
capable of discerning between SLE and MCTD patients $(p \leq 0.05)$. Recognizing that validation of these findings is required, the data described have the potential to improve the accurate clinical diagnosis of SLE and MCTD which in turn could increase the patient's prognosis and life quality. 


\section{CHAPTER 1}

Uncovering the IgM autoimmune response for U1Ap in patients diagnosed with SLE or MCTD 


\section{Introduction}

The small nuclear ribonucleoprotein (snRNP) A (referred to here as "U1Ap"), in combination with $\mathrm{U} 1-70 \mathrm{~K}$ and $\mathrm{U1C}$, is a specific U1 RNP polypeptide that, along with the U1-RNA and Sm proteins, forms an active U1 snRNP complex. The complex, in turn, plays an essential role in pre-mRNA processing as a functional unit of the spliceosome (Moore and Sharp, 1993). The spliceosomal composite is formed of two RNA recognition motifs (RRM) located at the N- and C-terminal of the U1Ap and has been reported to be conserved across the Eukaryote domain (Scherly et al., 1989; Chen et al., 2007; Somarelli et al., 2010). The N-terminal RRM domain (RRM1) of U1Ap has been extensively studied and has been shown to be necessary and sufficient to bind U1-RNA via its stem loop II and facilitate the splicing process (Scherly et al., 1989, Jessen et al., 1991, Somarelli et al., 2010). By contrast, little is known about the potential function of the U1Ap C-terminal RRM domain (RRM2) despite similar characteristics to other RNA binding domains including U1Ap RRM1 (Scherly et al., 1989, Tang and Rosbash, 1996). The RRM2 of U1Ap exhibits unusual RNA binding properties since it does not bind to U1, U2 or U5 stem loops or interact with random RNA sequences (Lu and Hall, 1995).

Autoimmune responses to U1 snRNP specific proteins, including U1Ap, have been described in patients diagnosed with Systemic Lupus Erythematosus (SLE) and Mixed Connective Tissue Disease (MCTD) (de Wildt et al., 1997; Faig and Lutz , 2003; McClain et al., 2004; Sato et al., 2010). In some patient cohorts, anti-U1Ap responses have been reported to be the first anti-U1-snRNP to develop (McClain et al., 2004). Major organ involvement, including lung and kidney, are common in these individuals (Gutsche et al., 2012; Braun-Moscovici et al., 2013). Though MCTD was described as a 
separate disorder (Sharp et al., 1972), there is much controversy regarding its independent nature because of the great number of overlapping auto-antigens and clinical manifestations shared with SLE (Rebora and Parodi, 1990; Swanton and Isenberg, 2005; Nowicka-Sauer et al., 2012). Nevertheless, there are auto-antigens and clinical symptoms that are more frequently exhibited in one disease group than the other. For example, SLE patients show elevated immunoglobulin $\mathrm{G}(\mathrm{IgG})$ autoimmune responses to Sm proteins while those with the autoimmune response directed to snRNP subunits are frequently MCTD individuals (Luyckx et al., 2005). Clinically, kidney damage is more frequent in SLE while lung malfunction is often observed in MCTD patients (De Clerck et al., 1989; Sawai et al 1994; Yoshida et al., 1994; Watanabe et al., 2012). Previous studies have described elevated IgG autoimmune response to U1Ap fragments in both SLE and MCTD patients (Sato et al., 2010). In addition, Vlachoyiannopoulos et al. (1996) reported that SLE but not MCTD patients showed a predominant immunoglobulin M (IgM) response to snRNP subunits, including U1Ap. Furthermore, a recent study revealed that U1Ap antigenicity against IgM could aid in the differentiation between these two autoimmune disorders (Mesa et al., 2013).

The aim of the present study is to examine the IgM responses to U1Ap as a molecular indicator to assess differences between SLE and MCTD, and to uncover potential relevance of anti-U1Ap IgM reactivity in predicting organ targeting. To accomplish the goal, a total of 17 U1Ap peptides encompassing most of the protein's sequence were monitored for their IgM antigenicity in sera from SLE and MCTD patients with or without kidney and/or lung involvement. The results support previous findings that SLE but not MCTD patients have prevalent IgM responses to U1Ap peptides 
(Vlachoyiannopoulos et al., 1996, Mesa et al., 2013). Furthermore, IgM reactivity to specific U1Ap fragments has potential to identify patients with kidney and lung involvement with an accuracy of $72 \%$ and $71 \%$, respectively $(p \leq 0.005)$. Consequently, this investigation provides evidence to support that the IgM response to U1Ap peptides could be employed as a predictive blood marker for kidney and lung damage in patients diagnosed with either SLE or MCTD while contributing additional molecular evidence to support the separate etiology of these autoimmune syndromes.

\section{Materials and Methods}

\section{Patients recruitment}

In this study, SLE $(\mathrm{n}=56)$ and MCTD $(\mathrm{n}=26)$ individuals presenting in either outpatient or inpatient settings to the Division of Rheumatology at the University of Miami Miller School of Medicine, consented to participate in research studies following IRB-approved protocols between 2005 and 2010. Healthy individuals $(\mathrm{n}=10)$ also consenting to participate following IRB-approved guidelines were included as negative controls. The American College of Rheumatology (ACR) classification criteria (Hochberg et al., 1997) and the Alarcon Segovia criteria (Amigues et al., 1996) were used to classify patients as having SLE and MCTD, respectively. In cases where both criteria sets were satisfied, patient diagnoses were determined by the chart-documented diagnoses of their clinical rheumatologists. All SLE and MCTD individuals included in this investigation represent well characterized patients and have been subjects of previous studies (Maldonado et al., 2006; Perkins et al., 2008; Somarelli et al., 2011, Mesa et al., 2013). 


\section{Medical records selection}

Kidney involvement was defined following the American College of Rheumatology SLE Classification Criteria's renal criterion (Hochberg et al., 1997) and/or renal biopsy. Sufficient information was available to make a determination in 70 of the 82 study patients. Kidney involvement was present in 22 patients (19 SLE and 3 MCTD), and was absent in 48 patients (26 SLE and 22 MCTD). Lung disease was designated to be present if pulmonary fibrosis was confirmed by chest X-ray or CT-scan, or if pulmonary artery pressure by right heart catheterization or right ventricular systolic pressure estimated by echocardiography meter exceeded $40 \mathrm{mmHg}$. Sufficient information existed to make a determination about lung involvement in 52 patients, of whom 26 patients had lung involvement ( $\mathrm{SLE}=18$ and $\mathrm{MCTD}=8)$ and 26 did not have lung involvement $(\mathrm{SLE}=20$ and $\mathrm{MCTD}=6)$. All the medical records were obtained following the IRB protocols from University of Miami (IRB numbers: 20030724 and 20040286) and Florida International University (IRB number: 040308-00).

\section{Selection and synthesis of U1Ap peptides}

Auto-antigenic U1Ap peptides known to elicit an IgG autoimmune reaction in SLE patients were obtained from literature review to be tested for IgM antigenicity (Barakat et al., 1991; Arbuckle et al., 1998; Talken et al., 2001; Poole et al., 2009; Somarelli et al., 2011). In addition, amino acid sequences corresponding to each of the two RNA recognition motifs (RRMs) were included as peptides (P4 and P14, Table 1). All peptides were commercially synthesized by BioMatik Corporation (Wilmington, DE, USA) and purified by high performance liquid chromatography to $\geq 90 \%$ purity. 


\section{Assessing IgM autoimmune response for U1A protein peptides}

Whole blood from SLE (67 samples from 56 patients), MCTD (29 samples from 26 patients) and healthy (11 samples from 10 persons) individuals were obtained at the moment of the recruitment and subsequent follow up visits, when applicable. Supernatant serum from each patient was diluted 1:100 in phosphate buffered saline (1X PBS) containing $10 \mathrm{mg} / \mathrm{ml}$ bovine serum albumin (BSA) and $0.5 \mathrm{mM}$ phenylmethylsulphonyl fluoride (PMSF) and subsequently stored at $-80^{\circ} \mathrm{C}$ until tested. Diluted sample sera from SLE, MCTD and healthy individuals were used to determine IgM reactivity for U1Ap peptides via indirect-ELISA as previously described (Somarelli et al., 2011, Mesa et al., 2013). Goat anti-human IgM horseradish peroxidase conjugated second antibody (Southern Biotech, Birmingham, AL, USA) used at 1:2000 in BSA/PBS containing 0.05\% Tween-20 (BSA/PBS-T). All ELISAs were performed in triplicate. Each ELISA plate contained no peptide, no serum, no conjugate and no substrate controls. The optical density (OD) value of the IgM anti-U1Ap titers in each patient was normalized by the average IgM anti-U1Ap reactivity in the healthy group per peptide examined and expressed as OD\% following established methods (Muñoz-Paredes et al. 1999).

\section{Generating and evaluating the U1Ap three-dimensional structure}

A three-dimensional (3D) structural model of the full-length U1Ap (amino acids 1-282) was required to analyze the IgM anti-U1Ap titers given that currently the nuclear magnetic resonance (NMR) structure for human U1Ap only includes residues 2 to 102 (Protein Data Bank (PDB) ID number: 1DZ5). To generate a complete U1Ap 3D structure, the U1Ap linear sequence was retrieved from the National Center for 
Biotechnology Information (NCBI) protein data bank (accession number: P09012) and submitted to the I-TASSER server for protein structure and function prediction (http://zhanglab.ccmb.med.umich.edu/I-TASSER/) (Roy et al., 2010 and 2012). A total of five models were generated for U1Ap with confidence scores (C-score) ranging from 2.19 to -3.98 . Each of the U1Ap 3D models was superimposed on the U1Ap NMR 3D structure (PDB ID: 1DZ5 containing 12 ensemble structures) using PyMOL (version 1.30) to obtain the most accurate structure possible. The best U1Ap model was selected by finding the highest ratio of overlaid atoms to root mean square deviation (RMSD) during super-positioning on each of the NMR structures in the ensemble. The I-TASSER model 2 paired with ensemble structure 12 given that the assemble yielded the highest ratio $(565: 1.679=318.0$; detailed protocol for generating and evaluating U1 Ap 3D models is included in Appendix 1).

Mapping IgM response onto U1A protein 3D structure in SLE and MCTD patients

The observed IgM responses for U1Ap peptides in SLE and MCTD patients were mapped independently onto the U1Ap 3D model. To construct the IgM reactivity gradient for each peptide, the average value of the healthy group was adjusted to a baseline of 0.5. Subsequently, the average IgM reactivity recorded in each of the SLE and MCTD groups was expressed as a proportion relative to that baseline. Reactivity lower or higher than the healthy patient averages per peptides resulted in proportional values below or above 0.5 , respectively. On the basis of the proportional value, each peptide was mapped on a heat map with the scale ranging from blue for the lowest antigenicity, to green, yellow, and finally red for the highest antigenicity. 


\section{Statistical analysis}

Significant differences in the average peptide antigenicity against IgM, in SLE and MCTD patients were assessed by independent sample $t$-test. Correlation analyses were performed to verify the IgM responses for U1Ap peptides were not correlated to peptide size $(p \leq 0.05)$. A Chi-square test was employed to compare clinical and laboratory categorical variables between SLE and MCTD patients. Spearman's correlation was employed to assess the association between IgM anti-U1Ap titers and kidney or lung involvement. Binomial Logistic Regression (BLR) was used to assess which combination of IgM reactivity for U1Ap peptides enhanced the discrimination between patients presenting with kidney or lung involvement versus those lacking these manifestations. Peptides that were found to be not significant in BLR analysis were not included in subsequent tests. Receiving Operating Characteristics (ROC) curves were used to confirm results obtained by BLR and determine the cut off values to ensure the best sensitivity and specificity for kidney and lung models which were 0.5 and 0.6 , respectively. All the statistical analyses were performed using PASW statistical Data Editor, version 18 , with $p \leq 0.05$ set as the standard for statistical inference for all the tests executed.

\section{Results}

U1Ap peptides showed contrasting IgM antigenicity in SLE and MCTD patients

Indirect ELISAs were employed to assess IgM responses for U1Ap peptides in sera from SLE, MCTD and healthy individuals. In general, SLE patients exhibited higher IgM anti-U1Ap titers when compared to the healthy individuals (P1-P11 and P13, Figure 
1). By contrast, except for $\mathrm{P} 5, \mathrm{P} 8$ and $\mathrm{P} 9$, MCTD patients had lower IgM responses to U1Ap peptides than healthy individuals (Figure 1). Interesting, IgM anti-U1 Ap-P16 IgM reactivity was significantly lower in both SLE and MCTD patients compared to healthy controls $(p \leq 0.04)$ (Figure 1). SLE patients showed trends toward higher IgM reactivity for U1Ap subunits than MCTD patients (P4, P6, P7, P10, P11 and P13 were the most antigenic U1Ap fragments against IgM with 1.3 fold higher levels in SLE than MCTD patients), but the differences were not significant ( $p>0.05$, Figure 1). Specifically, P7 and P17 represented the biggest (137\%) and smallest (96\%) differences between the SLE and MCTD subsets.

Auto-antigenic IgM response is directed to non-RNA recognition domain regions of $U 1 A p$

To compare the IgM reactivity in the RNA recognition domain versus non-RNA recognition domain fragments of $\mathrm{U} 1 \mathrm{Ap}$, the average peptide reactivity corresponding to regions identified as RNA recognition motif (RRM) 1 (P1-P4), RRM2 (P14-17) and the non-domain area (P4-P13) were calculated in SLE, MCTD and healthy populations. Patients showed elevated IgM anti-U1Ap responses to non-domain areas of the U1Ap (P5-P13) when compared to RRM1 (P1-P4) and RRM2 (P14-P17) (Figure 1). However, only the SLE and not the MCTD patient subgroup exhibited significantly elevated average IgM response to peptides in U1Ap non-domain regions when compared to the average IgM reactivity for peptides covering RRM1 or RRM2 $(p \leq 0.003)$. The IgM response to the U1Ap C-terminal end, which encompasses RMM2, was noticeably lower in both SLE and MCTD patients than in control samples (Figure 1). 
IgM derived UIAp 3D epitope maps for SLE and MCTD patients

The IgM reactivity for each U1Ap peptide monitored in sera from SLE and MCTD patients was used to create two independent epitope maps of U1Ap (Figure 2 and detailed protocol in Appendix 1). In general, the IgM reactivity was not always directed to exposed fragments of the U1Ap, given that superficial peptides appeared to have an equal chance to be highly antigenic (P7 in SLE and P9 in MCTD) or not (P17 in SLE and P4 in MCTD) (Figure 2). Likewise, different molecular structures like $\alpha$-helices (P4), $\beta$ sheets (P15) and loops (P8) seemed to elicit antigenic IgM responses to U1Ap. However, $\beta$-sheets were the least antigenic of all three forms (P15 and P16 in Figure 2). When comparing the SLE and MCTD subgroups, higher U1Ap IgM reactivity was directed to superficial peptides with $\alpha$-helical structure in both SLE (P7) and MCTD (P4) (Figure 2). The lowest IgM responses were observed for peptides corresponding to exposed $\beta$-sheet fragments of the U1Ap in both SLE and MCTD (e.g., P16 in both SLE and MCTD patients in Figure 2).

IgM anti-U1Ap titers discriminate between patients with and without kidney involvement

The IgM responses to specific U1Ap peptides (P1, P2, P4, P5, P12, P15 and P16) across the entire patient group significantly correlated with kidney involvement ( $p \leq$ 0.05). BLR analyses using all 17 U1Ap peptides confirmed that the combined IgM reactivity for P2, P8, P11, P14, P15 and P17 (referred to as "U1Ap kidney model") represented the best predictor to identify patients with kidney disease $(p \leq 0.0001)$ (Figure 3A). Specifically, ROC analysis confirmed that the U1Ap kidney model had significant power $(\mathrm{AUC}=0.828)$ to separate between patients with kidney and without 
kidney disease with $85 \%$ specificity, $45 \%$ sensitivity and $73 \%$ overall accuracy to correctly categorize patients $(p \leq 0.005)$ (Figure 3B). Furthermore, the analyses revealed that the capacity of the U1Ap kidney model to distinguish an SLE patient with or without kidney disease was not significantly different than that observed in patients with MCTD $(p>0.05)$

\section{IgM anti-U1Ap reactivity patterns and lung involvement}

No anti-U1Ap peptide responses in univariate analyses were found to significantly correlate with lung damage. However, BLR analysis revealed that the combined IgM response to peptides P4, P9, P12 and P15 (the "U1Ap lung model") distinguished between patients with or without lung involvement similarly to the performance of the kidney model above $(\mathrm{AUC}=0.822)$ (Figure $4 \mathrm{~A})$. The overall accuracy of the U1Ap lung model to classify patients was $79 \%$ with $81 \%$ sensitivity $77 \%$ specificity (Figure 4B). As expected, the capacity of the U1Ap lung model to identify a patient with or without lung disease was not significantly different when SLE or MCTD subsets were contrasted.

\section{Discussion}

New markers that differ between SLE and MCTD patients are being described as the understanding of these autoimmune syndromes increases (Sasaki et al., 2011; Lage et al., 2012; Mesa et al., 2013; Jin et al., 2013). In the present study, the IgM reactivity for peptides covering the full length of the U1Ap was explored to find potential novel U1Ap antigens unique to either autoimmune disorder as well as to determine associations that 
might exist between IgM responses to U1Ap and organ targeting. The present investigation reported differences between SLE and MCTD patients regarding their antiU1Ap responses, provided the first IgM derived epitope mapping of U1Ap for these autoimmune disorders, and describe two patterns of IgM anti-U1Ap peptide reactivity that are associated with kidney or lung disease.

The mapping of the IgM response onto the predicted 3D structure of the full length U1Ap represented a unique approach to examine the behavior of the autoimmune reaction for this protein in SLE and MCTD patients (Figure 2), especially since only the U1Ap's RRM1 NMR has been described (Varani et al., 2000). In concordance with a previous report (McClain et al., 2004), U1Ap fragments that do not participate in protein or RNA binding show the highest IgM antigenicity in both SLE and MCTD (P5-P13 in Figures 1 and 2). Nevertheless, only SLE but not MCTD patients showed significant differences when domains RRM1 and RRM2 were compared to non-domain areas (U1Ap amino acids 87-206, $p \leq 0.05$ ). The present study revealed that bound and unbound region of U1Ap are capable of elicit an autoimmune response and therefore suggest that unbound regions of U1Ap are not sufficient to elicit IgM antigenicity. Consequently, other factor(s) like molecular mimicry from defective immune response to viral infections described by Migliorini et al. (2005) could be essential in promoting antiU1Ap IgM responses in SLE but not MCTD patients. Contrary to the common believe that antigenic fragments are located on superficial protein regions (McClain et al., 2004), the data suggest that the IgM response to U1Ap does not appear to rely only on peptide accessibility in the intact form of the protein. Consequently, it is reasonable to hypothesize that the IgM response in SLE and MCTD patients could form prior to U1Ap 
reaching its native state or after deficient clearance of U1Ap apoptotic material like that reported by the deleterious role of granzyme B in autoimmune diseases (Casciola-Rosen et al., 1999; Mevorach, 2003). The fact that SLE and MCTD patients' sera were unable produce an autoimmune reaction for U1Ap RRM2 (P14-P17 in Figures 1 and 2) when compared to U1Ap RRM1 (P1-P4) was not surprising given that RRM2 sequence differs by $78 \%$ from that of RRM1 and its binding capacity has been shown to not resemble that of a typical RNA binding protein ( $\mathrm{Lu}$ and Hall, 1995). Taken all together, the 3D epitope map not only allows for visualization of the IgM antigenicity of U1Ap fragments determined by their location and molecular structure but also provides a basis to develop a new hypothesis regarding the IgM response to U1Ap (Figure 2).

The binomial analysis revealed that the combined IgM reactivity of six U1Ap peptides (P2, P8, P12, P14, P15 and P17) allowed the detection of kidney damage in either SLE or MCTD patients with an overall accuracy of $72 \%(p \leq 0.005)$ (Figure 3). Interestingly, the power of the U1Ap kidney model did not significantly differ between SLE and MCTD with kidney malfunction $(p \leq 0.05)$. The present study describes for the first time an U1Ap model as a predictive serological biomarker for kidney disease. However, levels of neutrophil gelatinase-associated lipocalin (NGAL), soluble vascular cell adhesion molecule 1 (VCAM-1), Interleukin 6 (IL-6) and nucleosome have been described as molecular determinants for kidney disease only for SLE but not reported for MCTD patients (Yang et al., 2012; Pizarro et al., 2007; Brugos et al., 2012; Simón et al., 2004). Currently, NGAL is considered the gold standard for the diagnosis and prognosis of kidney injury with sensitivity (70.8\%) and specificity (87.5\%) in SLE patients (Haase et al., 2009; Yang et al., 2012). Nevertheless, previous research derived from NGAL has 
not recognized the inclusion of MCTD patients therefore its power to detect kidney disease in these unrecognized illness is unknown. Consequently, the proposed U1Ap kidney model represents the only available blood marker for kidney disease for patients diagnosed with either SLE or MCTD.

The combination of IgM reactivity for four U1Ap subunits (P4, P9, P12, and P15) had significant power to identify patients with lung disease diagnosed with either SLE or MCTD with an overall accuracy of 79\% $(p \leq 0.002)$ (Figure 4). The U1Ap lung model did not show significant difference in predicting lung damage when SLE and MCTD were compared. However, lung biomarker homogeneity like the one observed in the present study has been reported in patients suffering from autoimmune disorders (Nishimaki et al., 1999). The proposed lung model is congruent with previous studies given that auto-antigenicity against U1Ap has been associated with lung disease in SLE and MCTD patients (Nishimaki et al., 1999; Bertoli et al., 2007; Cojocaru et al., 2011; Lian et al., 2012) and has even been shown to be elevated in three different types of lung cancer (Zhang et al., 2005 and 2008). Aside from these associations, no study has recorded the predicted accuracy of these correlations and, as a result, chest radiography has been the suggested method to diagnose lung injury (Levitt et al., 2013). Since evidence of lung damage is reported in both of these autoimmune syndromes and indicated to be the leading cause of mortalities in MCTD patients (Prakash, 1992; Pehlivan and Inanc, 2010; Allen et al., 2012), the U1Ap lung model should be considered as a new serological predictive factor for lung disease with the sensitivity and specificity of $81 \%$ and $77 \%$, respectively, in patients with either SLE or MCTD (Figure 5). 
In summary, the results are in agreement with previous studies given that there is a prevalence of IgM anti-U1Ap reactivity in SLE but not MCTD patients (Figures 1). The IgM derived U1Ap epitope map showed that peptide accessibility is not sufficient to justify the contrasting autoimmune reactions observed in SLE and MCTD patients (Figure 2) and the data suggests that molecular mimicry from previous infection and/or deficient clearance of U1Ap apoptotic fragments are candidate factors for this difference. Consequently, these findings constitute additional molecular evidence to support the different etiology of these autoimmune disorders. Furthermore, for the first time, this work described two serological biomarkers with the predicted capacity of $72 \%$ of detecting kidney damage and $71 \%$ of identifying lung injury in patients diagnosed with either SLE or MCTD (Figures 4 and 5). With acknowledgement that additional validation of the U1Ap proposed models for identification of kidney and lung malfunction is required, future research on biomarkers associated with organ malfunction in SLE population should strongly consider the recognition of MCTD patients given the great number of overlapping characteristics shared by these two autoimmune syndromes. 
Table 1: U1A protein peptides characterization

\begin{tabular}{ccccc}
\hline $\begin{array}{c}\text { Peptide } \\
\text { Number }\end{array}$ & $\begin{array}{c}\text { Peptide } \\
\text { Position }\end{array}$ & Peptide Sequence & $\begin{array}{c}\text { Peptide } \\
\text { length }\end{array}$ & Reference \\
\hline P1 & $1-11$ & 11 & Barakat et al. (1991) \\
P2 & $35-58$ & MAVPETRPNHT & 24 & Barakat et al. (1991) \\
P3 & $47-59$ & 13 & Arbuckle et al. (1998) \\
P4 & $60-95$ & KEVSSATNALRSMQGFPFYDKPMRIQYAKTDSDIIA & 36 & No previously tested \\
P5 & $96-103$ & RSLKMRGQAFVIF & 8 & Poole et al. (2009) \\
P6 & $112-119$ & 8 & Somarelli et al. (2011) \\
P7 & $118-127$ & KMKGTFVE & 10 & Poole et al. (2009) \\
P8 & $143-154$ & 12 & Poole et al. (2009) \\
P9 & $159-178$ & TPATKKAVQG & 20 & Poole et al. (2009) \\
P10 & $165-172$ & GMPPMTQAPRIM & 8 & Talken et al. (2001) \\
P11 & $178-185$ & GQPPYMPPPGMIPPPGLAPG & 8 & Somarelli et al. (2011) \\
P12 & $180-193$ & PPPGMIPP & 14 & Poole et al. (2009) \\
P13 & $196-203$ & GQIPPGAM & 8 & Somarelli et al. (2011) \\
P14 & $204-235$ & NPPNHILFLTNLPEETNELMLSMLFNQFPGFK & 32 & No previously tested \\
P15 & $236-242$ & EVRLVPGR & 8 & Poole et al. (2009) \\
P16 & $239-251$ & IPPGAMPPQQLMPG & 13 & Arbuckle et al. (1998) \\
P17 & $257-282$ & AGAARDALQGFKITQNNAMKISFAKK & 26 & Barakat et al. (1991)
\end{tabular}




\section{Figures Legends}

Figure 1: SLE but not MCTD patients show predominant IgM response to U1Ap subunits. The diagram under U1A protein is a graphical representation of the linear structure of this protein where RNA recognition motif 1 (RRM1) and 2 (RRM2) are labeled. The amino acids covered by each of the peptides (P1-P17) are indicated under peptide position. The red, blue and gray columns correspond to SLE ( $\mathrm{n}=56)$, MCTD (n $=26)$ and healthy $(n=10)$ individuals, respectively. The lines on top of each column represent the standard error.

Figure 2: U1A protein epitope map for IgM antigencity in SLE and MCTD patients. The IgM optical density percentage (OD\%) based on the healthy group IgM reactivity obtained from SLE (top) and MCTD (bottom) patients was mapped onto the 3D structure of U1A protein. The IgM antigenic scale is included at the bottom of the figure where blue and red represent the lowest and highest IgM reactivity for U1A protein, respectively. Gray areas on the SLE and MCTD epitope maps correspond to regions of unknown IgM antigenicity since no peptide covers these specific fragments. The rectangle embedded in the middle represents the U1A protein $3 \mathrm{D}$ structure where RNA recognition motif 1 (RRM1) is labeled in red, RRM2 is colored in blue while the gray fragments are regions free of RNA and protein interactions.

Figure 3: IgM reactivity for U1Ap is a candidate marker for kidney damage. The observed IgM response to U1A protein (U1Ap) peptides was analyzed by binomial logistic regression (BLR) to assess which peptide combination increase could 
significantly identify patients with kidney damage in either SLE or MCTD populations ( $p$ $\leq 0.05$ ). The classification ability of each of these peptides and predicted models were corroborated by receiving operating characteristic (ROC) curves analysis $(p \leq 0.05)$ A. ROC curves revealed the power of U1A peptides in classifying patients with kidney damage. In the graph, the peptides and predicted U1Ap kidney model are on the xaxis while the area under the curve (AUC) resulting from ROC curves analysis is indicated on the $y$ axis. The larger the number, the higher the probability of identifying an individual with kidney disease compared to a healthy individual. The lines on top of each column correspond to standard deviation. The $p$ values $\leq 0.05, \leq 0.001$ and 0.0001 are represented with one $(*)$, two $\left({ }^{* *}\right)$ or three $(* * *)$ asterisks, respectively. B. Distribution of patients with kidney damage based on the U1Ap kidney model. Patients with evidence of kidney damage and healthy individuals are on the $\mathrm{x}$ axis while the predicted probabilities obtained from BLR analysis are on the y axis. The black and white dots indicate true positive (TP) and true negatives (TN) while the crosses represent either false positives (FP) or false negatives (FN). A cut off value of 0.5 (from a range of 0 to 1 ) was selected to allow equal chances to FP and FN ( $p \leq 0.05)$.

Figure 4: IgM anti-U1Ap titers are potential biomarkers for lung damage. The IgM reaction for U1A protein (U1Ap) peptides was analyzed by binomial logistic regression (BLR) to uncover peptide combinations with power to discern between patients with lung damage and healthy individuals in either SLE or MCTD populations $(p \leq 0.05)$. The grouping capability of each of these peptides and predicted models were corroborated by receiving operating characteristic (ROC) curves analysis $(p \leq 0.05)$ A. ROC curves 
showed the classification power of the U1Ap lung model. In the graph, the peptides and predicted U1Ap lung model and area under the curve (AUC) resulting from ROC curves analysis are on the $\mathrm{x}$ and $\mathrm{y}$ axes. The bigger the AUC, the higher the classification power for lung disease. The lines on top of each column correspond to standard deviation. The asterisks $\left(^{* * *}\right)$ represent $p \leq 0.0001$. B. Segregation of patients with lung damage utilizing the U1Ap lung model as classifier. In the plot, patients and predicted probabilities of kidney damage are on the $\mathrm{x}$ and $\mathrm{y}$ axes. The black and white dots indicate true positive (TP) and true negatives (TN), respectively, while the crosses represent either false positives (FP) or false negatives (FN). A cut off value of 0.5 (from a range of 0 to 1 ) was selected to allow equal chances to FP and $\mathrm{FN}(p \leq 0.05)$. 
Figure 1: SLE but not MCTD patients show predominant IgM response to U1Ap subunits

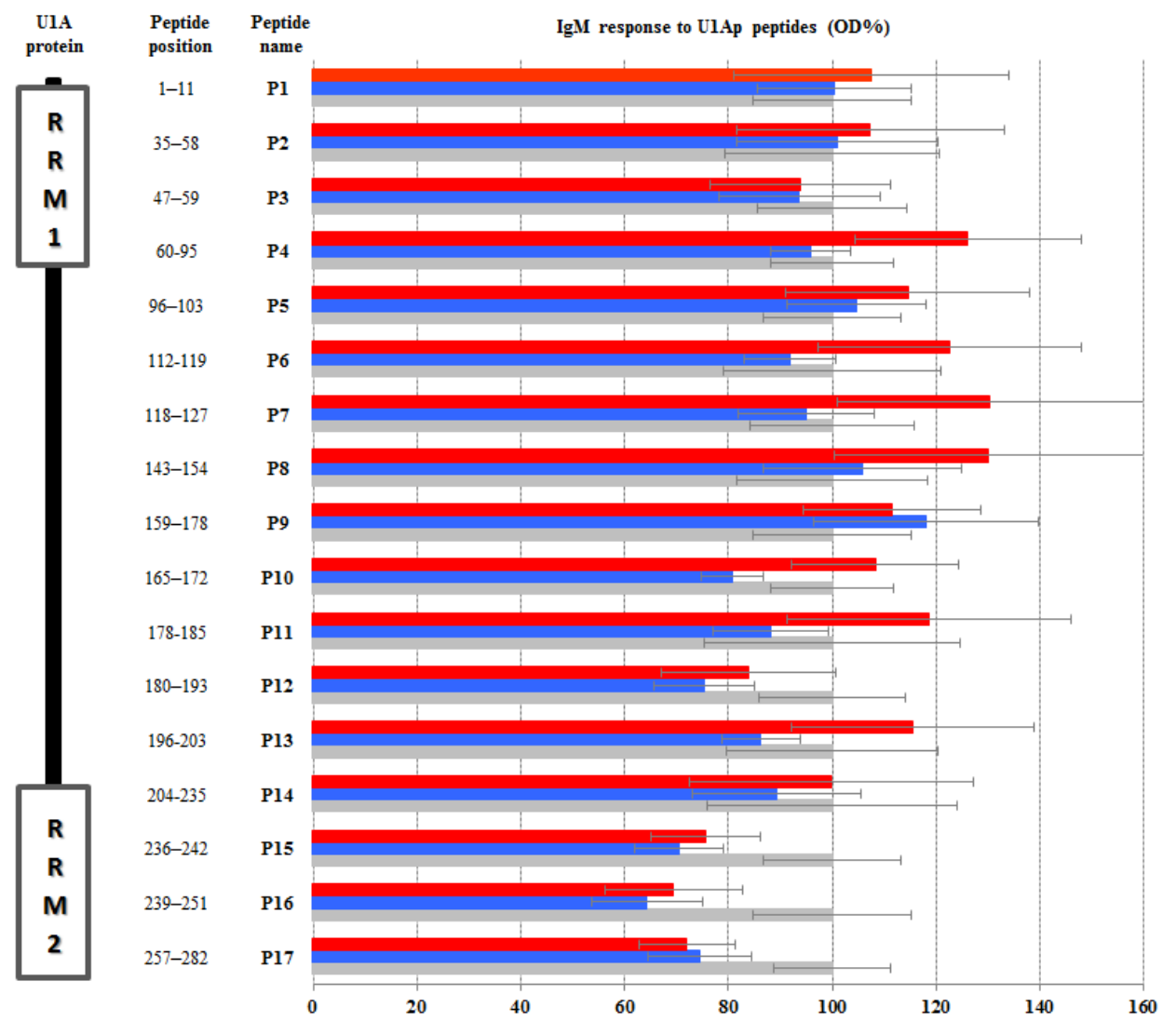


Figure 2: U1A protein epitope map for IgM antigencity in SLE and MCTD patients.

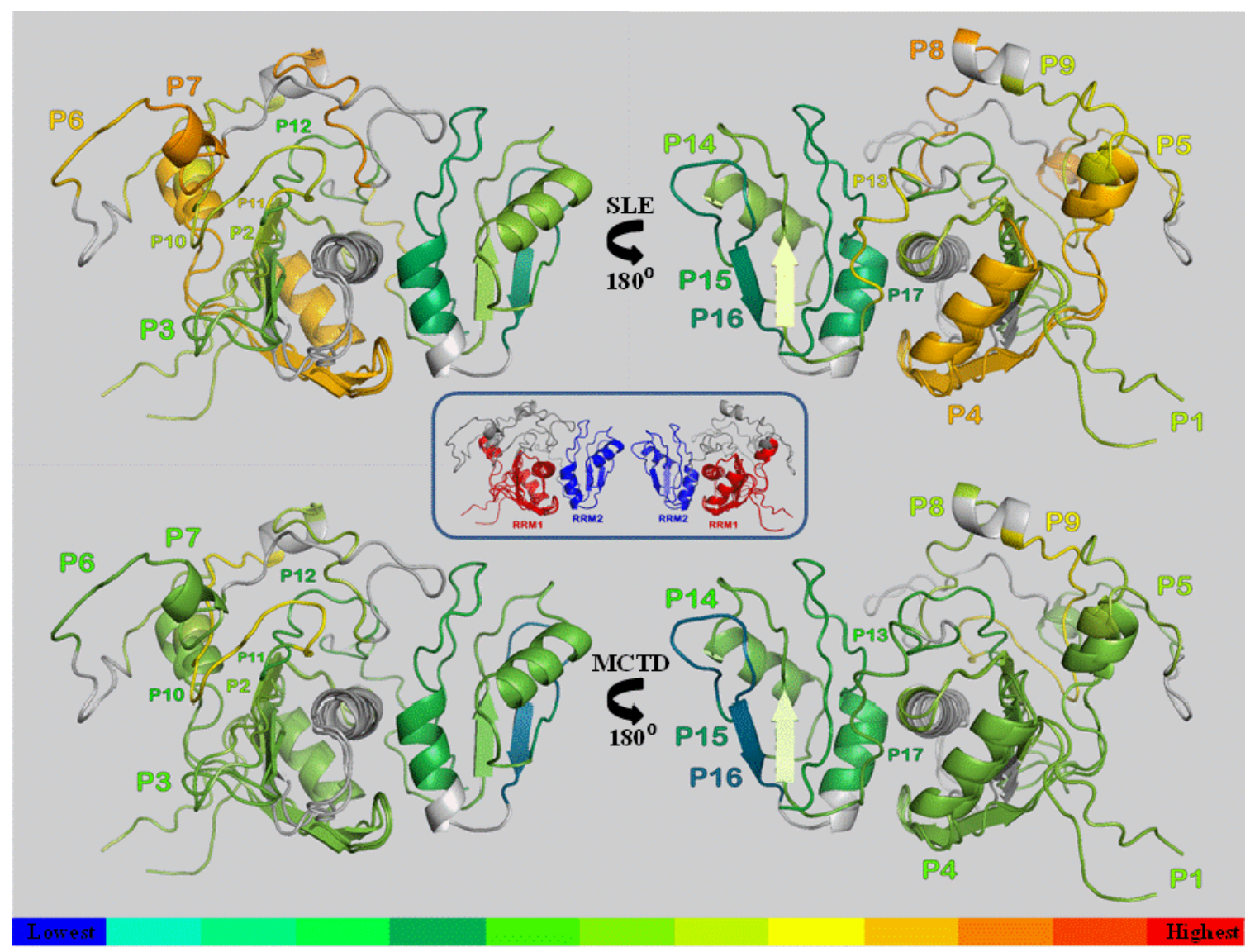


Figure 3: IgM reactivity for U1Ap is a candidate marker for kidney damage.
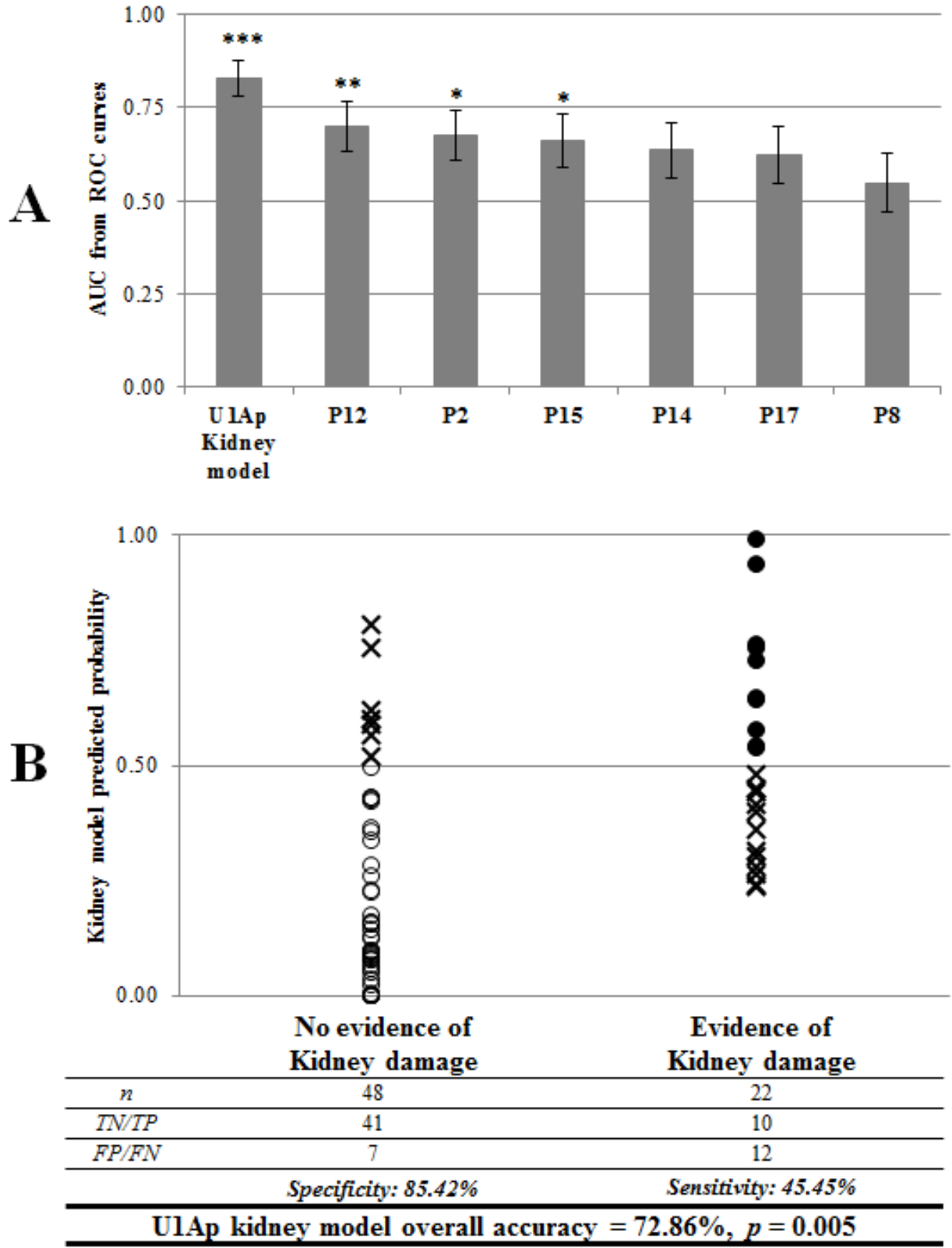
Figure 4: IgM anti-U1Ap titers are potential biomarkers for lung damage.

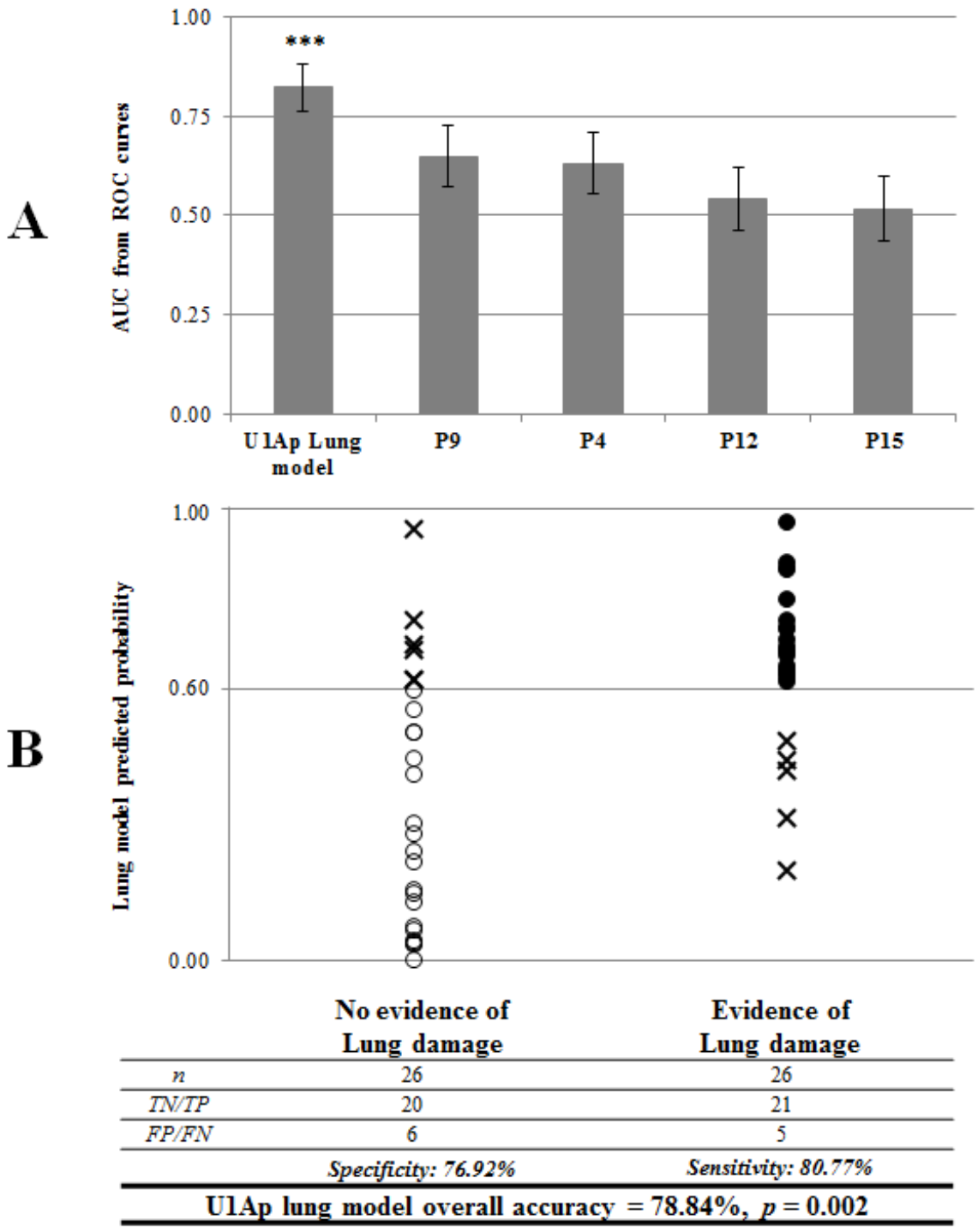




\section{CHAPTER 2}

Production of spliceosomal derived biomarkers for identification of SLE and MCTD 


\section{Introduction}

Systemic Lupus Erythematosus (SLE) and Mixed Connective Tissue Disease (MCTD) are systemic autoimmune disorders with overlapping clinical manifestations that possess aberrant immune responses against common auto-antigens (Zdrojewicz et al., 1999; Egner 2000; Greidinger and Hoffman , 2001; Riemekasten and Hahn, 2005; Neogi et al., 2006; Liu and Ahearn, 2009). Despite its description as an independent autoimmune disease (Sharp et al., 1972), the classification of MCTD as distinct from SLE remains controversial because of the high number of common clinical features between SLE and MCTD patients (López-Longo et al., 1994; Aringer et al., 2005; Swanton et al., 2005; Venables, 2006; von Bierbrauer et al., 2008; Nowicka-Sauer et al., 2012). Nevertheless, the concept of MCTD has been reported as a useful definition in clinical practice (Zdrojewicz et al., 1999; Venables, 2006; von Bierbrauer et al., 2008; NowickaSauer et al., 2012), and clinical and serological features segregate the two illnesses (Isenberg et al., 2007; Breda et al., 2010). The American College of Rheumatology (ACR) has created universal classification parameters for SLE (Hochberg, 1997); however, four different criteria sets exist for MCTD patients, with the Alarcón-Segovia criteria being the most widely accepted (Amigues et al., 1997).

Currently, there is no single test with sufficient specificity and sensitivity to discriminate between SLE and MCTD, which has hampered the identification of MCTD as a separate syndrome (Egner 2000; Reveille, 2004; Perkins et al., 2008; Liu and Ahearn, 2009; Hoffman et al., 2012). A positive diagnosis by any set of criteria requires a patient to exhibit at least four clinical symptoms and/or tests out of those included in each list, which can take years to develop (Liu and Ahearn, 2009; Hoffman et al., 2012). 
Moreover, traditional laboratory tests are performed with numerous commercially available kits that can vary in principle and cut-off values, which may alter the final results and diagnoses (Egner 2000; Reveille, 2004; Mahler et al., 2005; Isenberg et al., 2007; Chiaro et al., 2011). These and other factors complicate proper diagnosis of these two closely related and overlapping illnesses.

Previous investigations have demonstrated that SLE and MCTD patients often exhibit 1000-fold greater auto-reactivity to subunits of the U1 small nuclear ribonucleoprotein particle (snRNP) than to any other cellular component (Hoet et al., 1993; Vlachoyiannopoulos et al., 1996). The U1 snRNP is an RNA-protein complex that is responsible for pre-mRNA processing and is composed of 10 proteins (U1-70K, U1A, U1C and seven Smith antigen (Sm) proteins) (Luyckx et al., 2005; Mesa et al., 2008; Buratti et al., 2010; Somarelli et al., 2010). In general, previous studies aimed at finding biomarkers for SLE and MCTD have focused on IgG-specific responses to nuclear components, including the U1 snRNP; however, some studies have revealed differential IgM reactivity for nuclear components in SLE and MCTD patients (Zhang et al., 1995; Vlachoyiannopoulos et al., 1996; Witte et al., 1998; Palafox Sánchez et al., 2009). Yet, the potential use of the IgM response as a molecular tool to classify SLE and MCTD patients has not been fully explored.

To determine whether SLE and MCTD represented distinct disorders and test whether the two patient groups can be segregated, the IgG- and IgM-specific responses of patients with SLE and MCTD and healthy individuals against 15 different U1 snRNP peptides (named P1-15) were evaluated by indirect enzyme-linked immunosorbent assays (ELISAs). Interestingly, higher IgG-specific reactivity for U1 snRNP peptides was 
observed in individuals with SLE or MCTD compared to healthy individuals, but elevated IgM responses in SLE patients compared to those with MCTD and healthy adults. The IgM response to two peptides, P4 and P10 (P4/P10), exhibited 71.3\% accuracy in segregating between these two autoimmune disorders $(p \leq 0.05)$. In summary, these data support the notion that SLE and MCTD are, indeed, distinct disorders and highlight the potential clinical use of the IgM anti-U1 snRNP system as a molecular tool to assist in the classification of SLE and MCTD patients.

\section{Materials and Methods}

\section{Collection and preparation of sample sera}

Sera were obtained from whole blood of 122 patients previously diagnosed with SLE $(n=81)$ or MCTD $(n=41)$ and 31 healthy individuals. Samples were collected following the Institutional Review Board (IRB) accepted protocols of the University of Miami (IRB numbers: 200307-24 and 200402-86) and Florida International University (IRB number: 040308-00). The SLE and MCTD patients (collectively refer as ill or patient group) were clinically diagnosed according to the American College of Rheumatology (ACR) criteria and the Alarcón-Segovia criteria, respectively, along with clinician judgment (Amigues et al., 1996; Hochberg, 1997). The laboratory tests considered in the present study were commercially performed by Quest Diagnostic Incorporated and their positive values are included in Table 3. Details of the flare or remission period in these SLE and MCTD patients were not recorded at the moment of whole blood collection and therefore disease activity for these SLE and MCTD patients is not been considered in this study. 


\section{Selection of U1 snRNP peptides}

The U1 snRNP peptides included were previously reported in Somarelli et al., (2011) and commercially synthesized by BioMatik Corporation (Wilmington, DE, USA) The observed IgM reactivity for each of the U1 snRNP peptides was ranked from most (1) to least (15) antigenic for each disease state (Table 3).

Monitoring IgM reactivity for U1 snRNP peptides by indirect ELISAs

The indirect ELISA protocol employed to assess IgM reactivity for each peptide and sample included was previously described (Somarelli et al., 2011). The average IgM derived OD value for each peptide was normalized using the average OD value of the healthy group per peptide examined and was expressed as OD\% based on the following formula (Muñoz-Paredes et al., 1999):

$$
O D \%=\left(\frac{\bar{X} \text { OD of sample in } P x}{\bar{X} \text { OD of control group in } P x}\right) \times 100
$$

where " $\bar{X} O D$ of sample in $P_{x}$ " is the average OD value of the sample group (SLE or MCTD) and " $\bar{X} O D$ of control in $P_{x}$ " indicates the average OD of the control group (healthy group) from each of the peptides included in this study (P1-P15). To evaluate the relative reactivity contributed by IgM and IgG in SLE, MCTD and healthy populations, the average OD values from IgG-specific ELISAs previously reported by Somarelli et al., (2011), which used the same samples and U1 snRNP peptides included in this study, were re-analyzed and converted to OD\% using the equation described above (MuñozParedes et al., 1999). 


\section{Statistical analyses}

Significant differences in $\mathrm{IgG}$ and IgM reactivity between patients (SLE and MTCD) and healthy groups and between SLE and MCTD individuals for each of the peptides was assessed using independent sample $t$-tests. Clinical tests and symptoms were evaluated by independent sample $t$-tests (numerical data) or Chi $(X)$ squared tests (nominal data). Receiver Operating Characteristic (ROC) curves were generated with the PASW software package (version 18). Forward binary logistic regression (BLR) analyses using the IgM and IgG anti-U1 snRNP titers in ill (SLE and MCTD) and healthy individuals as well as SLE and MCTD patients were performed with the PASW software package (version 18). P-values $\leq 0.05$ were considered statistically significant for all tests. Correlations between each IgM anti-U1snRNP peptide titers and IgM anti-Rheumatoid Factor (RF) antibody titers were performed using PASW software package (version 18), however; since none of them were significantly correlated, they were not further considered in this study.

\section{Results}

IgM anti-U1 snRNP reactivity is elevated in SLE but not MCTD patients

The IgM response to U1 snRNP peptides was monitored via indirect ELISAs and reported as OD\% (Figure 5A). IgM anti-U1 snRNP titers were significantly higher in the SLE group than either the MCTD population or healthy individuals $(p \leq 0.05)$. In fact, in many instances, IgM responses to U1 snRNP peptides in MCTD patients were equal to or below those exhibited by healthy individuals (P3, P4 and P9-P15 in Figure 5A). The discrimination capacity of IgM-anti-U1 snRNP peptide ELISAs was assessed by ROC 
curve analysis and indicates that IgM reactivity for $\mathrm{P} 1$ and $\mathrm{P} 13$ provides significant power to classify SLE and MCTD patients; however, none of the IgM responses were sufficient to discern SLE and MCTD from non-disease controls with statistical significance (Figures 1C-D and Appendix 2).

SLE and MCTD patients exhibit an elevated IgG response for U1 snRNP peptides

As previous studies have reported (Fries et al., 1984; Nishimaki et al., 1999; Lindorfer et al., 2001; Routsias et al., 2010; Ryu et al., 2011; Somarelli et al., 2011; ), the IgG-mediated reactivity for each of the U1 snRNP peptides was significantly higher in both SLE and MCTD populations than in the healthy group; however, IgG reactivity does not differ between the two autoimmune disorders (Figure 5B). ROC curve analyses on IgG anti-U1 snRNP titers per peptide ascertain their individual ability to discern between patients (SLE and MCTD) and healthy individuals and between SLE and MCTD patients (Figure 5C-D, respectively; and Appendix 2). As previously reported (Somarelli et al., 2011), all but IgG anti-P2 responses were capable of significantly discriminating ill (SLE and MCTD) and healthy individuals with IgG anti-P4 being the best $(p \leq 0.05)$; however, none of the IgG anti-U1 snRNP titers had a statistically significant ability to classify SLE and MTCD patients (Figure 5D).

Differential auto-immune responses and symptoms are observed in SLE and MCTD patients

The results showed that SLE and MCTD patients exhibit significantly different IgM anti-U1 snRNP reactivity $(p \leq 0.05)$ despite similar IgG-mediated antigenicity for 
the same peptides (Figures 1A-B). To further support the idea that SLE and MCTD represent distinct auto-immune illnesses, statistical analysis of 42 standard laboratory tests were performed with blood samples from the SLE and MCTD patient cohort. These analyses revealed that 11 out of the 42 clinical tests were significantly different in SLE and MCTD patients $(p \leq 0.05)$ (Table 2). Specifically, differences were observed in tests designed to detect nuclear auto-antigens (RNP, Sm, Scl70, dsDNA, elevated DNA), renal function (creatine phosphokinase levels, renal proteinuria, renal hematuria) and immune system components (C3 and C4 complement levels) $(p \leq 0.05)$. These findings support the idea that SLE and MCTD represent distinct autoimmune manifestations, with specific antigenic targets and antibody class reactivities.

Similarly, statistical assessment of 40 clinical symptoms from patients in the SLE and MCTD cohort indicated that 16 out of the 40 clinical characteristics evaluated were significantly different between SLE and MCTD patients (Table 4). Most of the significantly different clinical manifestations involved the skin and joints of these patients; however, the data also confirmed that neuropsychiatric disorders and problems in the circulatory system were also significantly different between the two groups. Once again, the fact that clinical symptoms differ in SLE and MCTD populations supports the hypothesis that these maladies may be clinically distinct.

Antibody class reactivities for U1 snRNP peptides segregate among SLE, MCTD and healthy individuals

The IgM and IgG responses for all U1 snRNP peptides were combined in a BLR to determine which peptide and auto-antibody combinations might provide the highest 
segregation between patient (SLE and MCTD) and healthy populations. These analyses revealed that the combined IgG-specific response for P2, P4, P5, P10 and P13 has the greatest capacity to discern between sick and healthy individuals with an overall accuracy of 94\% ( $p \leq 0.05$ ) (Figure 6A) where the probability of correctly predicting a patient with either SLE or MCTD is higher than that for correctly predicting a healthy individual (96.7\% and $83.9 \%$, respectively).

Additional BLRs were performed with the individual IgG and IgM reactivities for each U1 snRNP peptide to assess which peptide and Ig class combination significantly discriminates between SLE and MCTD patients. These analyses indicated that only the combined IgM response for P4 (U1C) and P10 (U1A) significantly discriminate between SLE and MCTD patients, with an overall accuracy of $71.3 \%(p \leq 0.05)$ (Figure 6B). Remarkably, most of the classification power derives from the proper classification of SLE patients (95.1\%) rather than proper grouping of MCTD patients (24.4\%) (Figure 6B). Consequently, the data demonstrate that by first combining the $\mathrm{IgG}$ reactivity for $\mathrm{P} 2$, $\mathrm{P} 4, \mathrm{P} 5$ and $\mathrm{P} 10$ and then the titers for IgM anti-P4/P10, an overall accuracy of $73.9 \%$ at discriminating among SLE, MCTD and healthy groups can be achieved.

\section{Comparing the power of IgM anti-P4/P10 with conventional clinical tests}

To determine the classification power of the proposed IgM-specific P4/P10 ELISA-based system, ROC curves were used to compare this system with eight conventional clinical tests. The individual IgM reactivities for P1 and P13 were also included in the ROC curves analyses because they discriminate between SLE and MCTD (Figure 5D). The 11 laboratory tests that significantly differ between SLE and MCTD 
patients were performed only in a small portion of each sub-population (Table 2). Not all tests could be analyzed as result of the reduced sample size. Instead, eight of the most frequently-used laboratory tests that are part of the classification criteria to diagnose SLE or MCTD were included in the ROC curve analysis (FANA titers, dsDNA ELISA, elevated serum DNA titers and positive results for RNP, Sm, SSA, SSB and Scl-70) (Egner, 2000; Mahler et al., 2005; Isenberg et al., 2007; Breda et al., 2010). When using the subset of individuals for whom clinical test results were available (SLE $=59$ and MCTD $=24)$, the IgM anti-P4/P10 titers and IgM anti-P1 reactivity displayed the greatest discrimination capacity to classify SLE and MCTD patients $(p \leq 0.05)$ (Figure 7 and Appendix 2). The ROC curves confirmed that among the conventional tests evaluated, elevated DNA and positive results for Sm are the third and fourth best at significantly segregating SLE and MCTD $(p \leq 0.05)$.

\section{Improving the discriminatory capacity of IgM anti-P4/P10 titers}

The BLR analyses were performed to assess whether the combination of the IgM anti-P4/P10 system and any of the eight laboratory tests employed to diagnose SLE or MCTD (FANA titers, dsDNA ELISA, elevated serum DNA titers and positive results for RNP, Sm, SSA, SSB and SCL-70) ${ }^{4 ; 15-16 ; 21-22}$ might provide greater capacity to distinguish between these syndromes. The individual IgM reactivities for P1 and P13 were considered in this BLR analysis because they showed a significant ability to classify SLE and MCTD patients $(p \leq 0.05)$ (Figure 5D). The BLR analyses indicated that the combination of the IgM-based reactivity for P4/P10 and an elevated DNA assay represent the best combination of variables to segregate SLE from MCTD when compared with 
IgM anti-P4/P10, -P1, or-P13 and any single laboratory test examined $(p \leq 0.0001)$

(Figure 7 and Appendix 2). None of the other clinical test combinations improved the power of discrimination between SLE and MCTD patients over that exhibited by the individual tests alone $(p \leq 0.05)$. The analyses also suggest that, when combined with the standard elevated DNA test, the IgM response against P4/P10 may be useful in enhancing the current segregation of SLE from MCTD.

\section{Discussion}

Despite the fact that MCTD was described as a distinct rheumatic syndrome in 1972 (Sharp et al., 1972), placement of this disorder as a separate auto-immune illness remains controversial. Opinions are divided regarding classification of MCTD as a separate malady due to the number of auto-antigens and clinical symptoms that show overlap with SLE (López-Longo et al., 1994; Aringer et al., 2005; Swanton et al., 2005; Venables, 2006; von Bierbrauer et al., 2008; Nowicka-Sauer et al., 2012). The immune responses of SLE and MCTD patients for overlapping 'self' antigens coupled with the diversity of commercially available clinical tests with differing protocols, reagents and cut-off values have impeded the development of standard and uniform assays to segregate these syndromes (Egner, 2000; Mahler et al., 2005; Neogi et al., 2006; Liu and Ahearn, 2009). With the exception of a few studies (Vlachoyiannopoulos et al., 1996; Zhang et al., 1995; Witte et al., 1998; Palafox Sánchez et al., 2009), most investigations have focused on IgG-mediated reactivity toward specific antigens as potential molecular tools to differentiate between SLE and MCTD patients (Fries et al., 1984; Lindorfer et al., 2001; Routsias et al., 2010; Ryu et al., 2011). Given that SLE and MCTD patients are 
characterized by elevated blood titers of multiple Ig classes, including IgM (Pollar and Tan. 1985; Kingsmore et al., 1989; Vlachoyiannopoulos et al., 1996), it was hypothesized that IgM responses to a number of U1 snRNP peptides may allow us to increase the present discrimination between SLE and MCTD and provide additional molecular evidence to claim the independent nature of these two disorders.

The data indicate that the combined IgM reactivity for fragments of U1C (P4) and U1A (P10) is capable of classifying SLE and MCTD patients with an accuracy of $71.3 \%$ (Figure 6B), a value higher than previously reported peptide-based immunoassays that have been used to segregate these disorders (Mahler et al., 2005). These findings are in concordance with previous reports, which revealed a preponderance of IgM anti-U1 snRNP antibodies in SLE, but not MCTD patients (Zhang et al., 1995; Vlachoyiannopoulos et al., 1996). Therefore, the present work is congruent with prior investigations and demonstrates the potential utility of differential Ig class responses as a classification tool for SLE and MCTD. The current work also provides molecular evidence to support the distinct etiology of these syndromes.

The binomial analyses identified combinations of laboratory tests and/or peptide reactivities that significantly discern between these maladies. Interestingly, the IgM antiP4/P10 ELISA-based system provided the greatest capacity to segregate between SLE and MCTD disorders and eight other conventional laboratory tests $(p \leq 0.0001)$ (Figure 7). Additionally, we revealed that the combination of IgM anti-P4/P10 antigenicity with the elevated DNA test segregated $79.8 \%$ of SLE and MCTD patients, even in the smaller subset of patients for whom clinical test results were available ( $n=59$ for SLE and $n=24$ for MCTD) (Figure 7). It is not surprising that the dsDNA test contributes to the 
differentiation of these diseases given that antibodies against DNA have been detected in approximately $70 \%$ of SLE patients and shows $95 \%$ specificity for this disorder (Reveille, 2004; Breda et al., 2010). Yet, the fact that the dsDNA test alone exhibits a lower ability to segregate SLE and MCTD patients (66.4\%) than the IgM anti-P4/P10 system (73.1\%), indicates the significant contribution of this ELISA-based system in discerning between these two maladies (Figure 7).

A total of 16 out of 40 clinical manifestations studied significantly differ between SLE and MCTD patients (Table 4). On average, MCTD patients exhibited hand/joint swelling and muscle weakness with $25 \%$ higher frequency than SLE patients. Similarly, malar and discoid rashes were found to be more prevalent in the SLE than the MCTD group ( $46 \%$ and $10 \%$ versus $13 \%$ and $0 \%$, respectively). These findings are in concordance with previous studies that reported these clinical manifestations as key features in SLE or MCTD patients (Perkins et al., 2008; Hoffman et al., 2010). Evidence of mental illness was also found to be $32 \%$ higher in MCTD than SLE patients. Although selection bias of the clinicians diagnosing these disorders cannot be ruled out, the results obtained from a subset of SLE and MCTD patients suggest that the immune response of SLE patients seems to be directed to skin areas on the face while those suffering from MCTD appear to develop a more systemic immune response that attacks the skin, joints and muscles throughout various parts of the body. Furthermore, these findings highlight specific clinical manifestations that appear to differ between SLE and MCTD patients and should be considered as clinical evidence that they may be distinct diseases.

Overall, this study further highlights the current challenges in developing quantitative tests for the classification of SLE and MCTD and therefore the recognition of MCTD as 
a separate entity (Egner, 2000; Mahler et al., 2005; Neogi et al., 2006; Liu and Ahearn, 2009). Here, a novel approach based on differential antibody class (IgM and $\operatorname{IgG}$ ) responses has been described as a mechanism to discriminate between SLE and MCTD patients with better accuracy than conventional laboratory tests currently employed as part of the classification criteria to diagnose these syndromes. In addition, the data revealed contrasting frequencies of clinical symptoms characterizing these auto-immune syndromes whereby SLE patients showed a concentrated auto-immune manifestation directed to skin areas on the face while those suffering from MCTD developed more systemic immune responses that attack the skin, joints and muscles throughout various parts of the body. Consequently, these results provide further evidence to support the fact that there are molecular and clinical aspects of SLE and MCTD to indicate that these diseases are, indeed, two distinct autoimmune syndromes. 
Table 2: Clinical tests evaluated in SLE and MCTD patients

\begin{tabular}{|c|c|c|c|c|c|c|}
\hline & \multirow{2}{*}{ Clinical test name } & \multicolumn{2}{|c|}{ SLE } & \multicolumn{2}{|c|}{ MCTD } & \multirow{2}{*}{$\begin{array}{c}P \\
\text { value }\end{array}$} \\
\hline & & Positive & Total & Positive & Total & \\
\hline \multirow{38}{*}{ 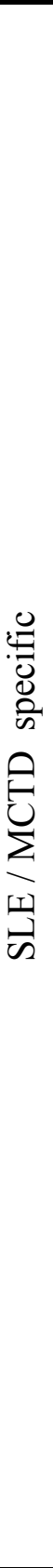 } & Fluorescence antinuclear Abs titers & $76.56 \%$ & 64 & $90.63 \%$ & 32 & 0.3860 \\
\hline & Fluorescence antinuclear Abs pattern & $86.30 \%$ & 73 & $85.71 \%$ & 35 & 0.4430 \\
\hline & IgG anticardiolipin positive & $23.53 \%$ & 68 & 23.81 & 21 & 0.8480 \\
\hline & IgM anticardiolipin positive & $6.06 \%$ & 66 & $18.18 \%$ & 22 & 0.0870 \\
\hline & Rheumatoid factor titer by latex & $8.33 \%$ & 12 & $20.00 \%$ & 5 & 0.0870 \\
\hline & IgM anti-rheumatoid factor Abs by ELISA & $41.86 \%$ & 43 & $38.10 \%$ & 21 & 0.8480 \\
\hline & IgM anti-rheumatoid factor Abs titer & $20.93 \%$ & 43 & $23.81 \%$ & 21 & 0.9040 \\
\hline & RNP positive & $84.00 \%$ & 75 & $100 \%$ & 40 & 0.0080 \\
\hline & Sm positive & $60.27 \%$ & 73 & $28.21 \%$ & 39 & 0.0010 \\
\hline & SSA positive & $58.11 \%$ & 74 & $47.22 \%$ & 36 & 0.2820 \\
\hline & SSB positive & $21.62 \%$ & 74 & $11.11 \%$ & 36 & 0.1800 \\
\hline & SCL 70 positive & $1.45 \%$ & 69 & $16.13 \%$ & 31 & 0.0040 \\
\hline & Elevated serum DNA titer & $64.10 \%$ & 78 & $29.73 \%$ & 37 & 0.0010 \\
\hline & Anti-dsDNA positive & $49.35 \%$ & 77 & $27.03 \%$ & 37 & 0.0010 \\
\hline & IgG anti U1-70K Abs* & $37.84 \%$ & 37 & $55.00 \%$ & 20 & 0.2130 \\
\hline & IgG anti SmB/B' Abs* & $44.12 \%$ & 34 & $50.00 \%$ & 20 & 0.7700 \\
\hline & IgG anti SmD Abs* & $73.53 \%$ & 34 & $63.16 \%$ & 19 & 0.7260 \\
\hline & Anemia & $25.00 \%$ & 80 & $22.50 \%$ & 40 & 0.7630 \\
\hline & Hemolytic anemia & $3.23 \%$ & 62 & $8.33 \%$ & 12 & 0.4120 \\
\hline & White blood count & $8.77 \%$ & 57 & $6.06 \%$ & 33 & 0.2780 \\
\hline & Leukopenia & $11.54 \%$ & 78 & $12.50 \%$ & 40 & 0.8780 \\
\hline & Lymphopenia & $36.71 \%$ & 79 & $42.5 \%$ & 40 & 0.5400 \\
\hline & Thrombocytopenia & $10.13 \%$ & 79 & $2.50 \%$ & 40 & 0.1370 \\
\hline & Thrombocytosis & $5.13 \%$ & 78 & $2.56 \%$ & 39 & 0.5180 \\
\hline & Creatine phosphokinase positive & $91.07 \%$ & 56 & $74.29 \%$ & 35 & 0.4770 \\
\hline & Creatine phosphokinase elevated & $7.02 \%$ & 57 & $25.71 \%$ & 35 & 0.0120 \\
\hline & Serum creatinine & $10.53 \%$ & 76 & $5.26 \%$ & 38 & 0.4500 \\
\hline & Renal cellular cast & $10.67 \%$ & 75 & $2.56 \%$ & 39 & 0.1280 \\
\hline & Renal proteinuria & $40.85 \%$ & 71 & $13.51 \%$ & 37 & 0.0040 \\
\hline & Renal hematuria & $18.92 \%$ & 74 & $2.70 \%$ & 37 & 0.0180 \\
\hline & $\mathrm{C}$ reactive protein & $20.83 \%$ & 72 & $18.18 \%$ & 33 & 0.4850 \\
\hline & Elevated $\mathrm{C}$ reactive protein & $23.61 \%$ & 72 & $20.59 \%$ & 34 & 0.7290 \\
\hline & Low $\mathrm{C} 3$ complement & $41.77 \%$ & 79 & $15.00 \%$ & 40 & 0.0030 \\
\hline & C3 complement level & $56.96 \%$ & 79 & $82.50 \%$ & 40 & 0.0001 \\
\hline & Low $\mathrm{C} 4$ complement & $48.10 \%$ & 79 & $30.77 \%$ & 39 & 0.0730 \\
\hline & C4 complement level & $44.30 \%$ & 79 & $69.23 \%$ & 39 & 0.0001 \\
\hline & Erythrocyte sedimentation rate & $57.89 \%$ & 79 & $52.27 \%$ & 40 & 0.8530 \\
\hline & Elevated erythrocyte sedimentation rate & $56.48 \%$ & 76 & $55.00 \%$ & 40 & 0.8710 \\
\hline \multirow{4}{*}{$\begin{array}{l}\bar{\pi} \\
\stackrel{\pi}{0} \\
\stackrel{0}{0}\end{array}$} & IgG anti-rheumatoid factor Abs & $41.86 \%$ & 43 & $42.86 \%$ & 21 & 0.9400 \\
\hline & IgG anti-rheumatoid factor Abs titer & $41.86 \%$ & 43 & $38.10 \%$ & 21 & 0.8480 \\
\hline & Immunoglobulin isotypes for RF factor & $79.07 \%$ & 43 & $76.19 \%$ & 21 & 0.5300 \\
\hline & Lymphocyte absolute value & $74.14 \%$ & 58 & $75.86 \%$ & 29 & 0.3460 \\
\hline
\end{tabular}


Table 3: Overview of $U 1$ snRNP peptides used in the study

\begin{tabular}{cccccc}
\hline $\begin{array}{c}\text { Peptide } \\
\text { number }\end{array}$ & $\begin{array}{c}\text { U1 snRNP } \\
\text { protein }\end{array}$ & $\begin{array}{c}\text { Peptideregion } \\
\text { (amino acid range) }\end{array}$ & $\begin{array}{c}\text { Peptide } \\
\text { sequence }\end{array}$ & \multicolumn{2}{c}{$\begin{array}{c}\text { Observed IgM } \\
\text { reactivity ranked }\end{array}$} \\
\hline $1^{\dagger *}$ & U1A & $196-203$ & PPAQPLSE & 1 & 6 \\
$2^{\dagger *}$ & Sm E & $63-70$ & EIHSKTKS & 3 & 2 \\
$3^{\dagger *}$ & Sm F & $46-53$ & NTEEYIDG & 12 & 9 \\
$4^{\dagger *}$ & U1C & $90-97$ & GMMPAPHM & 11 & 8 \\
$5^{*}$ & U1-70K & $337-344$ & PDGPDGPE & 6 & 4 \\
$6^{\dagger *}$ & Sm B & $83-90$ & EGPPPKDT & 2 & 3 \\
$7^{\dagger *}$ & Sm G & $1-8$ & MSKAHPPE & 5 & 5 \\
$8^{\dagger *}$ & Sm D3 & $20-27$ & CETNTGEV & 4 & 1 \\
$9^{\dagger *}$ & Sm F & $77-84$ & EEEEDGEM & 9 & 12 \\
$10^{\dagger *}$ & U1A & $112-119$ & KPKSQETP & 13 & 13 \\
$11^{\dagger *}$ & Sm D2 & $14-21$ & EELQKREE & 10 & 11 \\
$12^{\dagger *}$ & Sm D1 & $22-29$ & GTQVHGTI & 8 & 10 \\
$13^{\dagger *}$ & U1A & $178-185$ & GQIPPGAM & 14 & 14 \\
$14^{\dagger *}$ & U1-70K & $325-332$ & APPDDGPP & 15 & 15 \\
$15^{\dagger *}$ & U1C & $66-73$ & PFSAPPPA & 7 & 7 \\
\hline
\end{tabular}

The peptide designation, region and sequences as well as the U1 snRNP protein column displayed in this table (first four columns) were previously published by Somarelli et al. (2011). The observed IgM antigenicity (columns 5 and 6, from left to right) was ranked from 1 to 15 where " 1 " represents the peptide with the highest IgM antigenicity and " 15 " indicates the peptide with the lowest IgM antigenicity. Daggers $(\dagger)$ indicate IgM peptide antigenicities that significantly differ between SLE and MCTD patients while the asterisks (*) represent IgG reactivities for U1 snRNP peptides that significantly differ between ill (SLE and MCTD) and healthy individuals $(p \leq 0.05)$. 
Table 4: List of clinical symptoms observed in SLE and MCTD

\begin{tabular}{|c|c|c|c|c|c|}
\hline \multirow{2}{*}{ Clinical symptom name } & \multicolumn{2}{|c|}{ SLE } & \multicolumn{2}{|c|}{ MCTD } & \multirow{2}{*}{$p$-value } \\
\hline & Positive & Total & Positive & Total & \\
\hline Skin telangiectasia & $5 \%$ & 79 & $15 \%$ & 40 & 0.0650 \\
\hline Skin nasal/oral ulcers & $29 \%$ & 79 & $23 \%$ & 39 & 0.4880 \\
\hline Raynaud's syndrome & $53 \%$ & 80 & $85 \%$ & 40 & 0.0001 \\
\hline History of hand swelling & $41 \%$ & 81 & $61 \%$ & 41 & 0.0120 \\
\hline Observed hand swelling & $19 \%$ & 81 & $39 \%$ & 41 & 0.0140 \\
\hline Acrosclerosis & $4 \%$ & 80 & $26 \%$ & 38 & 0.0001 \\
\hline Skin digital pitting & $8 \%$ & 80 & $8 \%$ & 39 & 0.9700 \\
\hline Proximal scleroderma & $3 \%$ & 79 & $0 \%$ & 39 & 0.3160 \\
\hline Skin alopecia & $58 \%$ & 80 & $72 \%$ & 39 & 0.1310 \\
\hline Malar rash & $46 \%$ & 78 & $13 \%$ & 39 & 0.0001 \\
\hline Discoid rash & $10 \%$ & 78 & $0 \%$ & 39 & 0.0380 \\
\hline Skin rash & $33 \%$ & 78 & $38 \%$ & 39 & 0.5840 \\
\hline Skin photosensitivity & $57 \%$ & 76 & $58 \%$ & 38 & 0.8940 \\
\hline Skin calcinosis & $1 \%$ & 79 & $5 \%$ & 38 & 0.2000 \\
\hline $\begin{array}{l}\text { Sicca, xerophthalmia and } \\
\text { xerostomia }\end{array}$ & $49 \%$ & 81 & $66 \%$ & 41 & 0.1330 \\
\hline Erosive inflammatory arthritis & $43 \%$ & 23 & $45 \%$ & 20 & 0.9200 \\
\hline Lymphadenopathy & $24 \%$ & 79 & $20 \%$ & 40 & 0.6180 \\
\hline Fever & $22 \%$ & 78 & $15 \%$ & 40 & 0.7780 \\
\hline Proximal muscle weakness & $29 \%$ & 76 & $49 \%$ & 39 & 0.0360 \\
\hline Myositis & $6 \%$ & 79 & $27 \%$ & 33 & 0.0020 \\
\hline Myalgia & $54 \%$ & 80 & $48 \%$ & 40 & 0.8970 \\
\hline Morning stiffness & $53 \%$ & 73 & $64 \%$ & 36 & 0.3000 \\
\hline $\begin{array}{l}\text { Swelling of three or more } \\
\text { joints }\end{array}$ & $42 \%$ & 78 & $63 \%$ & 40 & 0.0380 \\
\hline Joint tenderness & $35 \%$ & 79 & $69 \%$ & 39 & 0.0010 \\
\hline Joint swelling & $29 \%$ & 78 & $63 \%$ & 40 & 0.0010 \\
\hline Symmetric swelling & $27 \%$ & 78 & $64 \%$ & 39 & 0.0001 \\
\hline Rheumatoid nodule & $6 \%$ & 77 & $10 \%$ & 40 & 0.5000 \\
\hline Arthralgia & $82 \%$ & 79 & $84 \%$ & 38 & 0.7950 \\
\hline Neuropathy & $31 \%$ & 77 & $28 \%$ & 40 & 0.6810 \\
\hline Seizure & $4 \%$ & 80 & $0 \%$ & 40 & 0.2150 \\
\hline
\end{tabular}


Table 4, continuation

\begin{tabular}{lccccc}
\hline \multirow{2}{*}{ Clinical symptom name } & \multicolumn{2}{c}{ SLE } & \multicolumn{2}{c}{ MCTD } & \multirow{2}{*}{-value } \\
& Positive & Total & Positive & Total & \\
\hline Psychosis & $3 \%$ & 79 & $0 \%$ & 39 & 0.3160 \\
Neuropsychiatric disorder & $19 \%$ & 78 & $51 \%$ & 39 & 0.0001 \\
Hypomotility in cine & $41 \%$ & 78 & $58 \%$ & 40 & 0.0890 \\
deglutition esophageal & $22 \%$ & 45 & $23 \%$ & 26 & 0.6330 \\
Pulmonary fibrosis & $37 \%$ & 78 & $23 \%$ & 39 & 0.1250 \\
Pleuritic pain or rubbing heard & $30 \%$ & 73 & $18 \%$ & 39 & 0.1610 \\
Pericarditis & $3 \%$ & 74 & $0 \%$ & 33 & 0.3040 \\
Avascular necrosis & $1 \%$ & 75 & $12 \%$ & 34 & 0.0160 \\
Clotting & $0 \%$ & 73 & $11 \%$ & 35 & 0.0030 \\
Myocardial infarction & $6 \%$ & 81 & $2 \%$ & 41 & 0.3570 \\
\hline Stroke & & & & & \\
\hline
\end{tabular}




\section{Figure legends}

Figure 5: Contrasting IgM-specific anti-U1 snRNP peptide responses observed in SLE and MCTD patients. (A) and (B) represent the average percent optical density $(\mathrm{OD} \%)$ values for the IgM class and IgG classes, respectively. Peptide number and OD\% are on the $\mathrm{x}$ and $\mathrm{y}$ axes, respectively. The black, gray and white bars symbolize the average OD\% of SLE, MCTD and healthy groups, respectively. ( $\dagger$ ) and (*) indicate significantly different OD\% between SLE and MCTD as well as patients and healthy populations, respectively $(p \leq 0.05)$. (C) and (D) correspond to the area under the curve (AUC), derived from ROC curves, for ill (SLE and MCTD) vs. healthy individuals as well as SLE vs. MCTD patients, respectively. Peptide number per Ig class and their AUC values are indicated on the $\mathrm{x}$ and $\mathrm{y}$ axes, respectively. $(\bullet)$ and $(\bullet)$ symbolize significantly different AUC between patients and healthy individuals as well as SLE and MCTD patients, respectively $(p \leq 0.05)$. The dotted lines in $\mathbf{C}$ and $\mathbf{D}$ indicate the cut-off value (0.5). Black bars in all graphs represent standard error of the mean.

Figure 6: Identification of a two-step ELISA system for classification of SLE, MCTD and healthy individuals. (A) The combination of IgG-mediated antiP2/P4/P5/P10/P13 provides the best segregation between SLE and MCTD vs non-disease controls. The distribution of ill (SLE and MCTD) and healthy individuals and the predicted combined IgG-mediated reactivity are represented on the $\mathrm{x}$ and $\mathrm{y}$ axes, respectively. Gray and white circles indicate true positives (TP). (B) Combined IgManti-P4/P10 can classify SLE and MCTD patients. The distribution of SLE and MCTD patients' combined IgM anti-P4/P10 predicted values are on the $\mathrm{x}$ and $\mathrm{y}$ axes, 
respectively. Black and gray diamonds indicate true positive (TP) samples for SLE and MCTD patients, respectively. The crosses represent false negatives (FN) or false positives (FP). Predicted values were obtained using binomial logistic regression (BLR) with a cut-off of $0.5(p \leq 0.05)$.

Figure 7: Area under the curve analysis reveals the classification power of IgM antiP4/P10. Receiver operating characteristic (ROC) curves were generated using peptide antigenicities or laboratory tests. The columns in the graph represent the area under the curve (AUC) in the y axis for each variable tested. The bars on top of each column indicate standard error of the mean. FANA titers, dsDNA, $\uparrow$ DNA (elevated serum DNA) and positive results for RNP, Sm, SSA, SSB and SCL are clinical tests used during SLE and MCTD diagnosis. The "IgM anti-P4/P10" indicates the combined IgM anti-P4/P10 titer while "IgM anti-P4/P10 + $\uparrow \mathrm{DNA}$ " represents the combination of the $\operatorname{IgM}$ antiP4/P10 ELISA and the elevated DNA assay. The “*” and “**” indicate significant differences in classifying SLE and MCTD with $p$ values of $\leq 0.05$ and $\leq 0.0001$, respectively. 
Figure 5: Contrasting IgM-specific anti-U1 snRNP peptide responses observed in SLE and MCTD patients

(A) IgM anti-U1 snRNP titers

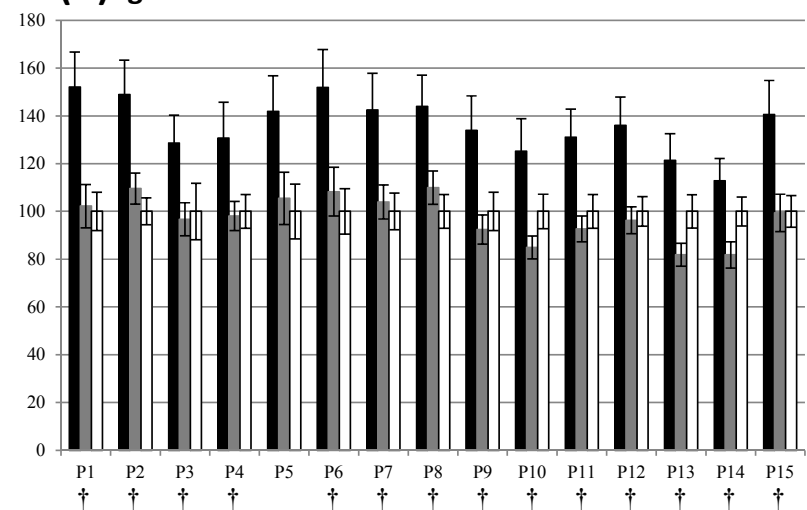

(C) AUC for ill vs healthy individuals



(B) IgG anti-U1 snRNP titers



(D) AUC for SLE vs MCTD patients

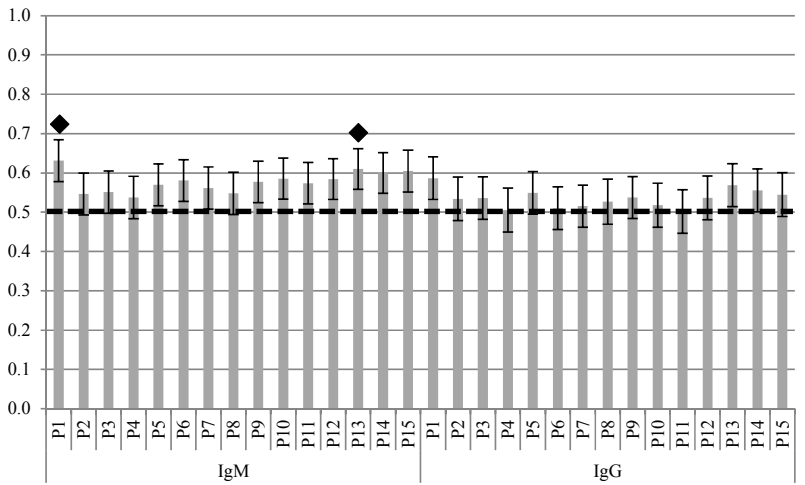


Figure 6: Identification of a two-step ELISA system for classification of SLE, MCTD and healthy individuals.

(A) IgG anti-P2/P4/P5/P10/P13 response segregates ill and healthy individuals

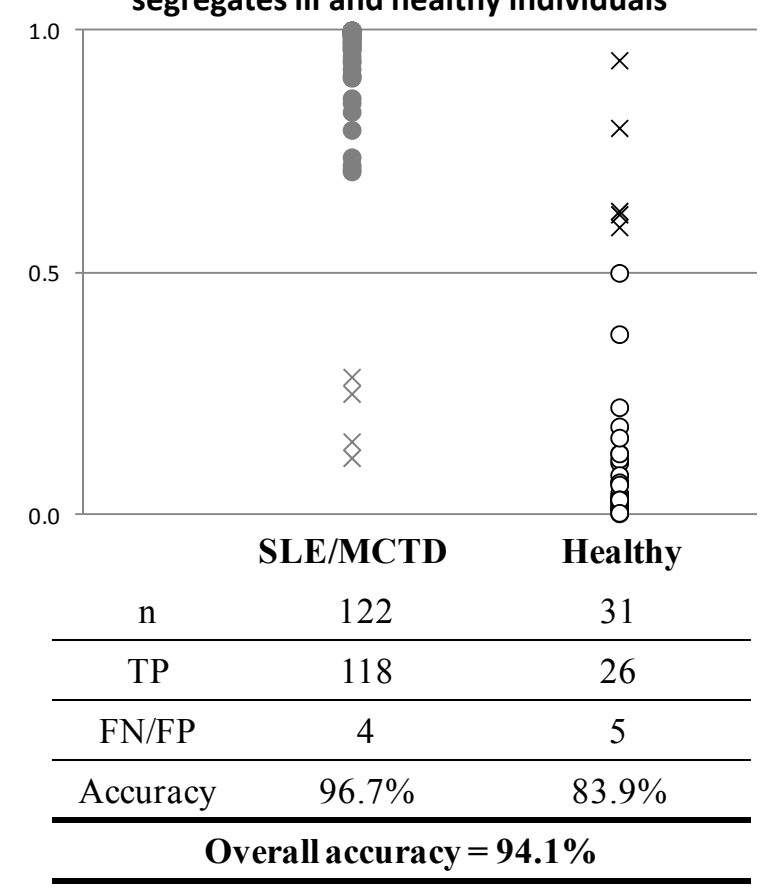

(B) IgM anti-P4/P10 reactivity discerns between SLE and MCTD patients

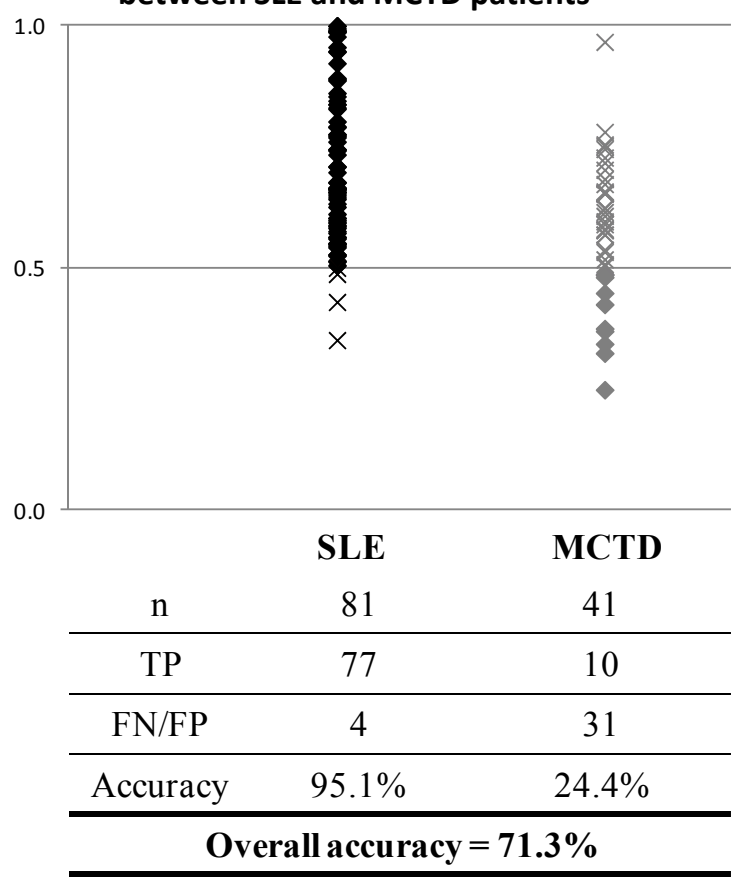


Figure 7: Area under the curve analysis reveals the classification power of IgM anti-

\section{P4/P10}

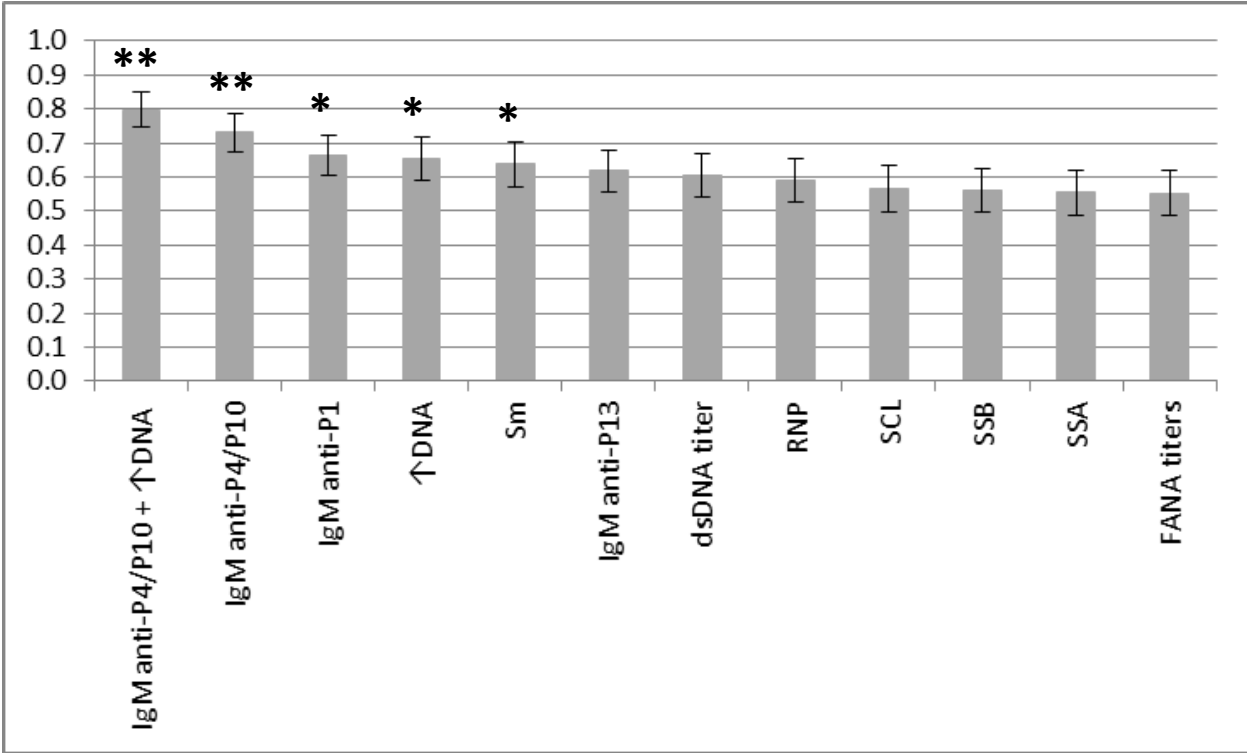




\section{CHAPTER 3}

Developing novel classification rules customized to distinguishing between SLE and MCTD patients 


\section{Introduction}

Mixed Connective Tissue Disease (MCTD), also known as Sharp's syndrome, was first described in 1972 as an autoimmune disease characterized by high titers of antibodies to U1 small nuclear ribonucleoprotein particle (snRNP) (Sharp et al., 1972). Since then, the concept of MCTD as a distinct clinical entity has been challenged due to the number of common characteristics share mainly with Systemic Lupus Erythematosus (SLE) (Aringer et al., 2005; Nowicka-Sauer et al., 2012) and less often with other autoimmune syndromes such as Polymyositis (PM), Systemic Sclerosis (SS) and Rheumatoid Arthritis (RA) (Mukerji and Hardin, 1993; Egner, 2000; Haustein, 2005). Even though the Alarcón-Segovia criteria is currently the most accepted criteria for MCTD, the fact that four different MCTD classification criteria sets currently coexist further add to the complexity observed in the diagnosis of these patients (Sharp, 1987; Kasukawa et al, 1988; Kahn et al., 1991; Amigues et al., 1996). Furthermore, the initial description of MCTD as a benign autoimmune disease (Sharp et al., 1972) most likely has jeopardized its relevance as independent identity. Nevertheless, involvement of vital organs such as lung and heart in MCTD patients has long been reported by several independent investigations (Badui et al., 1984; Smolen and Steiner, 1998; Venables, 2006; Watanabe et al., 2012; Gunnarsson et al., 2013), however; these findings have not caught sufficient attention from the research community. Consequently, new efforts to improve current classification methods for MCTD that could facilitate its early diagnosis and potential treatment have been limited.

Despite the lack of support MCTD has had to be recognized as an independent syndrome rather than an SLE like disease, there are a number of serological and clinical 
characteristics that support the independent nature of these autoimmune disorders. For example, typically MCTD patients express elevated autoantibodies targeting U1 small nuclear ribonucleoprotein (snRNP) specific proteins known as U1-70K, U1A and U1C while those with SLE show anti-Smith $(\mathrm{Sm})$ and anti-dsDNA antibodies (Luyckx et al., 2005). Moreover, even though some SLE patients develop anti-U1 snRNP response; they are able to retain IgM reactivity against these antigens while those with MCTD class switch to IgG response instead (Vlachoyiannopoulos et al., 1996; Somarelli et al., 2011; Mesa et al., 2013). Likewise, severe renal and central nervous system (CNS) manifestations are observed in SLE patients (Zidan et al., 2013) while lung and heart malfunctions are frequent in MCTD subjects (Watanabe et al., 2012; Gunnarsson et al., 2013).

As a result of contrasting clinical characteristics and specific organ involvement reported in SLE and MCTD patients, the recognition of MCTD remains useful in clinical practices (Madisson, 2000; Venable 2006; Ortega-Hernandez et al., 2012). Currently there is no available method capable of distinguish between these systemic autoimmune syndromes given that the two classification criteria sets for SLE and four classification rules for MCTD were designed to recognize either of these diseases but not to segregate between them (Sharp, 1987; Kasukawa et al, 1988; Kahn et al., 1991; Amigues et al., 1996; Hochberg et al., 1997; Petri et al., 2012).The aim of this study is to develop novel classification criteria specifically designed to segregate between SLE and MCTD patients. To do this, 183 clinical and traditional laboratory test variables, 33 experimental factors from cytokine and IgM response to antigens as well as six currently used classification criteria sets were evaluated in the patient cohort (121 SLE and 41 MCTD). 
Analysis of the results revealed eight new classification rules for SLE and MCTD distinction which are better classifiers than currently existent methods $(p \leq 0.0001)$. Furthermore, these analyses corroborated that the combination of Malar rash and positive results for double stranded DNA (dsDNA), FANA titers, elevated creatine proteinase kinase (CPK) and $\operatorname{IgM}$ reactivity for $\mathrm{SmD} 2_{\text {amino-aids }}$ 14-21 (novel model 1) represents the best classification criteria for SLE and MCTD patients with an overall accuracy of $80 \%$ ( $p \leq 0.0001)$. Additionally, we provide two panels of blood biomarkers that correlate with specific organ involvement in either SLE or MCTD patients. Likewise, we highlight a number of laboratory tests currently used to assist in the diagnosing of SLE or MCTD but lacked classification power for any of these autoimmune syndromes. In summary, this research described for the first time classification rules customized for the distinction of SLE and MCTD. Despite required validation, these findings could assist in the early diagnosis of patients with either SLE or MCTD which in turn may potentially allow the development of a specific medical treatment to prevent damage of vital organs frequently affected in these patient populations.

\section{Patients and Methods}

\section{Selection of SLE and MCTD patients}

In this study, a total of 165 patients previously diagnosed with either SLE (121 samples from 98 individuals) or MCTD (41 samples from 27 individuals) were obtained following the Florida International University and University of Miami Institutional Reviewed Board (IRB) accepted protocols (IRB numbers: 040308-00 as well as 20030724 and 20040286, respectively). Individuals were diagnosed with SLE by 
employing the American College of Rheumatology (ACR) criteria for lupus while Alarcón-Segovia criteria were utilized to diagnose those with MCTD (Amigues et al., 1996; Hochberg et al., 1997). All the individuals included represent well characterized patients that have been the subject of previous publications (Maldonado et al., 2006; Perkins et al., 2008; Somarelli et al., 2011; Mesa et al., 2013).

\section{Collection of clinical data}

A total of 183 clinical variables were obtained from the 165 patients, when available (Appendix 3). These variables include 74 clinical symptoms, 76 traditional laboratory tests and 33 experimental blood markers. All the clinical variables were recorded on the same date blood and/or urine samples were collected from the patient. The traditional laboratory tests refer to standardized commercial laboratory assays performed during the diagnosis of patients with SLE or MCTD. Experimental blood markers variables include 18 cytokines and IgM reactivity for 15 different peptides derived from U1 small nuclear ribonucleoprotein particle (snRNP). Detailed description of each of the clinical manifestations as well as normal range and cut off values for traditional and experimental laboratory tests are listed in Appendix 3.

Evaluation of classification criteria sets for SLE and MCTD patients

Two classification criteria sets available for diagnosing of SLE and four class criteria set for MCTD identification were compared regarding their capability to segregate patients with either autoimmune syndrome. The classification criteria sets for SLE are known as ACR and the recently described Systemic Lupus International 
Collaborative Clinics (SLICC) (Hochberg et al., 1997; Petri et al., 2012) while those for MCTD are named Alarcon-Segovia, Sharp, Kasukawa and Kahn (Sharp, 1987; Kasukawa et al, 1988; Kahn et al., 1991; Amigues et al., 1996). All clinical and laboratory tests available from the 183 computerized medical records were employed to assess the number of SLE and MCTD subjects from the patient cohorts that could fulfill each of the six classification criteria sets. The accuracy, sensitivity and specificity of each of the classification criteria sets were estimated using the standard clinical methods.

Construction of reduced classification criteria models for SLE and MCTD segregation derived from established class criteria sets

The variables composing each of the two classification criteria sets for SLE and four class criteria sets for MCTD diagnosis were employed in six independent forward Binomial Logistic Regression (BLR) analyses using SPSS (version 18). These analyses reveal which combinations of variables improve the segregation of SLE and MCTD when compared to each of the individual variables included per classification criteria evaluated $(p \leq 0.05)$. As result, six reduced models were obtained in which each of them correspond to a smaller version of each of the six classification criteria considered in the analysis. The accuracy, sensitivity and specificity for each of the reduced methods to classify SLE and MCTD patients were calculated. Receiving Operating Characteristics (ROC) curves were employed to rank the reduced models based in their power to segregate between SLE and MCTD patients. 
Identifying reduced number of variables to develop new classification rule for SLE and MCTD discrimination

Since this study includes 183 clinical variables but only 165 patients, an initial selection of variables was required to maintain stability and robustness of any subsequent statistical analysis performed. Knowing that the objective was to develop a new classification rule customized for the discrimination of SLE and MCTD patients, all the variables showing significant difference between patients with these autoimmune disorders were selected $(p \leq 0.05)$. Likewise, all clinical and laboratory features included in each of the reduced classification criteria models were also chosen given that forward BLR demonstrate their improved power to discriminate between SLE and MCTD patients $(p \leq 0.05)$. The variables selected to build a new classification rule include 21 clinical manifestations, 12 traditional laboratory tests and four experimental blood markers (Appendix 4). Valvular heart disease, laboratory blood tests for calcium, albumin/globulin and creatine kinase as well as the interleukin 17A (IL-17A) experimental assay were initially selected but could not be included in the subsequent statistical analysis given the reduced number of patients with available values for these variables.

Developing novel classification criteria models for SLE and MCTD segregation

A total of 37 pre-selected variables which include clinical symptoms as well as traditional and experimental laboratory tests (Appendix 4) were considered to develop new classification models tailored to segregate between SLE and MCTD patients using forward BLR analysis in SPSS (version 18). All 37 variables were considered to 
construct classification Model 1 while only clinical manifestations and standardized laboratory tests (33 variables) were evaluated to build classification Model 2. The probability of a patient to be classified as SLE or MCTD based on Model 1 or 2 are defined by the following equations, respectively:

$$
\begin{aligned}
& \text { Model } 1=\log \left(\frac{\operatorname{Pr}(S L E)}{\operatorname{Pr}(M C T D)}\right)=-35+54(\text { Malar rash })+53(\text { dsDNA })-35(\text { FANA titer }) \\
& -55(\mathrm{CPK} \text { elevated })+36 \text { (IgM anti-SmD2 reactivity) } \\
& \text { Model } 2=\log \left(\frac{\operatorname{Pr}(S L E)}{\operatorname{Pr}(M C T D)}\right)=19+4(\text { Malar rash })-22(\text { Synovitis })+3(\text { dsDNA })- \\
& 24(\mathrm{Scl} 170)+44(\mathrm{ANA})
\end{aligned}
$$

where each of the models symbolize the log ratio of the combined variables in the SLE group divided by that of the MCTD cluster $(p \leq 0.05)$. The probability of the sample to be SLE or MCTD in each model is calculated by plotting the values of each of the characteristics listed within parenthesis in each the independent equations. For each of the models, a probability $>0.5$ indicates the patients belong to the SLE group while a probability $<0.5$ classify the patient as MCTD.

\section{Statistical analysis}

Significant differences between SLE and MCTD patients for each of the 187 clinical variables included in this study were determined by Chi $(X)$ square or independent sample $\mathrm{T}$ test in SPSS (version 18) when the value was nominal or numerical, respectively $(p \leq 0.05)$. Correlations between laboratory tests and clinical 
manifestations observed in either SLE or MCTD patients were determined by Ttest/ANOVA with repeated measurements within patients for test with numerical values while a generalized linear mixed model was applied to assays with binary values ( $p \leq$ 0.05). The resulting p-values for each of the correlations were used to construct a heatmap for each autoimmune syndrome in $\mathrm{R}$ where significant correlations before and after Bonferroni correction as well as variables with no correlation are color coded in white, blue and red, respectively. Alopecia, swelling of neck lymph nodes, rheumatoid nodule, hemolytic anemia, avascular necrosis, pulmonary vascular lesions, renal clot, renal arterial stenosis, chorea and phychosis were not included during the correlation analysis because insufficient sample size and/or lack of sufficient variability in SLE and/or MCTD cohorts. Receiving Operating Characteristic (ROC) curves were performed in SPSS (version 18) to corroborate and compare classification power of each of the models resulting from forward BLR $(p \leq 0.05)$.

\section{Results}

Contrasting clinical and serological features are exhibited by SLE and MCTD patients

Each of the 183 clinical variables included in this research (Appendix 3) were evaluated to assess significant differences between SLE and MCTD populations. We identified 35 variables that significantly differ between these autoimmune diseases including clinical symptoms related to skin, muscle, kidney and heart tissues as well as a 18 serological assays $(p \leq 0.05)$ (Figure 8$)$. Interestingly, the skin derived variables (Raynaud's Malar and Discoid rashes) tend to be higher in SLE than MCTD patients ( $p \leq$ 0.05). Likewise, the study of muscle features showed that SLE patients appear to have 
greater inflammation of the joints and extremities while MCTD individuals exhibit prevalence of myositis and muscle weakness $(p \leq 0.05)$. As expected, renal disease and renal hematuria are elevated in SLE but not MCTD patients $(p \leq 0.05)$. Additionally, myocardial infarction is elevated in MCTD patients while valvular heart disease seems to be more frequent in SLE individuals $(p \leq 0.05)$. Evaluation of the serological assays revealed that with the exception of creatine phosphate kinase and positive antibodies for topoisomerase $(\mathrm{Scl}-70+)$, all the traditional laboratory tests were higher in the SLE population when compared to the MCTD group $(p \leq 0.05)$. Similarly, all the experimental tests which include identification of interleukin 17A and IgM reactivity for U1A, SmD1 and SmD2 are elevated only in SLE but not MCTD individuals $(p \leq 0.05)$. Consequently, this analysis showed that SLE and MCTD patients exhibit unique clinical manifestations and molecular markers $(p \leq 0.05)$.

Molecular markers associations with unique tissue damage are specific to either SLE or MCTD patients

Each of the laboratory tests analyzed in this study was individually correlated with clinical symptoms presented in patients diagnosed with SLE or MCTD (Figures 2 and 3). The resulting $p$-value heatmap uncovered the SLE cohort seven clinical manifestations significantly associated with IL33 (oral ulcers, leukopenia and lymphopenia), IL12p40 (telangiectasia and joints deformity), BAFF (Thrombosis) and positive protein in urine (renal disease) $(p \leq 0.05)$ (Table 5 and Figure 9). Different significant correlations were detected in the MCTD population where seven molecular markers were significantly associated with nasal ulcers (BAFF), oral ulcers (IL33), anemia (C3 and C4 level as well 
as IgM and IgG rheumatoid factor ELISA titer) and pleuritis (IL17A) $(p \leq 0.05)$ (Table 5 and Figure 10). It is noteworthy that IL33 correlates with oral ulcers equally in SLE and MCTD $(p \leq 0.05)$. Interestingly, 44\% (4/9) of the biomarkers that show significant correlations with specific clinical symptoms correspond to new experimental blood antigens that showed reactivity in SLE and/or MCTD patients. In this way, the $p$-value heatmaps resulting from correlation analysis suggest that correlations of molecular markers and clinical manifestations are unique to either SLE or MCTD patients $(p \leq$ $0.05)$.

Classification criteria sets are not designed for segregating SLE and MCTD patients

Each of the six criteria sets for the classification of either SLE or MCTD was applied to the patient cohorts to evaluate their capacity to segregate between these autoimmune syndromes (Table 6). These analyses revealed that there is virtually no difference in the accuracy of the new (Systemic Lupus International Collaborating Clinics (SLICC)) and old (ACR) SLE classification criteria sets $(p \leq 0.05)$ (Table 6). This is an important observation considering SLICC is composed by 25 additional variables that are not listed in the ACR class criteria (Hochberg et al., 1997; Petri et al., 2012). Specifically, SLICC and ACR showed elevated sensitivity (93.26\% and 85.39\%, respectively) but both have deficient specificity (13.33, and $24.44 \%$, respectively) (Table 6). When evaluating all the MCTD class criteria sets, the Alarcón-Segovia showed the best accuracy (72.39\%) at discriminating between SLE and MCTD even though Sharp, Kasukawa and Kahn class criteria sets also exhibited significant segregation between the two autoimmune disorders $(p \leq 0.05)$ (Table 6). In contrast to SLICC and ACR 
classification criteria, the Alarcón-Segovia exhibits moderate sensitivity (64.44\%) and specificity (76.40\%) in distinguishing between MCTD and SLE patients $(p \leq 0.05)$ (Table 6). Taken all these together, the data showed that the six established methods for the classification of SLE (ACR and SLICC) and MCTD (Alarcón-Segovia, Sharp, Kasukawa and Kahn) lack power to segregate patients diagnosed with either these syndromes.

Regression analysis of existent classification criteria sets uncover essential factors required for SLE and MCTD segregation

Six independent forward BLR analyses with variables corresponding to those listed in each of the six classification criteria were performed to construct six reduced models. Evaluation of the reduced models exposed 6 combinations from 18 essential features with significant power to differentiate between SLE and MCTD patients (Table 7). Comparison of all six reduced models reveals that the reduced Kasukawa (rKasukawa) shows the highest accuracy (85.5\%) at segregating between these autoimmune syndromes which power is derived by the combination of Raynaud's phenomenon, Malar rash, adenopathies, sclerodactyly and muscle weakness $(p \leq 0.05)$ (Table 7). Specifically, the rKasukawa not only showed superior sensitivity (75\%) and specificity (90.5\%) when compared to the other five reduced models but seems a better classifier than the AlarcónSegovia classification criteria to discriminate between SLE and MCTD patients (Table 7). Indeed, all the reduced models are better classifiers for SLE and MCTD patients when compared to their corresponding complete class criteria (Tables 2 and 3). Consequently, the forward BLR revealed four groups composed by combination of 18 core variables with the capacity to segregate between SLE and MCTD $(p \leq 0.05)$. 


\section{ROC curves confirmed the classification power of reduced class criteria models}

A total of six individual ROC curves analyses were performed to confirm the segregation power of the variable per criteria set when compared to the corresponding complete classification criteria (Table 6) as well as proposed reduced models (Table 7). As expected, the ROC analysis confirmed that all reduced models are a better classifier for these autoimmune syndromes than any of the complete class criteria or any variable included in them $(p \leq 0.0001)$ (Figure 11). Likewise, the analysis revealed that two laboratory tests previously identified by BLR (positive dsDNA and RNP in Table 7) have individual power to distinguish between SLE and MCTD patients $(p \leq 0.05)$ (Figure 11). Also, eight of the clinical symptoms predicted by BLR (synovitis, Malar rash, nonerosive arthritis, acrosclerosis, Raynaud's, esophageal hypomotility, sclerodactitily and muscle weakness in Table 7) showed to have individual power to segregate between SLE and MCTD $(p \leq 0.05)$ (Figure 11). In addition, the ROC analysis uncovered that swollen hands and negative laboratory results for $\mathrm{Sm}(\mathrm{Sm}-)$ each have independent capability to separate SLE from MCTD patients $(p \leq 0.05)$ (Figure 11). Therefore, the ROC analysis exposed ability of swollen hands and Sm- results in segregating between these autoimmune disorders as well as confirmed the power of 10 out of the 18 variables identified by BLR in differentiating between SLE and MCTD patients $(p \leq 0.05)$.

\section{Construction of novel class criteria sets to assist diagnosing of SLE and MCTD}

A total of 37 pre-selected variables (Appendix 4) were employed in forward BLR analysis to develop new predicted models tailored specifically for SLE and MCTD classification. When considering experimental and traditional laboratory assays as well as 
clinical symptoms, the analysis revealed that the combination of Malar rash, positive results for dsDNA and FANA titers, elevated creatine phosphate kinase (CPK) and IgM anti-SmD $2_{\text {amino-acids } 14-21}$ reactivity (referred to as Model 1) exhibits an overall accuracy of $80 \%$ in discriminating between SLE and MCTD patients with sensitivity and specificity of $92 \%$ and $74 \%$, respectively $(p \leq 0.0001)$ (Table 8 ). A separate forward BLR analysis was performed utilizing only traditional laboratory tests and clinical manifestations from patients with either SLE or MCTD. The data confirmed that the combination of Malar rash, synovitis as positive results for dsDNA, topoisomerase (Sc170) and anti-nuclear assay (ANA) (named Model 2) showed a 74\% accuracy at discerning between these two autoimmune syndromes with $83 \%$ sensitivity and $69 \%$ specificity $(p \leq 0.0001)$ (Table 8$)$. In summary, the BLR analysis uncovered two novel class criteria sets (Models 1 and 2) which were custom built for discriminating between SLE and MCTD patients ( $p \leq$ $0.0001)$

Model 1 represents the best classification rule to discern between SLE and MCTD patients

Novel proposed classification Models 1 and 2 (Table 8) were included in ROC curves analysis along with each of the classification criteria for SLE and MCTD (Table 6) and their corresponding reduced models (Table 7) to compare their classification power for SLE and MCTD patients. The analysis confirmed that Model 1 exhibits the highest capacity to discern between SLE and MCTD with AUC $=0.930(p \leq 0.0001)$ (Figure 12). Likewise, rKasukawa model, rACR model, rSharp model, Model 2, rSLICC model, rAlarcon-Segovia model and Sharp classification criteria occupy the second to 
eight place in having power to classify SLE and MCTD patients $(p \leq 0.05)$ (Figure 12). The rKahn model and the rest of the classification criteria sets (Kasukawa, AlarconSegovia, Kahn, ACR and SLICC) were unable to segregate patients diagnosed with any of these autoimmune syndromes (Figure 12). Therefore, ROC curves analysis confirmed that the combination of variables included in Model 1 are the best classification rule for SLE and MCTD patients when compared to Model 2, all six classification criteria sets available for these autoimmune disorders as well as their corresponding reduced models $(p \leq 0.0001)$

\section{Discussion}

Since its initial description by Sharp et al. (1972), the recognition of MCTD as an unique disease has been constantly challenged, mainly due to the number of overlapping characteristics shared by patients diagnosed with SLE (Aringer et al., 2005; NowickaSauer et al., 2012). Currently, in cases where the concept of MCTD is acknowledged, it is often portrayed as a subset of SLE patients with good prognosis despite exhibiting features listed in SLE and MCTD classification criteria sets and prevalence of lung and heart problems (Badui et al., 1984; Smolen and Steiner, 1998; Venables, 2006; Watanabe

et al., 2012; Gunnarsson et al., 2013; Bertsias et al., 2013). The reported contrasting organs involvement in patients with diagnosis of MCTD (lung and heart) when compared to those with SLE (kidney and CNS) provides evidence of the clinical relevance of the MCTD concept to prevent and/or treat organ malfunction in these autoimmune syndromes, regardless if MCTD is recognized as a separate illness or a SLE subtype. Given that available classification criteria sets were developed to identify either SLE or 
MCTD subjects but not to segregate between them, it seems imperative to design classification rules specifically tailored to discriminate SLE and MCTD patients since early class group identification could influence the type of medical plan developed to impede or reduce organ damage, thus potentially improving the patient's prognosis. This investigation provides, for the first time, eight different classification rules strategically derived for the segregation of SLE and MCTD patients. Analysis of the resulting data confirmed that all eight proposed models exhibit a higher power to correctly identify SLE or MCTD patients than any other available class criteria set $(p \leq 0.0001)$. Despite a required validation step, the proposed models highlight clinical and molecular features with power to segregate SLE and MCTD subjects while providing additional evidence to support the independent etiology of these autoimmune syndromes.

In congruency with previous reports (Vlachoyiannopoulos et al., 1996; Luyckx et al., 2005; Somarelli et al., 2011; Watanabe et al., 2012; Gunnarsson et al., 2013; Mesa et al., 2013; Zidan et al., 2013), the analysis of 187 medical records documented for SLE and MCTD patients revealed that 35 clinical manifestations and molecular features are significantly different in the two disease states (Figure 8). The prevalence of skin rashes in SLE while myositis and muscle weakness was presented in MCTD was expected since these are typical clinical manifestation associated with each of these autoimmune illnesses (Uthman et al., 1996; Belibou et al., 2012; Szodoray et al., 2012). Like others (Watanabe et al., 2012; Gunnarsson et al., 2013; Zidan et al., 2013), the data showed that specific organ malfunction was involved with each of these syndromes where renal disease was elevated in SLE cohort while myocardial infarction was more frequently in the MCTD population $(p \leq 0.002)$. Additionally, the correlation analyses support the idea 
that SLE and MCTD are indeed separate disorders given that unique correlations of molecular markers and clinical symptoms are observed in either SLE or MCTD cohorts (Figures 2 and 3). An interesting association revealed was between IL17A and pleuritis observed only in MCTD but not SLE subjects (Table 5). In addition to representing a novel potential blood biomarker, the association of IL17A and pleuritis might indicate pleural inflammation related to bacterial infections as has been recently reported (Monguilhott Dalmarco et al., 2011; Kollintza et al., 2013). It is noteworthy to mention that the frequency of lung disease in the SLE and MCTD cohorts does not differ (44\% and $48 \%$ respectively). Given that some studies have reported the predominance of lung disease in MCTD patients (Sasaki et al., 2011; Gunnarsson et al., 2012) while others have uncovered that lung malfunction in these patients is lower than expected (Gunnarsson et al., 2013), these results suggest that additional investigations encompassing bigger MCTD samples and inclusion of other autoimmune syndromes are required to assess if lung disease should be considered as a target organ during the diagnosis and treatment of MCTD. Consequently, the data provide grounds to suggest that new classification rules customized for SLE and MCTD segregation should be developed to prevent and/or reduce organ involvements in these patients.

The evaluation of ACR, SLICC, Alarcón-Segovia, Sharp, Kasukawa, and Kahn criteria sets revealed the average capability of segregating SLE and MCTD patients (Table 6). Specifically, the misclassification rate of patients using any of these methods ranges from $36 \%$ to $87 \%$ for MCTD subjects (16/45 and 39/45 MCTD incorrectly grouped by Alarcón-Segovia and SLICC, respectively) while varies from $7 \%$ to $56 \%$ for SLE (6/89 and 48/85 SLE mistakenly clustered by SLICC and Kasukawa, respectively). 
This deficiency of classification power was expected given that the inclusion of MCTD patients was not recognized during the development of SLE classification criteria sets (Tan et al., 1982; Hochberg et al., 1997; Petri et al., 2012). By contrast, patients diagnosed with SLE and other autoimmune syndromes were included during the production of each of the four classification criteria sets for MCTD (Amigues et al., 1996). Nevertheless, these studies did not included well characterized MCTD cases and rather choose the presence of positive anti-U1 snRNP antibodies as patient inclusion criteria despite knowing these antigens elicit a response in SLE and MCTD subjects (Amigues et al., 1996; Sato et al., 2010; Nagai et al., 2012, Mesa et al., 2013). Consequently, these findings provide evidence to suggest that currently available SLE and MCTD classification criteria sets do not exhibit sufficient power to correctly identify SLE or MCTD patients (Table 6) (Figure 11).

The regression analysis identified eight different novel classification rules (Tables 3 and 4) which exhibit significantly higher capability to segregate SLE and MCTD patients than any other classification criteria sets available $(p \leq 0.05)$ (Figure 12). Particularly, Model 1 composed by the presence of Malar rash, elevated CPK and positive results for dsDNA, FANA and IgM anti-SmD (Table 8), represents the best classifier to identify SLE and MCTD patients with an significant AUC of 0.930 ( $p \leq$ 0.0001) (Figure 12). The segregation power of the combination of variables in Model 1 was predicted given that, with the exception of elevated CPK; all the other clinical characteristics and lab tests have been repetitively reported elevated in SLE patients but reduced in MCTD subjects (Vlachoyiannopoulos et al., 1996; Luyckx et al., 2005; Somarelli et al., 2011; Mesa et al., 2013). The misclassification rate of proposed Model 1 
attains $8 \%$ for MCTD patients (2/24 incorrectly clustered) and $26 \%$ for SLE subjects (11/42 falsely grouped). In this way, the overall classification power for SLE and MCTD shown by Model 1 is significantly improved when contrasted with existent validated classification criteria sets $(p \leq 0.0001)$ (Figure 12). Additionally, the results revealed that rKasukawa, rACR, rSharp, Model 2, rSLICC and rAlarcón-Segovia follow Model 1 in their power to segregate between SLE and MCTD patients $(p \leq 0.05)$ (Figure 12). The ROC curves confirmed that Sharp classification criteria exhibit significant ability to discern between these autoimmune syndromes however the average AUC (0.684) highlights the average power of this criteria set $(p \leq 0.05)$ (Figure 12).

Taking all of this together, this study shows evidence to support the relevance of recognizing the MCTD concept while providing, for the first time, eight different classification rules tailored for the specific classification of SLE and MCTD patients. Given that these results and others have identified specific organ involvement in either SLE or MCTD patients (Figure 8) (Vlachoyiannopoulos et al., 1996; Luyckx et al., 2005; Watanabe et al., 2012; Gunnarsson et al., 2013; Mesa et al., 2013; Zidan et al., 2013), it highlights the clinical value of MCTD diagnosis given that the type of medical regime delivered to a patient will rely on the potential development of specific organ(s) malfunction. Aware of the lack of methods designed to segregate between these autoimmune disorders (Table 6 and Figure 11), we described eight different novel classification rules (Tables 3 and 4) from which Model 1 (derived by the combination of Malar rash, elevated CPK and positive results for dsDNA, FANA and IgM anti-SmD) represents the best classifier from those evaluated with a power of $93 \%$ to distinguish between SLE and MCTD patients (Figure 12). Noteworthy the limitations and the need 
for a validation step of the current findings, we believe that the time has come to recognize the clinical relevance of the MCTD concept to prevent and/or treat organ malfunction. Consequently, the proposed classification rules presented in this research pioneers the efforts to attain the development of new consensus criteria custom made for segregating between SLE and MCTD patients. 


\section{Table 5: List of molecular markers associated with clinical manifestations in SLE and MCTD patients}

\begin{tabular}{|c|c|c|c|}
\hline $\begin{array}{l}\text { Tissue } \\
\text { affected }\end{array}$ & $\begin{array}{l}\text { Molecular } \\
\text { markers }\end{array}$ & SLE & MCTD \\
\hline \multirow{2}{*}{ Skin } & $B A F F$ & $\varnothing$ & Nasal ulcers \\
\hline & IL33 & Oral ulcers & Oral ulcers \\
\hline \multirow{2}{*}{ Joints } & \multirow{2}{*}{ IL $12 p 40$} & Telangiectasia & $\varnothing$ \\
\hline & & Deformity & $\varnothing$ \\
\hline \multirow{7}{*}{ Blood } & C3 level & $\varnothing$ & \multirow{4}{*}{ Anemia } \\
\hline & C4 level & $\varnothing$ & \\
\hline & IgM RF ELISA titer & $\varnothing$ & \\
\hline & IgG RF ELISA titer & $\varnothing$ & \\
\hline & \multirow{2}{*}{ IL33 } & Leukopenia & $\varnothing$ \\
\hline & & Lymphonia & $\varnothing$ \\
\hline & $B A F F$ & Thrombosis & $\varnothing$ \\
\hline Heart & $I L 17 A$ & - & Pleuritis \\
\hline Kidney & Urine protein + & Renal disease & $\varnothing$ \\
\hline
\end{tabular}


Table 6: Evaluating SLE and MCTD classification criteria sets in patient cohort included in the present study

\begin{tabular}{|c|c|c|c|c|c|c|}
\hline & \multirow{2}{*}{$\begin{array}{c}\text { Classification } \\
\text { criteria sets }\end{array}$} & \multicolumn{2}{|c|}{ SLE } & \multicolumn{2}{|c|}{ MCTD } & \multirow{2}{*}{$p$-value } \\
\hline & & $\begin{array}{l}\text { Correctly } \\
\text { classified }\end{array}$ & $\begin{array}{l}\text { Incorrectly } \\
\text { classified }\end{array}$ & $\begin{array}{l}\text { Correctly } \\
\text { classified }\end{array}$ & $\begin{array}{c}\text { Incorrectly } \\
\text { classified }\end{array}$ & \\
\hline \multirow{3}{*}{$\begin{array}{l}\mathbf{S} \\
\mathbf{L} \\
\mathbf{E}\end{array}$} & SLICC & 83 & 6 & 6 & 39 & 0.207 \\
\hline & $A C R$ & 76 & 13 & 11 & 34 & 0.161 \\
\hline & Alarcón-Segovia & 68 & 21 & 29 & 16 & $<0.0001$ \\
\hline \multirow{3}{*}{$\begin{array}{c}M \\
C \\
T \\
D\end{array}$} & Sharp & 48 & 41 & 37 & 8 & $<0.0001$ \\
\hline & Kasukawa & 37 & 48 & 42 & 3 & $<0.0001$ \\
\hline & Kahn & 82 & 7 & 11 & 34 & 0.008 \\
\hline
\end{tabular}

SLICC and ACR stands for Systemic Lupus International Collaborating Clinics and American College of Rheumatology, respectively. The analysis were performed in SPSS (version 18) and included 89 SLE patients and 45 MCTD individuals. 
Table 7: Description of reduced models for each SLE and MCTD classification

\section{criteria}

\begin{tabular}{|c|c|c|c|c|}
\hline & $\begin{array}{l}\text { Reduced models for } \\
\text { each classification } \\
\text { criteria }\end{array}$ & Accuracy & $p$-value & $\begin{array}{l}\text { Features included in the } \\
\text { reduced models }\end{array}$ \\
\hline \multirow{2}{*}{$\begin{array}{l}\mathbf{S} \\
\mathbf{L} \\
\mathbf{E}\end{array}$} & $r S L I C C$ & $79.6 \%$ & $<0.0001$ & $\begin{array}{l}\text { Discoid rash, joint synovitis, leukopenia, } \\
\text { ANA }+, \text { dsDNA }+, \mathrm{Sm}^{+} \text {and phospholipid }+\end{array}$ \\
\hline & $r A C R$ & $74.4 \%$ & $<0.0001$ & $\begin{array}{l}\text { dsDNA }+ \text {, hemolytic anemia, Malar rash } \\
\text { and Non-erosive arthritis }\end{array}$ \\
\hline \multirow{4}{*}{$\begin{array}{l}M \\
C \\
T \\
D\end{array}$} & rAlarcón-Segovia & $74.2 \%$ & $<0.0001$ & Synovitis and acrosclerosis \\
\hline & rSharp & $78.4 \%$ & $<0.0001$ & $\begin{array}{c}\text { Severe myositis, Raynaud's or esophageal } \\
\text { hypomotility, RNP+, } \mathrm{Sm}+\end{array}$ \\
\hline & rKasukawa & $85.5 \%$ & $<0.0001$ & $\begin{array}{l}\text { Raynaud's, adenopathies, Malar rash, } \\
\text { sclerodactyly and muscle weakness }\end{array}$ \\
\hline & rKahn & $69.7 \%$ & $<0.0001$ & Raynaud's and synovitis \\
\hline \multicolumn{5}{|c|}{$\begin{array}{l}\text { SLICC and ACR stands for Systemic Lupus International Collaborating Clinics and American College of Rheumatology, } \\
\text { respectively. Anti Nuclear Antibody positive (ANA+) as well as positive antibody detection of double stranded DNA (dsDNA+), } \\
\text { Smith protein (Sm+) phospholipid (phospholipid +) and Ribo-Nucleo-protein (RNP+) are indicated. The analysis were performed } \\
\text { using the binomial logistic regression (BLR) function in SPSS (version 18) and included } 89 \text { SLE patients and } 45 \text { MCTD } \\
\text { individuals. }\end{array}$} \\
\hline
\end{tabular}


Table 8: Description of novel models for segregation of SLE and MCTD patients

\begin{tabular}{|c|c|c|c|c|}
\hline $\begin{array}{l}\text { Proposed } \\
\text { models }\end{array}$ & $\begin{array}{l}\text { Features included } \\
\text { in each model }\end{array}$ & Cut-off & Accuracy & $p$-value \\
\hline Model 1 & $\begin{array}{l}\text { Malar rash, dsDNA+, FANA titers, } \\
\text { elevated CPK and IgM reactivity for } \\
\operatorname{SmD} 2_{\text {amino-acids } 14-21} \text {. }\end{array}$ & 0.42 & $80.30 \%$ & $<0.0001$ \\
\hline Model 2 & $\begin{array}{c}\text { Malar rash, synovitis, dsDNA }+ \\
\text { Scl70+, ANA }+\end{array}$ & 0.28 & $73.64 \%$ & $<0.0001$ \\
\hline \multicolumn{5}{|c|}{$\begin{array}{l}\text { The models were obtained using binomial logistic regression (BLR) function in SPSS (version 18) when clinical } \\
\text { variables as well as traditional and experimental laboratory tests from SLE and MCTD patients were considered } \\
\text { (Appendix 4). Model } 1 \text { was built using experimental and traditional variables from } 42 \text { SLE and } 24 \text { MCTD patients } \\
\text { while only traditional variables derived from } 75 \text { SLE and } 35 \text { MCTD patients were considered for Model } 2 \text {. Values under } \\
\text { the cut off points will be classified as SLE while those above it will be identified as MCTD. Positive antibody detection } \\
\text { of double stranded DNA (dsDNA+), toposiomerase (Scl70+) and Anti Nuclear Antibody positive (ANA+) are indicated. } \\
\text { The experimental variable is denoted in italics. }\end{array}$} \\
\hline
\end{tabular}




\section{Figure legends}

Figure 8: SLE and MCTD differ in the prevalence of clinical characteristics and molecular factors. In each graph, the inner circle represents the MCTD cohort while the outside circle consists of the SLE population. Positive and negative values for each of the variables are represented by green and red, respectively. History of proximal muscle weakness, observed proximal muscle weakness, observed joints swelling, symmetric joints swelling, low extremity swelling are denoted by "H prox muscle weakness", "O prox muscle weakness", "O joints swelling", "S joints swelling" and "L extremity swelling", respectively. Positive laboratory tests for ribonucleoprotein (RNP), Smith proteins (Sm), double stranded DNA (dsDNA), Fluorescent Antinuclear Antibodies (FANA), anti-La antibodies (SSP) and topoisomerase (Scl) are indicated with "+". Experimental antigens as opposed to traditional laboratory tests are in italics.

Figure 9: Proposed biomarker panel for clinical manifestations observed in SLE patients. In the plot, the clinical symptoms and laboratory tests are on the " $\mathrm{x}$ " and " $y$ " axis, respectively. The white, blue and red boxes indicate significant correlations, significant correlations after Bonferroni corrections and no correlations, respectively $(p \leq$ 0.05). Hand swelling, proximal scleroderma, any heart clot, valvular heart diseases, pulmonary hypertension, pulmonary fibrosis, gastric reflux, lymph nodes swelling, morning stiffness, myocard infarction and interlukin receptor BAFFR were initially considered in the analysis but not included due to the reduced sample size for each of these variables. 


\section{Figure 10: Specific blood markers correlate with clinical symptoms in MCTD}

patients. Laboratory tests performed in MCTD subjects are displayed in the "y" axis while clinical manifestations exhibit in this patient population are on the " $\mathrm{x}$ " axis. The white, blue and red boxes indicate significant correlations, significant correlations after Bonferroni corrections and no correlations, respectively $(p \leq 0.05)$. Renal proteinuria, hematuria and cell cast, stroke, venous heart clot, lung disease, synovitis, symmetric swelling of the joints, observed proximal muscle weakness and calcinosis were initially considered for the correlations but not included in the final analyses given the reduced sample size available in the MCTD cohort for these variables.

Figure 11: Reduced models for each SLE and MCTD classification criteria exhibit better power in discriminating between SLE and MCTD patients. Each of the reduced models were obtained by applying binomial logistic regression (BLR) in SPSS (version 18) when all the variables per classification criteria were considered in SLE ( $\mathrm{n}=$ 89) and MCTD $(\mathrm{n}=45)$ patients. The Systemic Lupus International Collaborating Clinics (SLICC) and American College of Rheumatology (ACR) classification criteria sets for SLE diagnosis are denoted with $\mathbf{A}$ and $\mathbf{B}$, respectively. The Alarcón-Segovia (C), Sharp (D), Kasukawa (E) and Kahn (F) represent the classification criteria sets for diagnosing MCTD patients. In each plot, the area under the curve (AUC) from Receiving Operating Characteristics (ROC) curves are on the $\mathrm{y}$ axis. Each of the columns represent characteristics and the reduced model included per classification criteria. The lines on top of each column are standard error. Significant difference between SLE and MCTD 
patients with $p$-values $\leq 0.05, \leq 0.005$ and $\leq 0.0001$ are denoted with “*”, “**” and “***”, respectively.

Figure 12: Proposed Model 1 exhibits the highest discrimination power in identifying SLE and MCTD patients. The $\mathrm{x}$ axis includes the classification criteria for SLE and MCTD, their correspondent reduced models as well as the new proposed models (Model 1 and Model 2) for segregation of patients with these autoimmune syndromes. The $\mathrm{y}$ axis represents the area under the curve (AUC) resulting from the Receiving Operating Characteristics (ROC) curves analysis. Variables with significant power to differentiate between SLE and MCTD with $p$-values of $0.05,0.005$ and $\leq 0.0001$ are indicated with “*”, “**” and “***”, respectively. 
Figure 8: SLE and MCTD differ in the prevalence of clinical characteristics and molecular factors




Figure 9: Proposed biomarker panel for clinical manifestations observed in SLE

\author{
patients
}
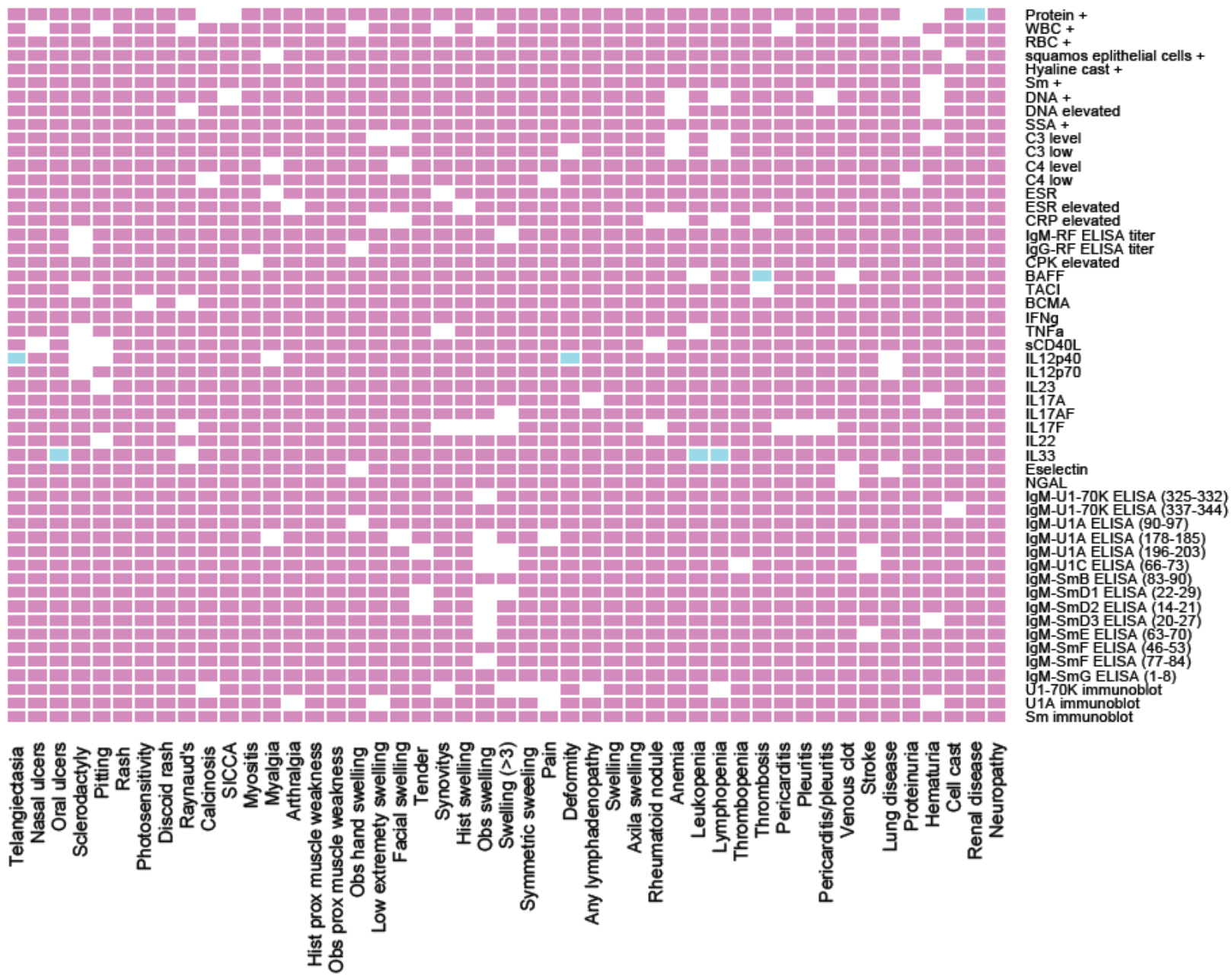
Figure 10: Specific blood markers correlate with clinical symptoms in MCTD

\author{
patients
}




Figure 11: Reduced models for each SLE and MCTD classification criteria exhibit better power in discriminating between SLE and MCTD patients
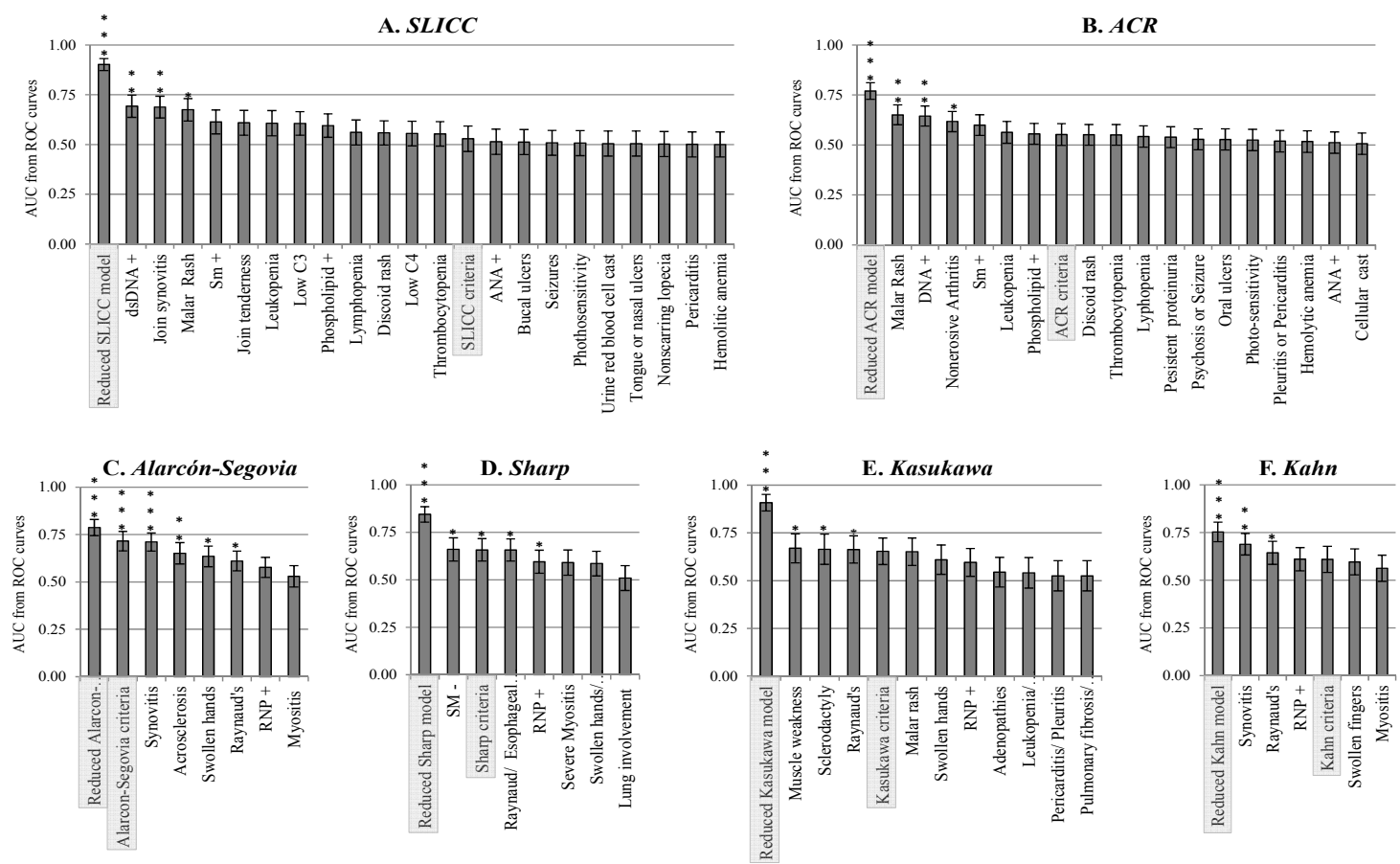
Figure 12: Proposed Model 1 exhibits the highest discrimination power in identifying SLE and MCTD patients






\section{CONCLUSIONS}

The recognition of MCTD as a separate disorder from SLE has remained debatable since its initial description in 1972 (Sharp et al., 1972; Aringer et al., 2005; Nowicka-Sauer et al., 2012). Nevertheless, the clinical relevance of the MCTD concept to identify individuals with different organ malfunction from patients that fulfill the SLE classification criteria has been documented (Badui et al., 1984; Smolen and Steiner, 1998; Venables, 2006; Watanabe et al., 2012; Gunnarsson et al., 2013; Bertsias et al., 2013). This investigation provides clinical and molecular evidence to support the independent etiology of SLE and MCTD. The experimental approach suggests that models resulting from the IgM anti-U1 snRNP titers could be considered as a potential blood biomarkers capable of differentiating SLE from MCTD patients as well as molecular indicators for lung and kidney disease in patients suffering from any of these disorders $(p \leq 0.005)$. Likewise, derivation of the data analysis resulted in the description of novel classification rules for SLE and MCTD with significant improved classification power when compared to available methods $(p \leq 0.005)$. Even knowing that these findings must be validated and recognizing the limitations of the approached utilized in this research, the results strongly suggest that the described biomarkers and classification criteria sets might have clinical relevance during the accurate identification of MCTD therefore potentially improving patients' prognosis. 


\section{LIST OF REFERENCES}

Adsay NV, Basturk O, Thirabanjasak D (2005). Diagnostic features and differential diagnosis of autoimmune pancreatitis. Semin Diagn Pathol. 22:309-317.

Allen D, Fischer A, Bshouty Z, Robinson DB, Peschken CA, Hitchon C, El-Gabalawy H, Meyers M, Mittoo S (2012). Evaluating systemic lupus erythematosus patients for lung involvement. Lupus. 12:1316-1325

Amigues JM, Cantagrel A, Abbal M and Mazieres B. Comparative study of 4 diagnosis criteria sets for MCTD in patients with anti-RNP antibodies (1996). Autoimmunity group of the hospital of Toulouse. J Rheumatol. 12:2055-2062.

Arbuckle MR, Schilling AR, Harley JB, James JA (1998). A limited lupus antispliceosomal response targets a cross-reactive, proline-rich motif. J Autoimmun. 11:431438.

Aringer M, Steiner G, Smolen JS (2005). Does mixed connective tissue disease exist? Yes. Rheum Dis Clin North Am. 31:411-20

Badui E, Robles Saavedra E, García Rubí D, Mintz Spiro G. (1984). Cardiovascular manifestations in mixed connective tissue disease in adults. Arch Inst Cardiol Mex. 54:493-497.

Barakat S, Briand JP, Abuaf N, Van Regenmortel MHV, Muller S (1991). Mapping of epitopes on U1 snRNP polypeptide A with synthetic peptides and autoimmune sera. Clin Exp Immunol. 86:71-78.

Belibou IC, Ancuţa C, Miu S, Ancuţa E, Păstrăguş C, Chirieac R (2012). Clinicobiological issues of systemic lupus erythematosus patients. Rev Med Chir Soc Med Nat Iasi. 116:83-89.

Bertsias GK, Pamfil C, Fanouriakis A, Boumpas DT (2013). Diagnostic criteria for systemic lupus erythematosus: has the time come? Nat Rev Rheumatol. 9:687-694.

Bertoli AM, Vila LM, Apte M, Fessler BJ, Bastian HM, Reveille JD, Alarcon GS. LUMINA Study Group (2007). Systemic lupus erythematosus in a multiethnic US Cohort LUMINA XLVIII: factors predictive of pulmonary damage. Lupus. 16:410-417.

Bodolay E, Dérfalvi B, Gergely P, Poór G (2007). When does an autoimmune disease begin? Importance of the early diagnosis. Orv Hetil. 8:148.

Braun-Moscovici Y, Butbul-Aviel Y, Guralnik L, Toledano K, Markovits D, Rozin A, Nahir MA, Balbir-Gurman A (2013). Rituximab: rescue therapy in life-threatening complications or refractory autoimmune diseases: a single center experience. Rheumatol Int. 33:1495-1504. 
Breda L, Nozzi M, De Sanctis S, Chiarelli F (2010). Laboratory tests in the diagnosis and follow-up of pediatric rheumatic diseases: an update. Semin Arthritis Rheum. 4:53-72.

Brugos B, Vincze Z, Sipka S, Szegedi G, Zeher M (2012). Serum and urinary cytokine levels of SLE patients. Pharmazie. 67:411-413.

Buratti E, Baralle D (2010). Novel roles of U1 snRNP in alternative splicing regulation. RNA Biol. 7:412-9.

Carroll MC (2004). A protective role for innate immunity in systemic lupus erythematosus. Nat Rev Immunol. 4:825-931.

Casciola-Rosen L, Andrade F, Ulanet D, Wong WB, Rosen A (1999). Cleavage by granzyme B is strongly predictive of autoantigen status: implications for initiation of autoimmunity. J Exp Med 190:815-26.

Cavagna L, Scorletti E, Romano M, Cagnotto G, Caporali R (2013). New perspectives in the classification and treatment of systemic lupus erythematosus: the central role of kidney involvement. G Ital Nefrol. 2013 30. pii: gin/30.4.9.

Chiaro TR, Davis KW, Wilson A, Suh-Lailam B, Tebo AE (2011). Significant differences in the analytic concordance between anti-dsDNA IgG antibody assays for the diagnosis of systemic lupus erythematosus--implications for inter-laboratory testing. Clin Chim Acta. 412:1076-80.

Cojocaru M, Cojocaru IM, Silosi I, Vrabie CD (2011). Pulmonary manifestations of systemic autoimmune diseases. Maedica (Buchar). 6:224-229.

de Clerck LS, Meijers KA, Cats A (1989). Is MCTD a distinct entity? Comparison of clinical and laboratory findings in MCTD, SLE, PSS, and RA patients. Clin Rheumatol. 8:29-36.

de Wildt RM, van den Hoogen FH, van Venrooij WJ, Hoet RM (1997). Isolation and characterization of single anti-U1A-specific B cells from autoimmune patients. Ann N Y Acad Sci. 815:440-442.

Egner W (2000). The use of laboratory tests in the diagnosis of SLE. J Clinical Pathol. 53:424-32.

Everett MA, Harrell Er Jr (1956). Hyperlipemia with renal failure due to systemic lupus erythematosus. AMA Arch Derm. 74:464-465.

Faig OZ, Lutz CS (2003). Novel specificity of anti-U1A autoimmune patient sera. Scand J Immunol. 57:79-84. 
Fries LF, Mullins WW, Cho KR, Plotz PH, Frank MM (1984). Monocyte receptors for the Fc portion of IgG are increased in systemic lupus erythematosus. J Immunol. 132:695-700.

Greidinger EL, Hoffman RW (2001). The appearance of U1 RNP antibody specificities in sequential autoimmune human antisera follows a characteristic order that implicates the U1-70 $\mathrm{kd}$ and $\mathrm{B}^{\prime} / \mathrm{B}$ proteins as predominant U1 RNP immunogens. Arthritis Rheum. 44:368-75.

Gunnarsson R, Aaløkken TM, Molberg Ø, Lund MB, Mynarek GK, Lexberg AS, Time K,Dhainaut AS, Bertelsen LT, Palm O, Irgens K, Becker-Merok A, Nordeide JL, Johnsen V, Pedersen S, Prøven A, Garabet LS, Gran JT (2012). Prevalence and severity of interstitial lung disease in mixed connective tissue disease: a nationwide,cross-sectional study. Ann Rheum Dis.71:1966-1972.

Gunnarsson R, Andreassen AK, Molberg $\varnothing$, Lexberg ÅS, Time K, Dhainaut AS, Bertelsen LT, Palm Ø, Irgens K, Becker-Merok A, Nordeide JL, Johnsen V, Pedersen S, Prøven A, Garabet LS, Garen T, Aaløkken TM, Gilboe IM, Gran JT (2013). Prevalence of pulmonary hypertension in an unselected, mixed connective tissue disease cohort: results of a nationwide, Norwegian cross-sectional multicentre study and review of current literature. Rheumatology (Oxford).52:1208-1213

Gutsche M, Rosen GD, Swigris JJ (2012). Connective Tissue Disease-associated Interstitial Lung Disease: A review. Curr Respir Care Rep. 21:224-232.

Haase M, Bellomo R, Devarajan P, Schlattmann P, Haase-Fielitz A; NGAL Metaanalysis Investigator Group (2009). Accuracy of neutrophil gelatinase-associated lipocalin (NGAL) in diagnosis and prognosis in acute kidney injury: a systematic review and meta-analysis. Am J Kidney Dis. 54:1012-1024.

Hochberg MC (1997). Updating the America College of Rheumatology revised criteria for the classification of systemic lupus erythematosus. Arthritis Rheum. 40:1725.

Hoet RM, Kastner B, Lührmann R and Walther J van V (1993). Purification and characterization of human auto-antibodies directed to specific regions on U1RNA; recognition of native U1RNP complexes. Nucleic Acids Res. 21:5130-5136.

Hoffman RW, Bezruczko N, Perkins K (2012). An external validation study of a classification of mixed connective tissue disease and systemic lupus erythematosus patients. J Appl Meas. 13:205-16.

Isenberg DA, Manson JJ, Ehrenstein MR, Rahman A (2007). Fifty years of anti-dsDNA antibodies: are we approaching journey's end? Rheumatology (Oxford).46:1052-6. 
Jessen TH, Oubridge C, Teo HC, Pritchard C and Nagai K (1991). Identification of molecular contacts between the U1A small nuclear ribonucleoprotein and U1 snRNA. The EMBO J 10:3447-3456.

Jin L, Weiqian C, Lihuan Y (2013). Peripheral CD24(hi) CD27(+) CD19(+) B cells subset as a potential biomarker in naïve systemic lupus erythematosus. Int J Rheum Dis. 16:698-708.

Kahn MF, Appelboom T. Syndrome de Sharp. In Kahn MF, Peltier AP, Meyer O and Piette JC. Les maladies systemiques, 3eme ed. Paris: Flammarion, 1991:545-556

Kasukawa R, Tojo T and Miyawaki S (1988). Mixed Connective Tissue Disease preliminary diagnostic criteria. Jpn J Rheumatol. 1:263-270

Kingsmore SF, Thompson JM, Crockard AD, Todd D, McKirgan J, Patterson C, Fay AC, McNeill TA (1989). Measurement of circulating immune complexes containing IgG, $\operatorname{IgM}, \operatorname{IgA}$ and IgE by flow cytometry: correlation with disease activity in patients with systemic lupus erythematosus. J Clin Lab Immunol. 30:45-52.

Kollintza A, Magkouta S, Psallidas I, Moschos C, Stratiki M, Esquerda A, Porcel JM, Kalomenidis I (2013). Interleukin-17A is involved in bacteria-related acute pleural inflammation. Respirology. 18:488-494.

Konforte D, Diamandis EP, van Venrooij WJ, Lories R, Ward MM (2012). Autoimmune diseases: early diagnosis and new treatment strategies. Clin Chem. 58:1510-1514.

Lage LV, de Carvalho JF, Caleiro MT, Yoshinari NH, da Mota LM, Khamashta MA, Cossermelli W (2012). Fluctuation of anti-endothelial cell antibody titers in "mixed connective tissue disease". Isr Med Assoc J. 14:84-87.

Levitt JE, Calfee CS, Goldstein BA, Vojnik R, Matthay MA (2013). Early acute lung injury: criteria for identifying lung injury prior to the need for positive pressure ventilation. Crit Care Med. 41:1929-1937.

Lin WH, Guo CY, Wang WM, Yang DC, Kuo TH, Liu MF, Wang MC (2013). Incidence of progression from newly diagnosed systemic lupus erythematosus to end stage renal disease and all-cause mortality: a nationwide cohort study in Taiwan. Int J Rheum Dis. 16:747-753.

Lindorfer MA, Schuman TA, Craig ML, Martin EN, Taylor RP (2001). A bispecific dsDNAxmonoclonal antibody construct for clearance of anti-dsDNA IgG in systemic lupus erythematosus. J Immunol Methods. 248:125-38.

Liu CC and Ahearn JM (2009). The search for lupus biomarkers. Best Pract Res Clin Rheumatol. 4:507-23. 
López-Longo FJ, Fernández J, Monteagudo I, Rodríguez-Mahou M, Sánchez-Atrio AI, Pérez T, Escalona M, González CM, Lapointe N, Carreño L (1994). Clinical and serologic course of patients with mixed connective tissue disease. Rev Clin Esp. 194:682688

Lu J and Hall KB (1995). An RBD that does not bind RNA: NMR secondary structure determination and biochemical properties of the C-terminal RNA binding domain from the human U1A protein. J Mol Biol. 247:739-752.

Lundberg IE (2005). The prognosis of mixed connective tissue disease. Rheum Dis Clin North Am. 31:535-547.

Luyckx A, Westhovens R, Oris E, Papisch W, Bossuyt X (2005). Clinical relevance of measurement of antibodies to individual snU1-RNP proteins. Clin Chem 51:1888-1890.

Maddison PJ. Mixed connective tissue disease: overlap syndromes (2000). Baillieres Best Pract Res Clin Rheumatol. 14:111-124

Mahler M, Stinton LM, Fritzler MJ (2005). Improved serological differentiation between systemic lupus erythematosus and mixed connective tissue disease by use of an SmD3 peptide-based immunoassay. Clin Diagn Lab Immunol. 1:107-113.

Maldonado ME, Perez M, Pignac-Kobinger J, Marx ET, Tozman EM, Greidinger EL, Hoffman RW (2008). Clinical and immunologic manifestations of mixed connective tissue disease in a Miami population compared to a Midwestern US Caucasian population. J Rheumatol.35:429-437.

McClain MT, Lutz CS, Kaufman KM, Faig OZ, Gross TF, James JA (2004). Structural availability influences the capacity of auto-antigenic epitopes to induce a widespread lupus-like autoimmune response. Proc Natl Acad Sci 101:3551-3556.

Mesa A, Somarelli JA and Herrera, RJ (2008). Spliceosomal Immunophilins. FEBS letters. $582: 2345-51$.

Mesa A, Somarelli J, Wu W, Martinez L, Blom M, Greidinger E, Herrera R (2013). Differential immunoglobulin class-mediated responses to components of the U1 small nuclear ribonucleoprotein particle in systemic lupus erythematosus and mixed connective tissue disease. Lupus. 22:1371-1381.

Mevorach D (2003). Systemic lupus erythematosus and apoptosis: a question of balance. Clin Rev Allergy Immunol. 25:49-60.

Migliorini P, Baldini C, Rocchi V, Bombardieri S (2005). Anti-Sm and anti-RNP antibodies. Autoimmunity. 38:47-54. 
Monguilhott Dalmarco E, Mendes de Córdova CM, Fröde TS (2011). Evidence of an anti-inflammatory effect of mycophenolate mofetil in a murine model of pleurisy. Exp Lung Res. 37:399-407.

Moore, M.J. and Sharp, P.A. (1993) Evidence for two active sites in the splicesome provided by stereochemistry of pre-mRNA. Nature 23:364-368.

Moore RE, Ge HY, Young MK, Lee TD, Stevens SW. 2007. Proteomic analysis of in vivo-assembled pre-mRNA splicing complexes expands the catalog of participating factors. Nucleic Acids Res 35:3928-3944.

Muñoz-Paredes JC, Oliveira LG, de Carvalho Braga A, Trevisol IM, Roehe PM (1999). Development and standardization of an indirect ELISA for the serological diagnosis of classical swine fever. Pesq Vet Bra 19:123-127.

Nagai K, Arito M, Takakuwa Y, Ooka S, Sato T, Kurokawa MS, Okamoto K, Uchida T, Suematsu N, Kato T (2012). Altered posttranslational modification on U1 small nuclear ribonucleoprotein $68 \mathrm{k}$ in systemic autoimmune diseases detected by $2 \mathrm{D}$ Western blot. Electrophoresis.33:2028-2035.

Natali PG, Tan EM (1972). Experimental renal disease induced by DNA-anti-DNA immune complexes. J Clin Invest. 51:345-355.

Neogi T, Gladman DD, Ibanez D, Urowitz M (2006). Anti-dsDNA antibody testing by Farr and ELISA techniques is not equivalent. J Rheumatol 33:1785-88.

Nishimaki T, Aotsuka S, Kondo H, Yamamoto K, Takasaki Y, Sumiya M, Yokohari R (1999). Immunological analysis of pulmonary hypertension in connective tissue diseases. J Rheumatol. 26:2357-2362.

Niţescu D, Nicolau A, Caraiola S, Predeţeanu D, Ionescu R, Tănăsescu C (2011). Neuromyelitis optica--complication or comorbidity in primary Sjögren's syndrome? Rom J Intern Med. 49:295-300.

Nowicka-Sauer K, Czuszynska Z, Majkowicz M, Smolenska Z, Jarmoszewicz K, Olesinska M, Siebert J (2012). Neuropsychological assessment in mixed connective tissue disease: Comparison with systemic lupus erythematosus. Lupus. 21:927-933.

Ortega-Hernandez OD, Shoenfeld Y (2012). Mixed connective tissue disease: an overview of clinical manifestations, diagnosis and treatment. Best Pract Res Clin Rheumatol. 26:61-72.

Palafox Sánchez CA, Satoh M, Chan EK, Carcamo WC, Muñoz Valle JF, Orozco Barocio G, Oregon Romero E, Navarro Hernández RE, Salazar Páramo M, Cabral Castañeda A, Vázquez Del Mercado M (2009). Reduced IgG anti-small nuclear ribonucleoprotein autoantibody production in systemic lupus Erythematosus patients with positive IgM anti-cytomegalovirus antibodies. Arthritis Res Ther 11:R27. 
Pehlivan O, Inanç M (2010). Pulmonary arterial hypertension related to connective tissue diseases. Anadolu Kardiyol Derg. 1:57-62

Pena JA, Lotze TE (2013). Pediatric multiple sclerosis: current concepts and consensus definitions. Autoimmune Dis. 2013:673947.

Perkins K, Hoffman RW, Bezruczko N (2008). A Rasch analysis for classification of systemic lupus erythematosus and mixed connective tissue disease. J Appl Meas. 9:136150 .

Petri M, Orbai AM, Alarcón GS, Gordon C, Merrill JT, Fortin PR, Bruce IN, Isenberg D, Wallace DJ, Nived O, Sturfelt G, Ramsey-Goldman R, Bae SC, Hanly JG, SánchezGuerrero J, Clarke A, Aranow C, Manzi S, Urowitz M, Gladman D, Kalunian K, Costner M, Werth VP, Zoma A, Bernatsky S, Ruiz-Irastorza G, Khamashta MA, Jacobsen S, Buyon JP, Maddison P, Dooley MA, van Vollenhoven RF, Ginzler E, Stoll T, Peschken C, Jorizzo JL, Callen JP, Lim SS, Fessler BJ, Inanc M, Kamen DL, Rahman A, Steinsson K, Franks AG Jr, Sigler L, Hameed S, Fang H, Pham N, Brey R, Weisman MH, McGwin G Jr, Magder LS (2012). Derivation and validation of the Systemic Lupus International Collaborating Clinics classification criteria for systemic lupus erythematosus. Arthritis Rheum. 64:2677-2686

Pizarro S, Monárrez Espino J, Ruiz A, Jara LJ, Nava A, Riebeling-Navarro C (2007). Soluble vascular cell adhesion molecule-1 indicates SLE disease activity and specific organ involvement. Rev Alerg Mex. 54:189-95.

Pomeranz Krummel DA, Oubridge C, Leung AK, Li J, Nagai K (2009). Crystal structure of human spliceosomal U1 snRNP at 5.5 A resolution. Nature. 458:475-480.

Poole BD, Schneider RI, Guthridge JM, Velte CA, Reichlin M, Harley JB, James, JA (2209). Early targets of nuclear RNP humoral autoimmunity in human systemic lupus erythematosus. Arthritis Rheum 60:848-859.

Pollard KM, Tan EM (1985). Purification of the Sm nuclear autoantigen. Detection and clinical significance of IgM antibody. Clin Exp Immunol. 60:586-596.

Quinkler M (2012). Addison's disease. Med Klin Intensivmed Notfmed. 107:454-459.

Rebora A, Parodi A (1990). Mixed connective tissue disease and correlated diseases. G Ital Dermatol Venereol. 125:357-362.

Reveille JD (2004). Predicted value of antibodies for activity of systemic lupus Erythematosus. Lupus 5:290-7.

Riemekasten G, Hahn BH (2005). Key autoantigens in SLE. Rheumatol (Oxford). 44:975-82. 
Routsias JG, Kyriakidis N, Latreille M, Tzioufas AG (2010). RNA recognition motif (RRM) of La/SSB: the bridge for interparticle spreading of autoimmune response to U1RNP. Mol Med. 16:19-26.

Roy A, Kucukural A, Zhang Y (2010). I-TASSER: a unified platform for automated protein structure and function prediction. Nat Protoc. 5:725-738.

Roy A, Yang J, Zhang Y (2012). COFACTOR: an accurate comparative algorithm for structure-based protein function annotation. Nucleic Acids Res. (Web Server issue): W471-7.

Ryu HJ, Takeuchi F, Kuwata S, Kim YJ, Lee EY, Lee EB, Song YW (2011). The diagnostic utilities of anti-agalactosyl IgG antibodies, anti-cyclic citrullinated peptide antibodies, and rheumatoid factors in rheumatoid arthritis. Rheumatol Int. 31:315-9.

Sasaki N, Kamataki A, Sawai T (2011). A histopathological study of pulmonary hypertension in connective tissue disease. Allergol Int. 60:411-417.

Sato T, Fujii T, Yokoyama T, Fujita Y, Imura Y, Yukawa N, Kawabata D, Nojima T, Ohmura K, Usui T, Mimori T (2010). Anti-U1 RNP antibodies in cerebrospinal fluid are associated with central neuropsychiatric manifestations in systemic lupus erythematosus and mixed connective tissue disease. Arthritis Rheum. 62:3730-3740.

Sawai T, Murakami K, Kurasono Y (1994). Morphometric analysis of the kidney lesions in mixed connective tissue disease (MCTD). Tohoku J Exp Med. 174:141-154.

Scherly D, Boelens W, van Venrooij WJ, Dathan NA, Hamm J, Mattaj W (1989) Identification of the RNA binding segment of human U1A protein and definition of its binding site on U1 snRNA. The EMBO J, 8:4163-4170.

Sharp GC, Irvin WS, Tan EM, Gould RG, Holman HR (1972). Mixed connective tissue disease - an apparently distinct rheumatic disease syndrome associated with a specific antibody to an extractable nuclear antigen (ENA). Am J Med 52:148-159.

Sharp GC (1987). Diagnostic criteria for classification of MCTD. In: Kasukawa R, Sharp GC, eds. Mixed Connective Tissue Disease and Antinuclear Antibodies. Amsterdam: Elsevier, 23-32.

Shi YH, Li R, Chen S, Su Y, Jia Y (2012). Analysis of clinical features and the outcome in 91 cases of mixed connective tissue diseases. Beijing Da Xue Xue Bao. 44:270-274.

Shirai Y, Yasuoka H, Okano Y, Takeuchi T, Satoh T, Kuwana M (2012). Clinical characteristics and survival of Japanese patients with connective tissue disease and pulmonary arterial hypertension: a single-centre cohort. Rheumatology (Oxford). 51:1846-1854. 
Simao LM (2010). Ophthalmologic manifestations commonly misdiagnosed as demyelinating events in multiple sclerosis patients. Curr Opin Ophthalmol. 21:436-441.

Simón JA, Cabiedes J, Ortiz E, Alcocer-Varela J, Sánchez-Guerrero J (2004). Antinucleosome antibodies in patients with systemic lupus erythematosus of recent onset. Potential utility as a diagnostic tool and disease activity marker. Rheumatology. 43:220224.

Smolen JC and Steiner G (1988). Mixed Connective Tissue Disease: to be or not to be. Arthritis and Rheumatism. 41:768-777.

Somarelli JA, Mesa A and Herrera RJ (2010). A three dimensional model of the U1 small nuclear ribonucleoprotein particle. Ent Res. 40:104-12.

Somarelli, JA, Mesa A, Fuller ME, Torres JO, Rodriguez CE, Ferrer CM and Herrera RJ (2010). Genome-based identification of spliceosomal proteins in the silk moth Bombyx mori. Arch of Insect Biochem and Physiol 75:231-263.

Somarelli JA, Mesa A, Rodriguez R, Avellan R, Martinez L, Zang YJ, Greidinger EL, Herrera RJ (2011). Epitope mapping of the U1 small nuclear ribonucleoprotein particle in patients with systemic lupus erythematosus and mixed connective tissue disease. Lupus. 20:274-289.

Staley JP, Guthrie C (1998). Mechanical devices of the spliceosome: motors, clocks, springs, and things. Cell. 92:315-326.

Swanton J, Isenberg D (2005). Mixed connective tissue disease: Still crazy after all these years. Rheum Dis Clin North Am 31:421-436.

Szodoray P, Hajas A, Kardos L, Dezso B, Soos G, Zold E, Vegh J, Csipo I, Nakken B, Zeher M, Szegedi G, Bodolay E (2012). Distinct phenotypes in mixed connective tissue disease: subgroups and survival. Lupus. 21:1412-1422.

Tan EM, Cohen AS, Fries JF, Masi AT, McShane DJ, Rothfield NF, Schaller JG, Talal N, Winchester RJ (1982). The 1982 revised criteria for the classification of systemic lupus erythematosus. Arthritis Rheum. 25:1271-1277.

Talken BL, Schafermeyer KR, Bailey CW, Lee DR, Hoffman RW (2001). T cell epitope mapping of the Smith antigen reveals that highly conserved Smith antigen motifs are the dominant target of $\mathrm{T}$ cell immunity in systemic lupus erythematosus. J Immunol 167:562-568.

Tang J and Rosbash M (1996). Characterization of yeast U1 snRNP A protein: identification of the N-terminal RNA binding domain (RBD) binding site and evidence that the C-terminal RBD functions in splicing. RNA. 10:1058-1070. 
Uthman I, Vázquez-Abad D, Senécal JL (1996). Distinctive features of idiopathic inflammatory myopathies in French Canadians. Semin Arthritis Rheum. 26:447-458

Varani L, Gunderson SI, Mattaj IW, Kay LE, Neuhaus D, Varani G (2000). The NMR structure of the $38 \mathrm{kDa}$ U1A protein - PIE RNA complex reveals the basis of cooperativity in regulation of polyadenylation by human U1A protein. Nat Struct Biol. 7:329-335.

Venables PJ (2006). Mixed connective tissue disease. Lupus. 15(3):132-137

Vlachoyiannopoulos PG, Guialis A, Tzioufas G, Moutsopoulos HM (1996). Predominance of IgM anti-U1RNP antibodies in patients with systemic lupus erythematosus. Br J Rheumatol. 35:534-541.

von Bierbrauer A, Willert J, Barth P (2008). Histomorphometrical analysis of microvascular abnormalities in connective tissue diseases. Rheumatol Int. 28:253-259.

Watanabe Y, Koyama S, Moriguchi M, Miwa C, Shiraishi M, Nomura M, Nokubi M, Terai C, Kawabata Y (2012). Rapidly progressive respiratory failure in mixed connective tissue disease: report of an autopsy case. Intern Med. 5:3415-3419.

Witte T, Hartung K, Sachse C, Matthias T, Fricke M, Deicher H, Kalden JR, Lakomek HJ, Peter HH, Schmidt RE (1998). IgM anti-dsDNA antibodies in systemic lupus erythematosus: negative association with nephritis. SLE Study Group. Rheumatol Int. 18:85-91.

Yoshida A, Morozumi K, Takeda A, Koyama K (1994). Nephropathy in patients with mixed connective tissue disease. Ryumachi. 34:976-980.

Yang CC, Hsieh SC, Li KJ, Wu CH, Lu MC, Tsai CY, Yu CL (2012). Urinary neutrophil gelatinase-associated lipocalin is a potential biomarker for renal damage in patients with systemic lupus erythematosus. J Biomed Biotechnol. 2012:759313.

Zdrojewicz Z, Budzyń-Kozioł E, Puławska J (1999). Mixed connective tissue disease-etiology, pathogenesis, clinical significance, treatment. Postepy Hig Med Dosw. 53:75166.

Zhang W, Reichlin M (1995). IgM anti-A and D SnRNP proteins and IgM anti-dsDNA are closely associated in SLE sera. Clin Immunol Immunopathol. 74:70-76.

Zhang L, Liu J, Zhang H, Wu S, Huang L, He D, Xiao X (2005). Discovery and identification of anti-U1-A snRNP antibody in lung cancer. Sci China C Life Sci. 48:641647.

Zhang Y (2008). I-TASSER server for protein 3D structure prediction. BMC Bioinformatics. 9:40. 
Zidan HE, Sabbah NA, Hagrass HA, Tantawy EA, El-Shahawy EE, Nageeb GS, AbdulSattar AB (2013). Association of Fc $\gamma$ RIIB and Fc $\gamma$ RIIA R131H gene polymorphisms with renal involvement in Egyptian systemic lupus erythematosus patients. Mol Bio Rep. Dec 24. [Epub ahead of print] 
APPENDICES 


\begin{abstract}
APPENDIX 1
Protocol for generating a 3D protein structure and applying a heat scale to residues of interest
\end{abstract}

This protocol assumes that the amino acid sequence of a protein of interest is available.

\title{
Generating a heat map scale
}

The goal for generating a heat map scale is to pick one group as a baseline and then compare how far above or below that baseline some other group performs. The resulting deviation should range from 0 to 1 . In general, one picks the control group (i.e. healthy subjects) as the baseline. For a four color heat scale of blue to green to yellow to red, with blue being least intense and red being most intense, the following procedure can be used.

1. For each value measured, calculate deviation by the test group from the control group using the formula:

\section{Deviation $=0.5+$ Test-Control}

2. Calculate the appropriate RGB values for the deviation.

a. In Excel, place the value for Deviation in cell B2.

b. To calculate the Red RGB value, place the following code in cell C2:

- $\quad=\mathrm{IF}(\mathrm{B} 2>0.67,255, \mathrm{IF}(\mathrm{B} 2>0.33,255 *(3 * \mathrm{~B} 2-\mathrm{FLOOR}(3 * \mathrm{~B} 2,1)), 0))$

c. To calculate the Green RGB value, place the following code in cell D2:

- $\quad=\mathrm{IF}\left(\mathrm{B} 2>0.67,-255^{*}(3 * \mathrm{~B} 2-\right.$

$\operatorname{FLOOR}(3 * \mathrm{~B} 2,1))+255, \mathrm{IF}\left(\mathrm{B} 2>0.33,255,255^{*}(3 * \mathrm{~B} 2-\right.$

$\operatorname{FLOOR}(3 * \mathrm{~B} 2,1))))$ 
d. To calculate the Blue RGB value, place the following code in cell E2:

$$
\text { - }=\mathrm{IF}(\mathrm{B} 2>0.33,0,-255 *(\mathrm{~B} 2 * 3-\mathrm{FLOOR}(\mathrm{B} 2 * 3,1))+255)
$$

3. Use the resulting RGB values as custom colors in some other application. An example is Case 1 step 5 below.

\section{Generating 3D structures}

In terms of an experimentally determined 3D structure of the protein, there are three cases that are addressed: (1) no such 3D structure is available; (2) a partial structure is available; or (3) a complete structure is available.

\section{Case 1}

1. Submit the amino acid sequence to the I-TASSER protein structure prediction server to generate 3D structures of your protein. The server is located at: http://zhanglab.ccmb.med.umich.edu/I-TASSER/.

2. Download and install PyMOL to visualize the predicted structures. It can be obtained at: http://www.pymol.org/.

3. Open the I-TASSER model of interest (usually the one with the highest C-score) in PyMOL.

4. Define your residues of interest using the select command.

- Example, to define residues 10 through 20 by the name p1, at the PyMOL > prompt type:

- $\quad$ select p1, resi 10-20

Define your custom colors from the heat map scale using the set_color command. 
- Example, to define a custom color with $\mathrm{RGB}$ values of $\mathrm{R}=127, \mathrm{G}=255$, $\mathrm{B}=212$, type:

- $\quad$ set_color $p 1 \_c o l o r=[127,255,212]$

Assign your custom colors to your residues of interest.

- For the example residues and color above, type:

- color p1_color, p1

Repeat steps 4 through 6 for each set of residues of interest.

Choose how you would like your structure represented. From the PyMOL viewer next to "all", click S for Show, then "as" and choose either lines, sticks, ribbon, or cartoon.

To change the background color to white, type:

- bg_color white

Orient the structure as desired, or click the Orient button in the PyMOL console. If planning to create an animation, be sure to leave sufficient white space around the structure.

To save a high quality image of the structure, type:

- ray

- Click on File->Save Image As->PNG... and select your filename

For a rotated image, type:

- rotate $\mathrm{y}, 180$

- Repeat step 11

Open your image in a graphics package (for example, Photoshop) to add labels. 
To create an animated GIF of your structure, first install ImageMagick. It can be obtained at: http://www.imagemagick.org/script/index.php.

Create a series of still images to serve as frames for your animation. From the PyMOL prompt, type:

- mset $1 \times 60$

- util.mrock $1,60,180$

- $\quad$ set ray_trace_frames $=1$

- mpng frame

Copy your frames to a temporary folder and open a command prompt. Type:

- convert -delay 1 -loop 0 frame*.png animated.gif

\section{Case 2}

1. Follow steps 1 and 2 as in Case 1 .

2. Compare your predicted structures to your experimentally determined structure in PyMOL by superposition.

a. Open your experimentally determined structure and your I-TASSER models in PyMOL.

b. For each comparison, where model is the name of your predicted structure and experimental is the name of your experimentally determined structure, type:

c. super model, experimental

d. Find the best ratio of retained atoms to RMS value from the final line of output. Using only the best superposition, follow steps 4 through 15 as in Case 1 . 


\section{Case 3}

1. Follow steps 2 and steps 4 through 15 as in Case 1 . 


\section{APPENDIX 2}

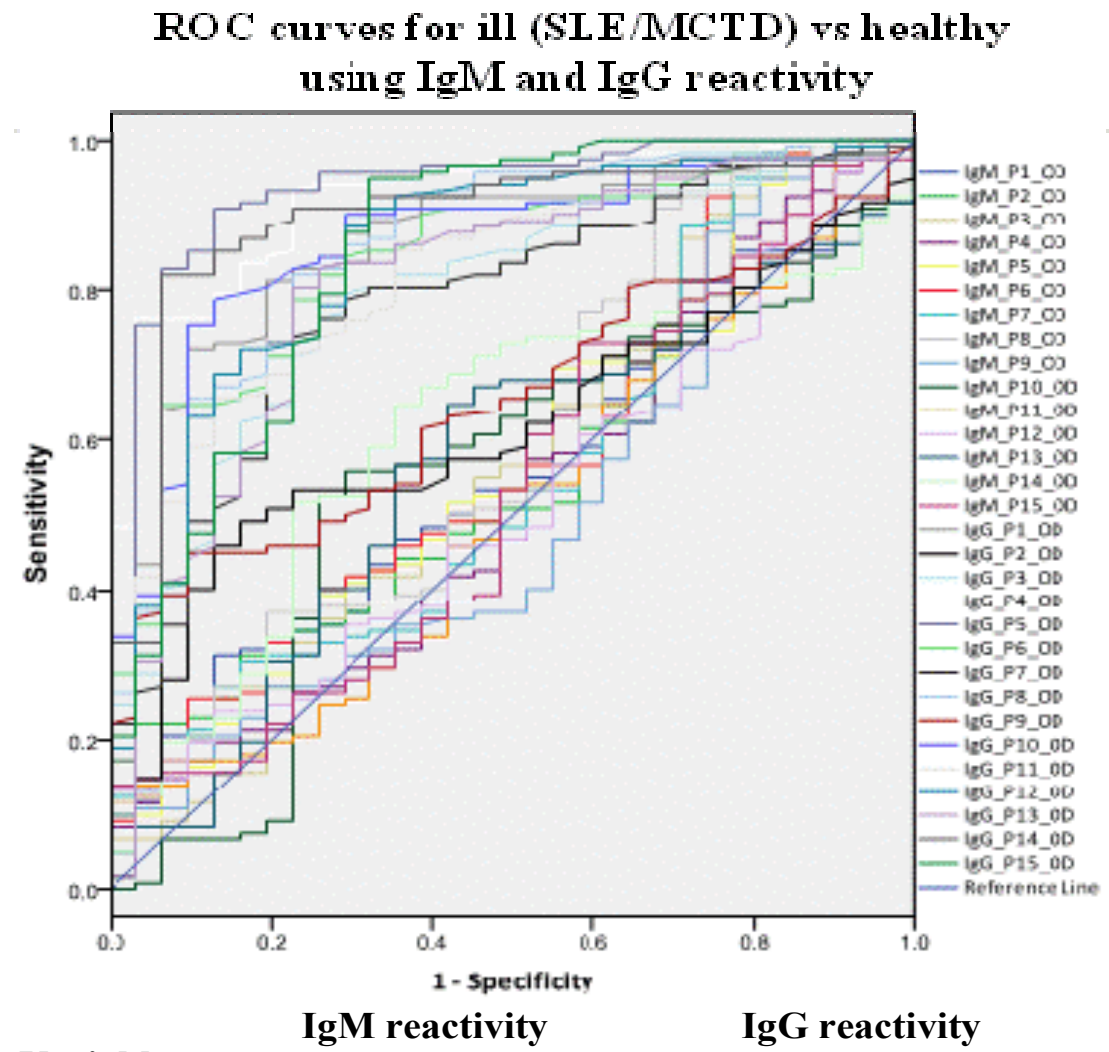

Variables

$\begin{array}{cccccc}\text { AUC } & \text { SE } & \boldsymbol{p} \text { value } & \text { AUC } & \text { SE } & \boldsymbol{p} \text { value } \\ .562 & .055 & .286 & \mathbf{. 8 6 3} & \mathbf{. 0 3 6} & <.0001 \\ .570 & .057 & .227 & .613 & .050 & .053 \\ .567 & .061 & .251 & .796 & \mathbf{. 0 4 3} & <.0001 \\ .522 & .059 & .710 & . \mathbf{9 2 5} & \mathbf{. 0 2 4} & <.0001 \\ .575 & .058 & .197 & \mathbf{. 9 3 3} & \mathbf{. 0 2 9} & <.0001 \\ .579 & .058 & .173 & \mathbf{. 8 4 2} & \mathbf{. 0 3 7} & <.0001 \\ .558 & .059 & .321 & . \mathbf{7 8 7} & \mathbf{. 0 4 4} & <.0001 \\ .598 & .060 & .091 & \mathbf{. 8 5 7} & \mathbf{. 0 3 9} & <.0001 \\ .508 & .060 & .890 & \mathbf{. 6 5 3} & \mathbf{. 0 4 7} & \mathbf{. 0 0 8} \\ .547 & .059 & .424 & \mathbf{. 8 6 7} & \mathbf{. 0 3 5} & <.0001 \\ .509 & .058 & .874 & \mathbf{. 8 1 7} & \mathbf{. 0 4 1} & <.0001 \\ .517 & .056 & .773 & \mathbf{. 8 5 0} & \mathbf{. 0 4 0} & <.0001 \\ .560 & .056 & .305 & \mathbf{. 8 0 4} & \mathbf{. 0 4 6} & <.0001 \\ .613 & .053 & .052 & \mathbf{. 8 9 5} & \mathbf{. 0 3 3} & <.0001 \\ .532 & .060 & .583 & \mathbf{. 8 4 9} & \mathbf{. 0 4 3} & <.0001\end{array}$




\section{ROC curves for SLE vs MCTD using $\operatorname{IgM}$ and $\mathrm{IgG}$}

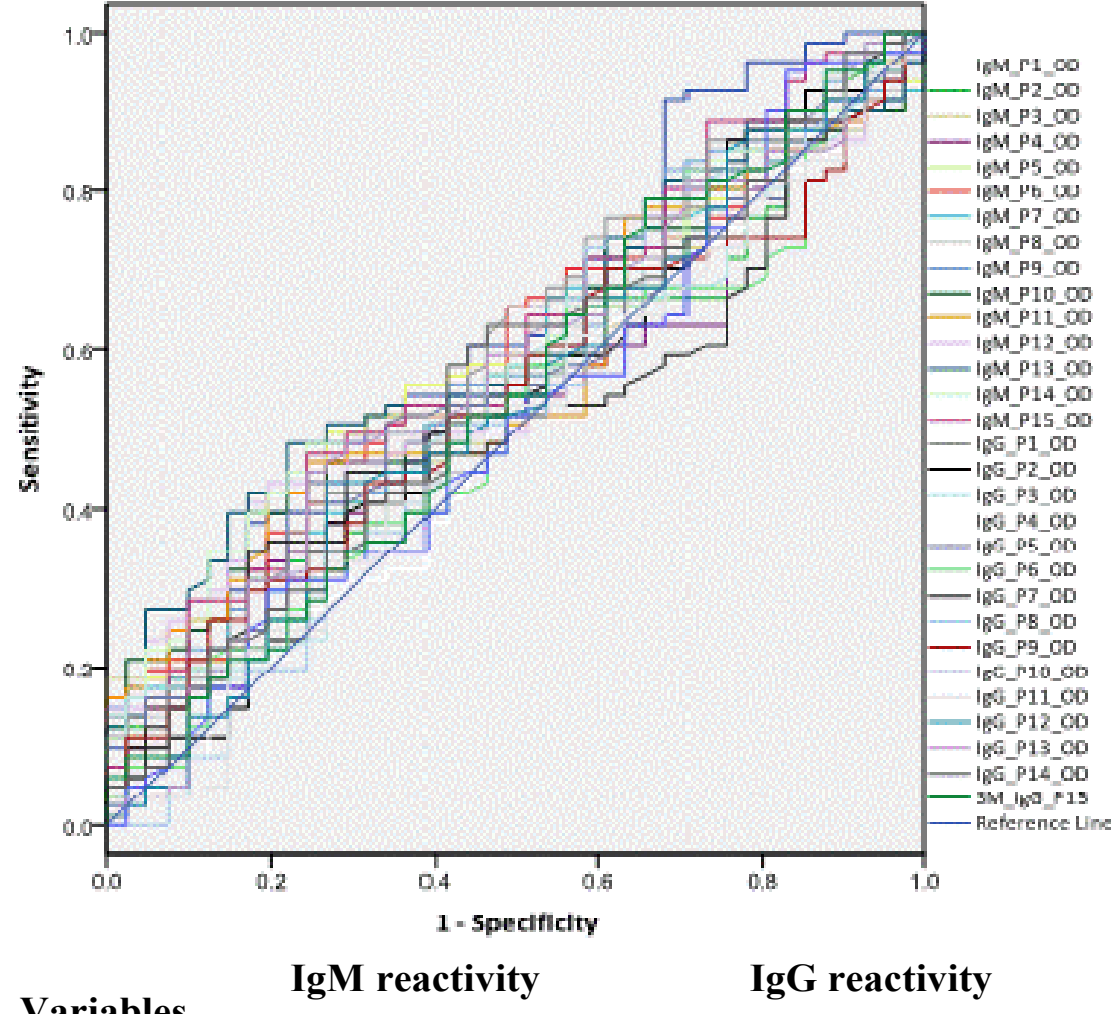

Variables

AUC SE $p$ value AUC SE $p$ value

$\begin{array}{lllllll}\text { P1 } & .631 & .053 & .018 & .587 & .054 & .119\end{array}$

$\begin{array}{lllllll}\mathrm{P} 2 & .547 & .053 & .402 & .534 & .056 & .540\end{array}$

$\begin{array}{lllllll}\mathrm{P} 3 & .551 & .054 & .358 & .536 & .054 & .517\end{array}$

$\begin{array}{lllllll}\mathrm{P} 4 & .537 & .054 & .500 & .505 & .056 & .922\end{array}$

$\begin{array}{lllllll}\text { P5 } & .570 & .053 & .210 & .549 & .054 & .374\end{array}$

$\begin{array}{lllllll}\text { P6 } & .581 & .053 & .147 & .510 & .055 & .852\end{array}$

$\begin{array}{lllllll}\mathrm{P} 7 & .561 & .054 & .269 & .516 & .054 & .780\end{array}$

$\begin{array}{lllllll}\text { P8 } & .548 & .054 & .387 & .527 & .057 & .624\end{array}$

$\begin{array}{lllllll}\text { P9 } & .577 & .053 & .164 & .538 & .053 & .498\end{array}$

$\begin{array}{lllllll}\mathrm{P} 10 & .585 & .052 & .124 & .528 & .056 & .745\end{array}$

$\begin{array}{lllllll}\mathrm{P} 11 & .574 & .052 & .185 & .502 & .056 & .978\end{array}$

$\begin{array}{lllllll}\mathrm{P} 12 & .584 & .052 & .128 & .536 & .056 & .512\end{array}$

$\begin{array}{lllllll}\mathrm{P} 13 & \mathbf{6 1 0} & \mathbf{. 0 5 1} & \mathbf{. 0 4 8} & .569 & .055 & .214\end{array}$

$\begin{array}{lllllll}\mathrm{P} 14 & .600 & .052 & .072 & .556 & .055 & .316\end{array}$

$\begin{array}{lllllll}\mathrm{P} 15 & .605 & .053 & .060 & .545 & .056 & .422\end{array}$ 


\section{ROC curves for SLE vs MCTD using IgM reactivity} and clinical tests

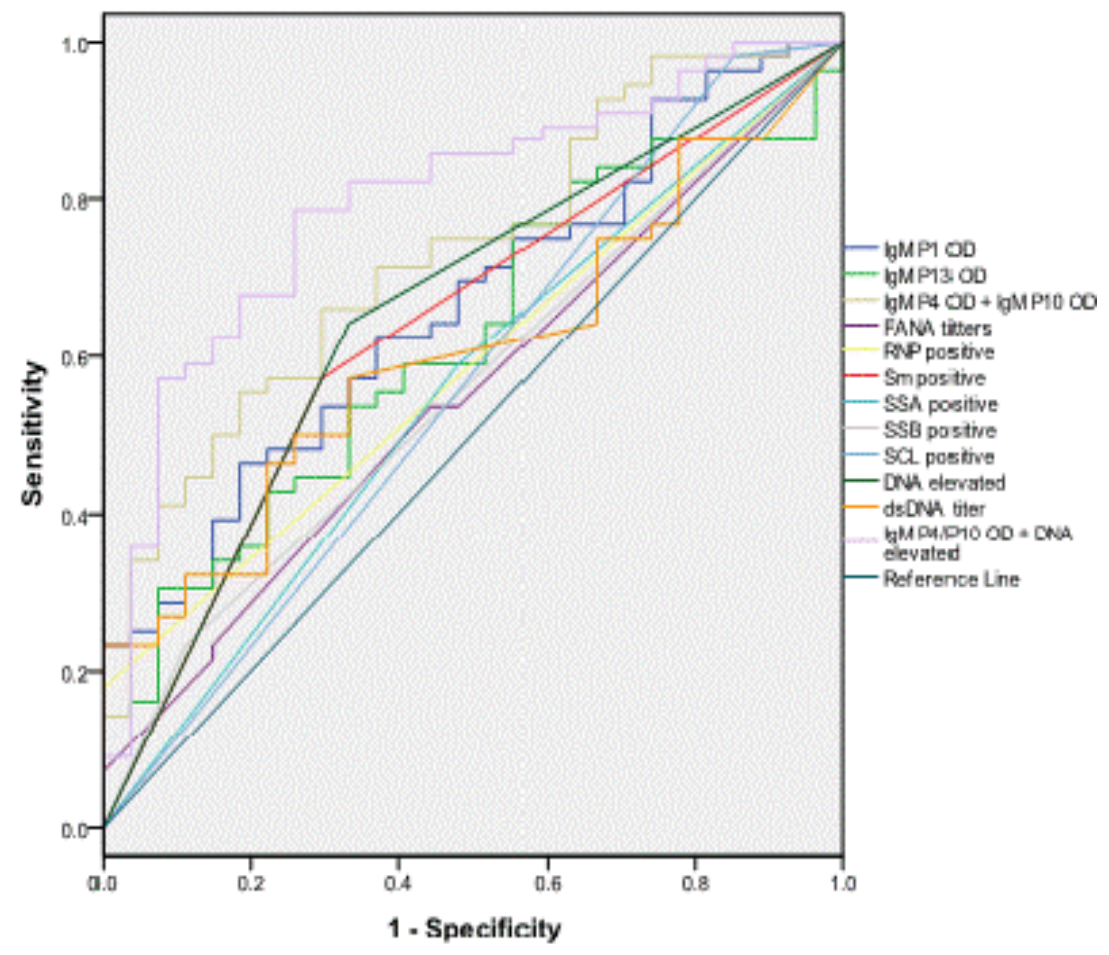

$\begin{array}{cccc}\text { Variables } & \text { AUC } & \text { SE } & \boldsymbol{p} \text { value } \\ \text { IgM P1 OD } & \mathbf{. 6 6 4} & \mathbf{. 0 6 1} & \mathbf{. 0 1 6} \\ \text { IgM P13 OD } & .618 & .063 & .084 \\ \text { IgM P4 OD + IgM P10 OD } & .731 & \mathbf{. 0 5 7} & \mathbf{. 0 0 1} \\ \text { FANA titters } & .553 & .066 & .437 \\ \text { RNP positive } & .589 & .063 & .189 \\ \text { Sm positive } & \mathbf{. 6 3 8} & \mathbf{. 0 6 5} & \mathbf{. 0 4 3} \\ \text { SSA positive } & .554 & .068 & .428 \\ \text { SSB positive } & .561 & .066 & .374 \\ \text { SCL positive } & .565 & .070 & .338 \\ \text { DNA elevated } & \mathbf{. 6 6 5} & \mathbf{. 0 6 5} & \mathbf{. 0 2 3} \\ \text { ds DNA titters } & .605 & .062 & .123 \\ \text { IgM P4/P10 OD + DNA elevated } & \mathbf{. 7 9 8} & \mathbf{. 0 5 2} & <. \mathbf{0 0 0 1}\end{array}$




\section{APPENDIX 3}

\begin{tabular}{|c|c|c|}
\hline & Variable & Definition \\
\hline \multirow{16}{*}{$\frac{\pi}{\pi}$} & Telangiectasia & Skin telengectasia observed \\
\hline & Nasal ulcers & Skin nasal ulcers observed \\
\hline & Oral ulcers & Skin oral ulcers observed \\
\hline & Raynaud & $\begin{array}{l}\text { Raynaud: a pattern of color changes in the fingers as } \\
\text { follows: pale/white followed by blue then red when the } \\
\text { hands are warmed; color changes are usually preceded } \\
\text { by exposure to cold or emotional upset }\end{array}$ \\
\hline & Skin hand swelling history & Hand swelling by history \\
\hline & Skin hand swelling observed & Hand swelling observed \\
\hline & Sclerodactyly & Skin sclerodacytyl / acrosclerosis \\
\hline & Pitting & Skin digital pitting \\
\hline & Alopecia & Skin alopecia-patchy or generalized \\
\hline & Malar rash & $\begin{array}{l}\text { Skin malar rash- fixed erythema, flat or raised, over the } \\
\text { malar eminences, tending to spare the solabial folds }\end{array}$ \\
\hline & Discoid rash & $\begin{array}{l}\text { Skin discoid rash- erythematous raised patches with } \\
\text { adherent keratotic scaling and follicular plugging. } \\
\text { Atrophic scaring seen in older lesions }\end{array}$ \\
\hline & Skin rash & Skin rash other by history or exam \\
\hline & Photosensitivity & $\begin{array}{l}\text { Skin photosensitivity- skin rash as a resulf of unusual } \\
\text { reaction to sunlight by history or exam }\end{array}$ \\
\hline & Calcinosis & Skin calcinosis observed \\
\hline & Proximal scleroderma & Skin proximal scleroderma / extend at or above wrist \\
\hline & Sicca & Skin sicca- xerophthalmia and xerostomia \\
\hline \multirow{9}{*}{$\frac{0}{\varrho}$} & Myositis & Myositis \\
\hline & Myalgia & $\begin{array}{l}\text { Myalgia-subjective muscle acking involving proximal } \\
\text { muscles }\end{array}$ \\
\hline & Arthralgia & Arthralgia \\
\hline & Observed proximal weakness & Any objective weakness in the proximal muscles \\
\hline & History proximal weakness & A subjective history of any proximal muscle weakness \\
\hline & Muscular HAND SWELLING SPECIFIC & At least one area swollen in a wrist, mcp, or pip joint \\
\hline & Muscular HAND SWELLING GENERAL & Muscular hand swelling \\
\hline & Muscular HAND SWELLING HISTORY & Swelling of the hand by history \\
\hline & Muscular HAND SWELLING OBSERVED & Swelling of the hands observed \\
\hline
\end{tabular}




\begin{tabular}{|c|c|c|}
\hline \multirow{9}{*}{$\stackrel{\frac{n}{ٍ}}{\stackrel{0}{\circ}}$} & Morning stiff & $\begin{array}{l}\text { Morning stifness lasting at least } 1 \text { hour before maximal } \\
\text { improvement }\end{array}$ \\
\hline & Join tender & Joint tenderness observed \\
\hline & Synovitys & Synovitys \\
\hline & Join swellling history & History of joint swelling \\
\hline & Join swellling obs & Joint swelling observed \\
\hline & Swelling joints $>\mathbf{3}$ & $\begin{array}{l}\text { Swelling of } 3 \text { or more joints (pip, mcp, wrist, elbow, } \\
\text { knee, ankle and mtp) }\end{array}$ \\
\hline & Symmetric swelling & Symetric swelling observed \\
\hline & Joints pain & Joints pain \\
\hline & Joints deformity & Joints deformity \\
\hline \multirow{6}{*}{ 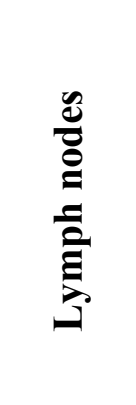 } & Any lymphadenopathy & Any lymphadenopathy \\
\hline & Lympnodes swelling & Lympnodes swelling \\
\hline & Neck lympnode Swelling & Neck lympnode swellin \\
\hline & Axila lympnode Swelling & Axila lympnode swellin \\
\hline & Groin lympnode Swelling & Groin lympnode swellin \\
\hline & Rheum nodule & $\begin{array}{l}\text { Observed rheumatoid nodule- subcutaneous nodules } \\
\text { over bony prominences or extensor surfaces, or in } \\
\text { juxtaarticular regions }\end{array}$ \\
\hline Gastro & Gastric reflux & $\begin{array}{l}\text { Gastric reflux as diagnosed by patient symptoms of } \\
\text { heartburn, acid reflux or chest pain and radiographic } \\
\text { studies and/or endoscopy }\end{array}$ \\
\hline \multirow{6}{*}{$\frac{\overline{8}}{\overline{0}}$} & Anemia & Anemia \\
\hline & Anemia hemolyti & Hemolytic anemia \\
\hline & Leukopenia & Leukopenia \\
\hline & Lymphopenia & Lymphopenia, total lymphocyte count $<1500 / \mathrm{mm}$ \\
\hline & Thrombopenia & Thrombocytopenia \\
\hline & Thrombosis & Thrombosis \\
\hline \multirow{10}{*}{$\underset{\mathscr{I}}{\mathbb{Z}}$} & Pleuritis & $\begin{array}{l}\text { Convincing history of pleuritic pain or rubbing heard by } \\
\text { a physician or evidence of pleural effusion }\end{array}$ \\
\hline & Pericarditis & $\begin{array}{l}\text { Pericarditis: documented by ecg or rub or evidence of } \\
\text { pericardial effusion }\end{array}$ \\
\hline & PLEURITIS and/or PERICARDITIS & $\begin{array}{l}\text { Pleuritis and/or pericarditis: either or both of two above } \\
\text { described }\end{array}$ \\
\hline & Venous clot & Venous clot \\
\hline & Arterial clot & Arterial clot \\
\hline & Any clot & Any clot \\
\hline & Myocard infarction & Myocardio infarction \\
\hline & Valvular disease & Valvular heart disease \\
\hline & Valvular disease site & Aortic, mitral, tricuspid, pulmonic \\
\hline & Numb valvuar & Based on the valvular disease type \\
\hline
\end{tabular}




\begin{tabular}{|c|c|c|}
\hline & Stroke & Stroke \\
\hline & Avascular necrosis & Avascular necrosis \\
\hline \multirow{4}{*}{$\stackrel{D}{\Xi}$} & Pulmonary hyperten & Pulmonary hypertension $\geq 40 \mathrm{mmhg}$ rvsp \\
\hline & Pulmonaru vasc lesion & Pulmonary vascular disease by biopsy or autopsy \\
\hline & Pulmonary fibrosis & Pulmonary fibrosis based on chest xray or ct scan \\
\hline & Evidence of lung disease & $\begin{array}{l}\text { Lung disease define by phtn (clin-p1) }+ \text { and/or } \\
\text { pulmonary fibrosis (clin-p3) }+\end{array}$ \\
\hline \multirow{6}{*}{ 胥 } & Evidence of renal disease & Renal disease define by acrrenal + and/or renal biopsy + \\
\hline & Renal cell cast & $\begin{array}{l}\text { Renal cellular cast- red, hemoglobin, granular, tubular, } \\
\text { or mixed }\end{array}$ \\
\hline & Renal proteinuria & Renal proteinuria- persistent $>0.5$ grams $/ 24 \mathrm{hrs}$ or $>3+$ \\
\hline & Renal hematuria & Renal hematuria- $>5 \mathrm{rbc}$ per high powered field \\
\hline & Renal clot & Reported renal clot \\
\hline & Renal artery stenosis & Reported renal arthery stenosis \\
\hline \multirow{5}{*}{ 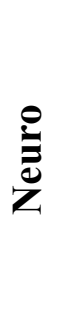 } & Seizure & $\begin{array}{l}\text { Seizure in the absence of offending drugs or known } \\
\text { metabolic derangements }\end{array}$ \\
\hline & Psychosis & $\begin{array}{l}\text { Psychosis in the absence of offending drugs or known } \\
\text { metabolic derangements }\end{array}$ \\
\hline & Neuropathy & Any neuropathy \\
\hline & Neuropsychiatric & Neuropsychiatric \\
\hline & Chorea & Chorea \\
\hline \multirow{18}{*}{  } & Glucose & Glucose normal range: $65-99 \mathrm{mg} / \mathrm{dl}$ \\
\hline & Ureanitrogen (BUN) & Urea nitrogen (bun) normal range: $7-25 \mathrm{mg} / \mathrm{ml}$ \\
\hline & Creatine & Creatine normal range: $0.5-1.4 \mathrm{mg} / \mathrm{dl}$ \\
\hline & Serum creatine & Serum creatine \\
\hline & BUN/Creatine ratio & Bun/creatine ratio normal range: $6-25$ calc \\
\hline & Sodium & Sodium normal range: $135-146 \mathrm{mmol} / 1$ \\
\hline & Potasium & Potasium normal range: $3.5-5.3 \mathrm{mmol} / 1$ \\
\hline & Chloride & Chloride normal range: $98-110 \mathrm{mmol} / \mathrm{l}$ \\
\hline & Carbon dioxide & Carbon dioxide normal range: $21-33 \mathrm{mmol} / 1$ \\
\hline & Calcium & Calcium normal range: $8.5-10.4 \mathrm{mg} / \mathrm{dl}$ \\
\hline & Total protein & Total protein normal range: $6-8.3 \mathrm{~g} / \mathrm{dl}$ \\
\hline & Albumin & Albumin normal range: $3.7-5.1 \mathrm{~g} / \mathrm{dl}$ \\
\hline & Globulin & Globulin normal range: $2.2-4.2 \mathrm{~g} / \mathrm{dl}$ \\
\hline & Albumun/globulin & Albumun/globulin normal range: $0.8-2$ calc \\
\hline & Bilirubin & Bilirubin normal range: $0.2-1.5 \mathrm{mg} / \mathrm{dl}$ \\
\hline & Alkaline phosphatase & Alkaline phosphatase normal range: $20-125 \mathrm{mg} / \mathrm{dl}$ \\
\hline & Ast & Ast normal range: $3-35 \mathrm{mg} / \mathrm{dl}$ \\
\hline & Alt & Alt normal range: $3-40 \mathrm{u} / 1$ \\
\hline
\end{tabular}




\begin{tabular}{|c|c|c|}
\hline & Creatine kinase & Creatine kinase normal range: $0-165 \mathrm{u} / 1$ \\
\hline \multirow{7}{*}{  } & Urine glucose & Urine glucose normal range: 0 \\
\hline & Urine protein & Urineprotein normal range: 0 \\
\hline & Urine WBC & Urine wbc normal range: $</=5$ \\
\hline & Urine RBC & Urine rbc normal range: $</=5$ \\
\hline & Urine squamos eplithelial cells & Urine squamos eplithelial cells normal range: $<=5$ \\
\hline & Urine bacteria & Urine bacteria normal range: 0 \\
\hline & Hyaline cast & Hyaline cast normal range: 0 \\
\hline \multirow{19}{*}{ 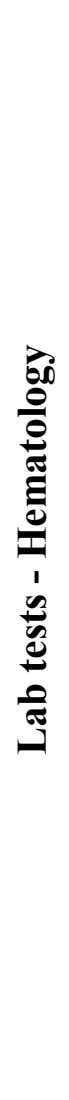 } & WBC count & Wbc count normal range: $3.8-10.8$ thous $/ \mathrm{mcl}$ \\
\hline & RBC count & Rbc count normal range: $4.20-5.80 \mathrm{mill} / \mathrm{mcl}$ \\
\hline & Hemoglobin & Hemoglobin normal range: $13.2-17.1 \mathrm{~g} / \mathrm{dl}$ \\
\hline & Hematocrit & Hematocrit normal range: $38.5-50 \%$ \\
\hline & Mev & Mcv normal range: $80-100 \mathrm{fl}$ \\
\hline & Mch & Mch normal range: $27-33 \mathrm{pg}$ \\
\hline & Mche & Mchc normal range: $32-36 \mathrm{~g} / \mathrm{dl}$ \\
\hline & Rdw & Rdw normal range: $11-15 \%$ \\
\hline & Platelet count & Platelet count normal range: $140-400$ thous $/ \mathrm{mcl}$ \\
\hline & Absolute neutrophils & $\begin{array}{l}\text { Absolute neutrophils normal range: } 1500-7800 \\
\text { cells/mcl }\end{array}$ \\
\hline & Absolute lymphocytes & $\begin{array}{l}\text { Absolute lymphocytes normal range: } 850-3900 \\
\text { cells/mcl }\end{array}$ \\
\hline & Absolute monocytes & Absolute monocytes normal range: $200-950$ cells $/ \mathrm{mcl}$ \\
\hline & Absolute eosinophils & Absolute eosinophils normal range: $15-500$ cells $/ \mathrm{mcl}$ \\
\hline & Absolute basophils & Absolute basophils normal range: $0-200$ cells $/ \mathrm{mhc}$ \\
\hline & Neutrophil \% & Neutrophil \% normal range: $35-80 \%$ \\
\hline & Lymphocyte \% & Lymphocyte $\%$ normal range: $18-44 \%$ \\
\hline & Monocyte \% & Monocyte $\%$ normal range: $0-10 \%$ \\
\hline & Eosinophyl \% & Eosinophyl \% normal range: $0-3 \%$ \\
\hline & Basophils \% & Basophils \% normal range: $0-1 \%$ \\
\hline \multirow{11}{*}{  } & Ana + & Ana \\
\hline & Anti-RNP + & Anti-rnp at hemagglutination titer $>1: 1600$ \\
\hline & Anti-Sm Abs + & Sm normal range: $0-20$ \\
\hline & Anti-DNA Abs + & Dsdna titer normal range: $5-9 \mathrm{iu} / \mathrm{ml}$ \\
\hline & Dna elevated & Elevated dna if $\geq 10 \mathrm{iu} / \mathrm{ml}$ \\
\hline & FANA titer & Fana titer normal range: $<320$ \\
\hline & Fana_pattr & $\begin{array}{l}\text { Fana pattern. Homo, speckled nucleolar, } \\
\text { homo/speckled, mixed, speckled/mixed, no-specific }\end{array}$ \\
\hline & Ssa_result & Ssa normal range: $<20 \mathrm{eu} / \mathrm{ml}$ \\
\hline & Ssb_result & Ssb normal range: $<20 \mathrm{eu} / \mathrm{ml}$ \\
\hline & Scl_result & Scl normal range: $<20 \mathrm{eu} / \mathrm{ml}$ \\
\hline & Anti-phospho-lipid Abs + & Anti-phospholipid abs + if $>10 \mathrm{gpl} \mathrm{u} / \mathrm{ml}$ \\
\hline
\end{tabular}




\begin{tabular}{|c|c|c|}
\hline & Anti cardolipin antibody & Anti cardolipin antibody if $>10 \mathrm{gpl} \mathrm{u} / \mathrm{ml}$ \\
\hline & Anticardiolipin igg LEVEL & Anticardiolipin igg normal ranger: $<10 \mathrm{gpl} \mathrm{u} / \mathrm{ml}$ \\
\hline & Anticardiolipin igg + & Anticardiolipin igg + if $>10 \mathrm{gpl} \mathrm{u} / \mathrm{ml}$ \\
\hline & Anticardiolipin igm Level & Anticardiolipin igm normal ranger: $<10 \mathrm{gpl} \mathrm{u} / \mathrm{ml}$ \\
\hline & Igm anticrd + & Igm anticrd + if $>10 \mathrm{gpl} \mathrm{u} / \mathrm{ml}$ \\
\hline & Anticardiolipin iga LEVEL & Anticardiolipin iga normal ranger: $<10 \mathrm{gpl} \mathrm{u} / \mathrm{ml}$ \\
\hline & Iga anticrd+ & Iga anticrd + if $>10 \mathrm{gpl} \mathrm{u} / \mathrm{ml}$ \\
\hline & C3 complement level & C3 complement normal range: $90-180 \mathrm{mg} / \mathrm{dl}$ \\
\hline & C3_low & C3_low if $<90 \mathrm{mg} / \mathrm{dl}$ \\
\hline & C4 complement level & $\mathrm{C} 4$ complement normal range: $16-47 \mathrm{mg} / \mathrm{dl}$ \\
\hline & C4_low & C4_low if $<16$ \\
\hline & Esr & Esr nomal ramnge: $<10 \mathrm{mg} / \mathrm{dl}$ \\
\hline & Esr_elevated & Esr_elevated if $>10 \mathrm{mg} / \mathrm{dl}$ \\
\hline & $\mathrm{C}$ reactive protein & $\mathrm{C}$ reactive protein nomal range: $1.0 \mathrm{mg} / \mathrm{dl}$ \\
\hline & Crp_elevated & Crp_elevated fi $.1 .0 \mathrm{mg} / \mathrm{dl}$ \\
\hline & RF latex Titer & Rf latex titer normal range: $14 \mathrm{iu} / \mathrm{ml}$ \\
\hline & RF ELISA igm Titer & Rf elisa igm titer normal range: $<20 \mathrm{iu} / \mathrm{ml}$ \\
\hline & RF ELISA igg Titer & Rf elisa igg titer normal range: $<20 \mathrm{iu} / \mathrm{ml}$ \\
\hline & Cpk level & Cpk normal range: $<165 \mathrm{u} / 1$ \\
\hline & CPK elevated & Cpkeleavted: > $165 \mathrm{u} / 1$ \\
\hline \multirow{13}{*}{ 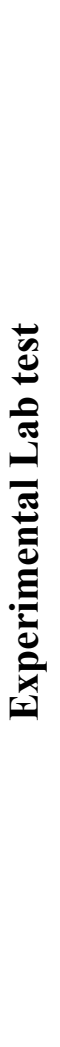 } & Baff & $\begin{array}{l}\text { Baff normal cytokine level }<1.19 \mathrm{ng} / \mathrm{ml} \\
\text { (based on healthy group average }+\mathrm{sd} \text { of healthy group) }\end{array}$ \\
\hline & Baffr & $\begin{array}{l}\text { Baffr normal cytokine level }<0.09 \mathrm{ng} / \mathrm{ml} \\
\text { (based on healthy group average }+\mathrm{sd} \text { of healthy group) }\end{array}$ \\
\hline & Taci & $\begin{array}{l}\text { Taci normal cytokine level }<0.02 \mathrm{ng} / \mathrm{ml} \\
\text { (based on healthy group average }+\mathrm{sd} \text { of healthy group) }\end{array}$ \\
\hline & Bema & $\begin{array}{l}\text { Bcma normal cytokine level }<1.64 \mathrm{ng} / \mathrm{ml} \\
\text { (based on healthy group average }+ \text { sd of healthy group) }\end{array}$ \\
\hline & Ifng & $\begin{array}{l}\text { Ifng normal cytokine level }<13.13 \mathrm{pg} / \mathrm{ml} \\
\text { (based on healthy group average }+\mathrm{sd} \text { of healthy group) }\end{array}$ \\
\hline & Tnfa & $\begin{array}{l}\text { Tnfa normal cytokine level }<7.58 \mathrm{pg} / \mathrm{ml} \\
\text { (based on healthy group average }+ \text { sd of healthy group) }\end{array}$ \\
\hline & Scd40I & $\begin{array}{l}\text { Scd } 401 \text { normal cytokine level }<1959.30 \mathrm{pg} / \mathrm{ml} \\
\text { (based on healthy group average }+ \text { sd of healthy group) }\end{array}$ \\
\hline & II12p40 & $\begin{array}{l}\mathrm{I} 112 \mathrm{p} 40 \text { normal cytokine level }<61.68 \mathrm{pg} / \mathrm{ml} \\
\text { (based on healthy group average }+\mathrm{sd} \text { of healthy group) }\end{array}$ \\
\hline & Il12p 70 & $\begin{array}{l}\mathrm{Il} 12 \mathrm{p} 70 \text { normal cytokine level }<18.77 \mathrm{pg} / \mathrm{ml} \\
\text { (based on healthy group average }+\mathrm{sd} \text { of healthy group) }\end{array}$ \\
\hline & Il23 & $\begin{array}{l}\text { Il } 23 \text { normal cytokine level }<348.34 \mathrm{pg} / \mathrm{ml} \\
\text { (based on healthy group average }+\mathrm{sd} \text { of healthy group) }\end{array}$ \\
\hline & II17a & $\begin{array}{l}\text { I117a normal cytokine level }<3.88 \mathrm{pg} / \mathrm{ml} \\
\text { (based on healthy group average }+\mathrm{sd} \text { of healthy group) }\end{array}$ \\
\hline & Il17af & $\begin{array}{l}\text { I117af normal cytokine level }<19.40 \mathrm{pg} / \mathrm{ml} \\
\text { (based on healthy group average }+\mathrm{sd} \text { of healthy group) }\end{array}$ \\
\hline & Il17f & $\begin{array}{l}\text { Il17f normal cytokine level }<38.00 \mathrm{pg} / \mathrm{ml} \\
\text { (based on healthy group average }+\mathrm{sd} \text { of healthy group) }\end{array}$ \\
\hline
\end{tabular}




\begin{tabular}{|c|c|}
\hline Il21 & $\begin{array}{l}\text { I121 normal cytokine level }<13.5 \mathrm{pg} / \mathrm{ml} \\
\text { (based on healthy group average }+ \text { sd of healthy group) }\end{array}$ \\
\hline Il22 & $\begin{array}{l}\text { Il2 } 2 \text { normal cytokine level }<31 \mathrm{pg} / \mathrm{ml} \\
\text { (based on healthy group average }+\mathrm{sd} \text { of healthy group) }\end{array}$ \\
\hline Il33 & $\begin{array}{l}\text { Il33 normal cytokine level }<12.3 \mathrm{pg} / \mathrm{ml} \\
\text { (based on healthy group average }+\mathrm{sd} \text { of healthy group) }\end{array}$ \\
\hline E-selectin & $\begin{array}{l}\text { Eselectin normal cytokine level }<23.63 \mathrm{ng} / \mathrm{ml} \\
\text { (based on healthy group average }+ \text { sd of healthy group) }\end{array}$ \\
\hline Ngal & $\begin{array}{l}\text { Ngal normal cytokine level }<79.10 \mathrm{ng} / \mathrm{ml} \\
\text { (based on healthy group average }+ \text { sd of healthy group) }\end{array}$ \\
\hline Igm anti-U1A (196-203) titer & P1-igm average normal range: $0-100$ \\
\hline Igm anti-sme (63-70) titer & $\mathrm{P} 2$-igm average normal range: $0-100$ \\
\hline Igm anti-smf (46-53) titer & $\mathrm{P} 3$-igm average normal range: $0-100$ \\
\hline Igm anti-U1C (90-97) titer & P4-igm average normal range: $0-100$ \\
\hline Igm anti-U1-70K (337-344) titer & P5-igm average normal range: $0-100$ \\
\hline Igm anti-smb (83-90) titer & P6-igm average normal range: $0-100$ \\
\hline Igm anti-smg (1-8) titer & P7-igm average normal range: $0-100$ \\
\hline Igm anti-smd3 (20-27) titer & P8-igm average normal range: $0-100$ \\
\hline Igm anti-smf (77-84) titer & P9-igm average normal range: $0-100$ \\
\hline Igm anti-U1A (112-119) titer & P10-igm average normal range: $0-100$ \\
\hline Igm anti-smd2 (14-21) titer & P11-igm average normal range: $0-100$ \\
\hline Igm anti-smd1 (22-29) titer & P12-igm average normal range: $0-100$ \\
\hline Igm anti-U1A (178-185) titer & P13-igm average normal range: $0-100$ \\
\hline Igm anti-U1-70K (325-332) titer & P14-igm average normal range: $0-100$ \\
\hline Igm anti-U1C (66-73) titer & P15-igm average normal range: $0-100$ \\
\hline ELISA anti-snrnp & Based on healthy group average + sd of healthy group \\
\hline Immunoblot anti-70KD & Based on healthy group average + sd of healthy group \\
\hline Immunoblot anti-Sm & Based on healthy group average + sd of healthy group \\
\hline Immunoblot anti-U1-A & Based on healthy group average + sd of healthy group \\
\hline
\end{tabular}




\section{APPENDIX 4}

\begin{tabular}{|c|c|c|}
\hline \multicolumn{2}{|c|}{ Biological system } & Variable \\
\hline \multirow{32}{*}{ 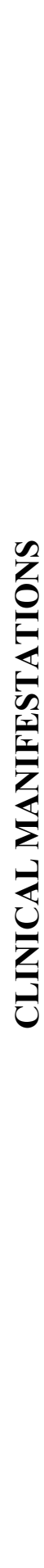 } & \multirow{15}{*}{ SKIN } & Telangiectasia \\
\hline & & Nasal ulcers \\
\hline & & Oral ulcers \\
\hline & & Hist hand swelling \\
\hline & & Obs hand swelling \\
\hline & & Sclerodactyly \\
\hline & & Pitting \\
\hline & & Alopecia \\
\hline & & Rash \\
\hline & & Photosensitivity \\
\hline & & Discoid rash \\
\hline & & Raynaud's \\
\hline & & Calcinosis \\
\hline & & Prox sclerodema \\
\hline & & Sicca \\
\hline & \multirow{9}{*}{ MUSCLE } & Myositis \\
\hline & & Myalgia \\
\hline & & Arthralgia \\
\hline & & Hist prox muscle weakness \\
\hline & & Obs prox muscle weakness \\
\hline & & Hist hand swelling \\
\hline & & Obs hand swelling \\
\hline & & Low extremety swelling \\
\hline & & Facial swelling \\
\hline & \multirow{8}{*}{ JOINTS } & Morning stiff \\
\hline & & Tender \\
\hline & & Synovitys \\
\hline & & Hist swelling \\
\hline & & Obs swelling \\
\hline & & Swelling (>3) \\
\hline & & Symmetric sweeling \\
\hline & & Pain \\
\hline
\end{tabular}




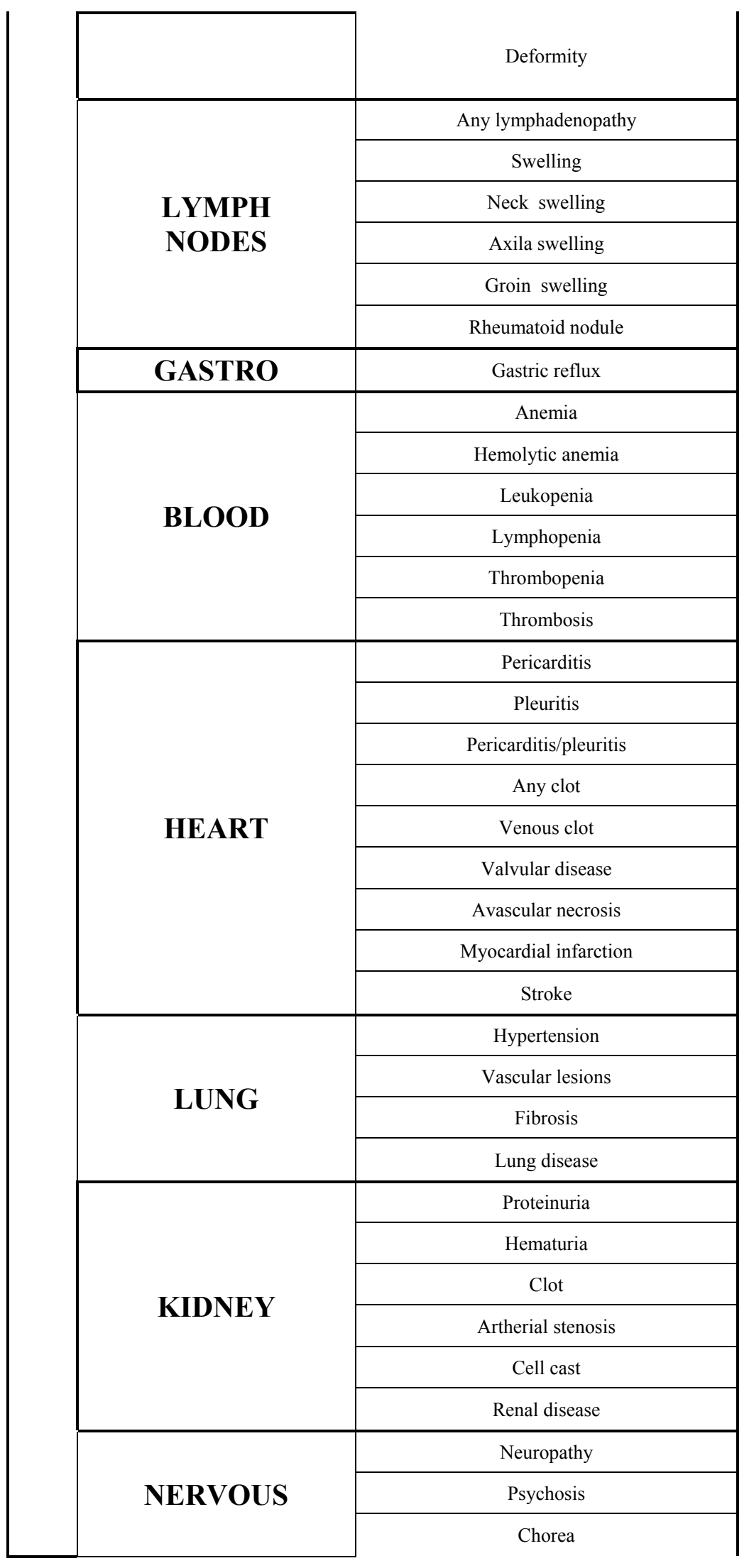


APPENDIX 4, continuation

\begin{tabular}{|c|c|c|}
\hline \multicolumn{2}{|c|}{ Lab tests } & Variable \\
\hline \multirow{6}{*}{\multicolumn{2}{|c|}{ 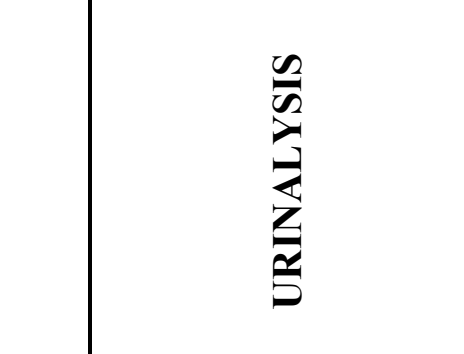 }} & Glucose + \\
\hline & & Protein + \\
\hline & & $\mathrm{Wbc}+$ \\
\hline & & $\mathrm{Rbc}+$ \\
\hline & & Squamos eplithelial cells + \\
\hline & & Hyaline cast + \\
\hline \multirow{27}{*}{ 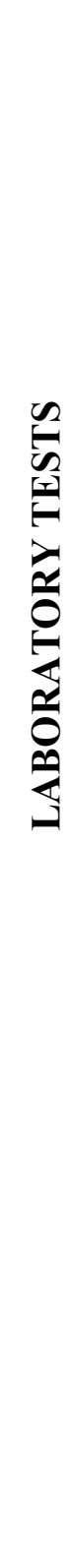 } & \multirow{22}{*}{ 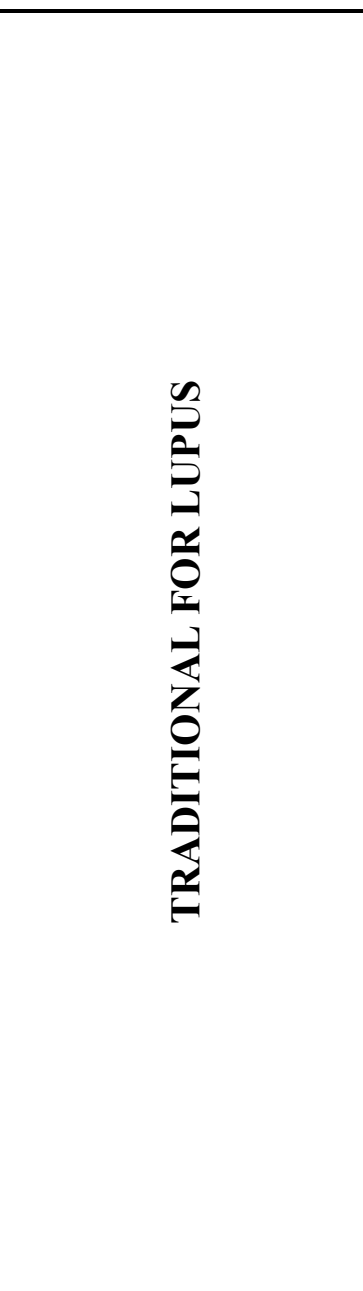 } & Sm level \\
\hline & & $\mathrm{Sm}+$ \\
\hline & & Dsdna titer \\
\hline & & Dna + \\
\hline & & DNA elevated \\
\hline & & FANA titer \\
\hline & & Fana + \\
\hline & & Ssa + \\
\hline & & C3 level \\
\hline & & C3 low \\
\hline & & C4 level \\
\hline & & C4 low \\
\hline & & Esr \\
\hline & & ESR elevated \\
\hline & & Crp \\
\hline & & CRP elevated \\
\hline & & Igm-RF ELISA titer \\
\hline & & Igm-RF + \\
\hline & & Igg-RF ELISA titer \\
\hline & & Igg-RF + \\
\hline & & CPK level \\
\hline & & CPK elevated \\
\hline & \multirow{5}{*}{ EXPERIMENTAL } & I117a \\
\hline & & Igm-U1A ELISA (112-119) \\
\hline & & Igm-U1A ELISA (196-203) \\
\hline & & Igm-smd2 ELISA (14-21) \\
\hline & & Igm-smd2 ELISA (14-21) \\
\hline
\end{tabular}


VITA

\section{ANNIA MESA}

Born, La Havana, Cuba

2004-2006

B.A., Biology

Florida International University

Miami, Florida

2008-2009

Teaching Assistant

Florida International University

Miami, Florida

2009-2011

M.S., Forensic Science

Florida International University

Miami, Florida

2009-2014

MBRS-RISE fellowship Award

Florida International University

Miami, Florida

2011-2014

Doctoral Candidate

Florida International University

Miami, Florida

2012

Biomedical Summer Internship Award

National Institute of Health

Baltimore, Maryland

2013-2014

Visiting fellow

University of Miami

Miami, Florida

\section{PUBLICATIONS}

Mesa A, Somarelli JA and Herrera RJ. (2007). The small nuclear RNA variants of three Bombyx mori strains. Entomol. Res. 38:61-68

Mesa A, Somarelli JA and Herrera RJ. (2008). Spliceosomal immunophilins. FEBS lett. 586:2345-2351.

Somarelli JA, Mesa A, Smail SS, Ares AL and Herrera RJ. (2009). U2 snRNA variants are differentially incorporated into spliceosomes. Entomol. Res 39:135-145. 
Somarelli JA, Mesa A, Roy A, Zhang Y and Herrera RJ. (2010). A three-dimensional model of the U1 small nuclear ribonucleoprotein particle. Entomol. Res. 40:104-112.

Somarelli JA, Mesa A, Fuller M, Torres J, Rodriguez CE, Ferrer C and Herrera RJ. (2010). Identification of spliceosomal polypeptides in the genome of the silk moth, Bombyx mori. Arch Insect Bioch and Phys. 75:231-263.

Somarelli JA, Mesa A, Rodriguez R, Avellan R, Martinez L, Greidinger EL, and Herrera RJ. (2010). Epitope mapping of the U1 small nuclear ribonucleoprotein particle in patients with Systemic Lupus Erythematosus and Mixed Connective Tissue Disease. Lupus 20:274-289.

Mesa A, Somarelli JA, Wensong W, Martinez L, Blom MB, Greidinger EL and Herrera RJ. (2013). Differential immunoglobulin class-mediated responses to components of the U1 small nuclear ribonucleoprtein partcle in systemic lupus erythematosus and mixed connective tissue disease. Lupus 22:1371-1381.

Rodriguez LM, Faridi MH, Martinez L, Shehadeh L, Duke JC, Wei Y, Mesa A, Pena A, Gupta V, Pham S, Vazquez-Padron R (2014). Macrophage-derived IL-18 and increased fibrinogen deposition are age-related inflammatory signatures of vascular remodeling. Amer J Phys - Heart and Circ Phys. Epub 2014 Jan 10

\section{PRESENTATIONS}

Mesa A, et al. Are human U1 snRNAs functional equivalent? $11^{\text {th }}$ Biomedical and Comparative Immunology Symposium. Florida International University. Miami, FL, March 4-5, 2009.

Mesa A. Surviving the writing of fellowships. Grant workshop for graduate students. Florida International University. Miami, FL, February 23, 2010.*Invited speaker by Dr Juan López, Assistant Director of Research Programs in College of Arts and Sciences at Florida International University.

Mesa A,* et al. Could the U1 snRNP carry the answer for diagnosing of SLE and MCTD? $12^{\text {th }}$ Biomedical and Comparative Immunology Symposium. Florida International University. Miami, FL, March 4-5, 2010. *First graduate winning prize.

Mesa A, et al. Could the U1 snRNP be used as screening tool for SLE and MCTD? Annual Scholarly Forum. Florida International University. Miami, FL, March 28-29, 2011.

Mesa A, et al. High IgM reactivity for U1 snRNP subunits in SLE but not MCTD patients. 2011 Florida Annual Meeting and Exposition (FAME 2011), Poster section II. Palm Harbor, FL, May 12-15, 2011. 